\title{
FACTORS INFLUENCING TURNOVER INTENTIONS OF NEW GRADUATE NURSES EMPLOYED IN FLOAT POOLS.
}

By

Sarah McDermid-Flabbi

BScN, Western University, London, Ontario, 2014

\author{
A thesis \\ presented to Ryerson University
}

in partial fulfillment of the

requirements for the degree of

Master of Nursing

In the program of Nursing

Toronto, Ontario, Canada, 2019

(C) Sarah McDermid-Flabbi 2019 


\section{AUTHOR'S DECLARATION}

I hereby declare that I am the sole author of this thesis. This is a true copy of the thesis, including any required final revisions, as accepted by my examiners.

I authorize Ryerson University to lend this thesis to other institutions or individuals for the purpose of scholarly research.

I further authorize Ryerson University to reproduce this thesis by photocopying or by other means, in total or in part, at the request of other institutions or individuals for the purpose of scholarly research.

I understand that my thesis may be made electronically available to the public. 


\author{
ABSTRACT \\ Sarah McDermid-Flabbi \\ Master of Nursing \\ Ryerson University, Toronto, 2019
}

Nursing turnover is a growing concern yet little is known about the turnover intentions of new graduate nurses (NGNs) employed in float pools. The purpose of this study was to describe the relationship between job satisfaction, work environment and psychological capital and turnover intentions among NGNs employed in float pools in acute care hospitals. A descriptive crosssectional, correlational non-experimental design was utilized with a sample of 56 NGNs employed in the float pool at two quaternary Canadian hospitals. Data were collected using an online survey and analyzed using multiple hierarchical regression. Job satisfaction was found to be the most significant predictor of turnover intentions and the overall study model accounted for $25-27 \%$ of variance of turnover intentions. Further development of organizational strategies is needed to improve job satisfaction, reduce turnover and improve retention to optimize patient care delivery, prevent loss of valuable clinical expertise and reduce costs of turnover. 


\section{ACKNOWLEDGEMENTS}

First and foremost, I would like to express my sincerest gratitude to my supervisor, Dr. Nancy Purdy for her support and encouragement, her contributions to this work and her expertise and guidance throughout this process. I would like to further extend my appreciation to my thesis committee members Helen Kelly, Dr. Donald Rose, Dr. Janet Yamada and Dr. Christina Catallo whose insightful thoughtful feedback and unique research perspectives have enhanced my capabilities as both a scholar and researcher.

Special acknowledgement goes to the new graduate nurses who willingly participated in this study. Without you, this work would not have been possible and for that I am grateful.

To my fellow colleagues at Ryerson, not only have you enhanced my graduate experience, but you provided me with unconditional support and much needed laughs throughout this process. I am grateful to have had the opportunity to share this MN program and thesis experience with all of you. We did it!

To my partner Zack, words are not enough to describe how grateful I am to you for your unconditional love and support throughout this process. To my family, thank you for being there for me whenever I needed you and for your unwavering love and encouragement throughout all of my academic and professional endeavours. I love you all to the moon and back. 


\section{DEDICATION}

This thesis is dedicated to my late nonna and grandpa. Nonna, you not only inspired me to follow a path into the nursing profession, but you instilled in me the love of learning and continuing my education. Grandpa, thank you for always believing that I could achieve greatness. I love you and miss you both dearly. This one is for you. 


\section{TABLE OF CONTENTS}

Page

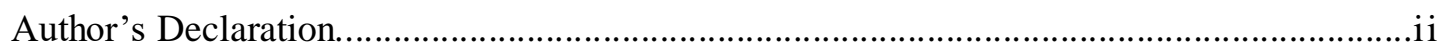

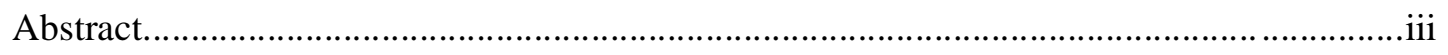

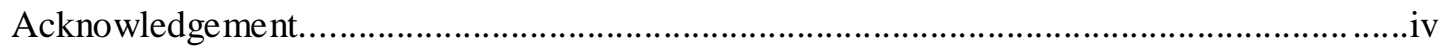

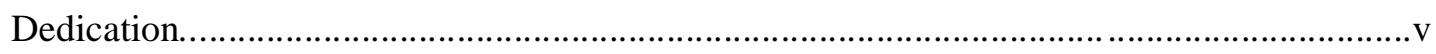

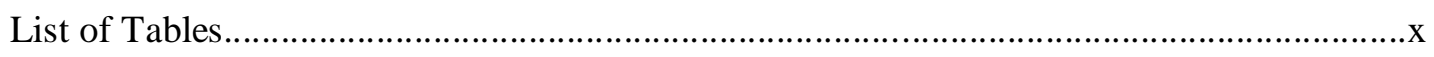

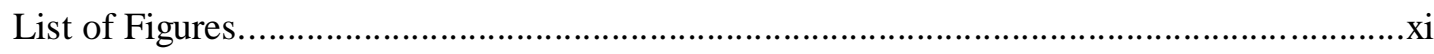

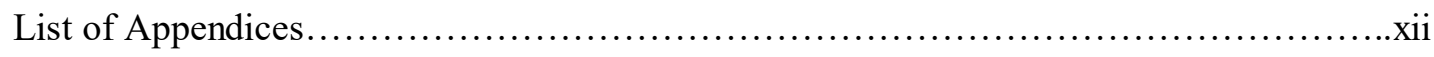

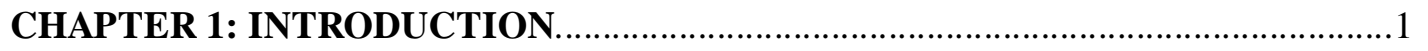

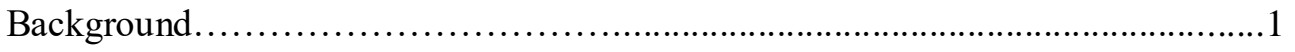

Nursing Turnover..............................................................

Turnover in New Graduate Nurses (NGNs)....................................... 3

New Graduate Guarantee (NGG) ..................................................

New Graduate Nurses Employed in Float Pools and Nursing Resource

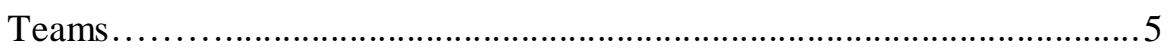

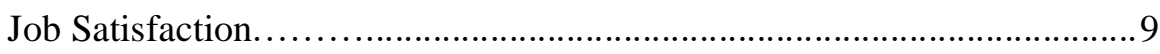

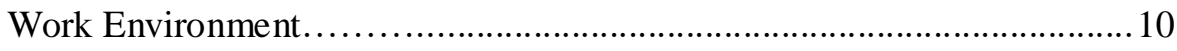

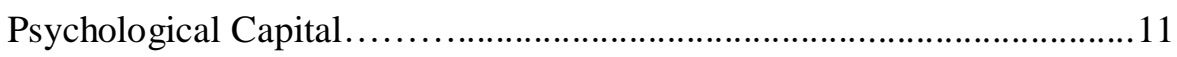

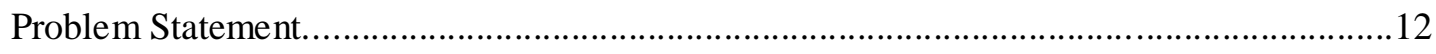

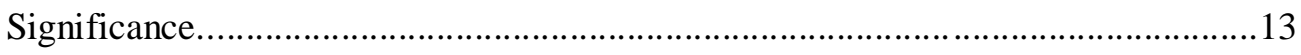

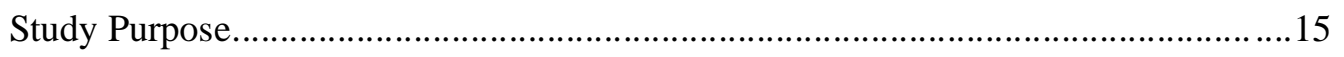




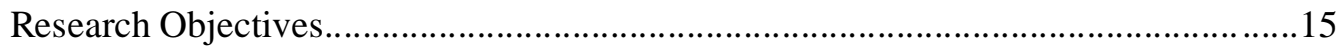

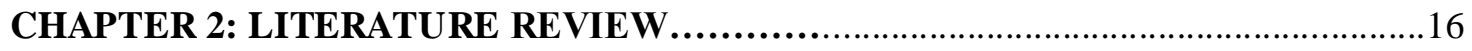

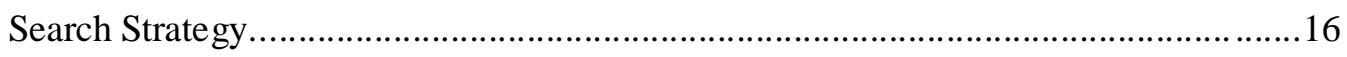

Theoretical Framework of Positive Organization Behaviour (POB)

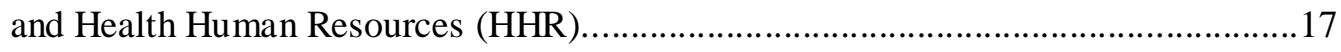

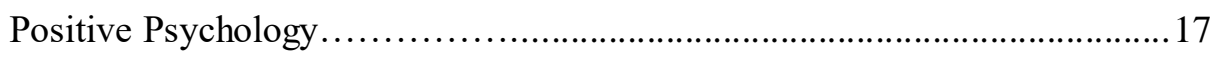

Positive Organizational Behaviour (POB) ............................................. 19

Context of Health Human Resources (HHR) .................................20

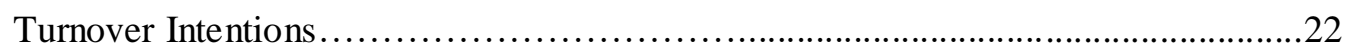

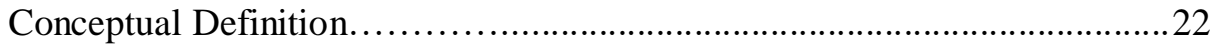

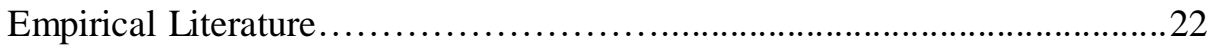

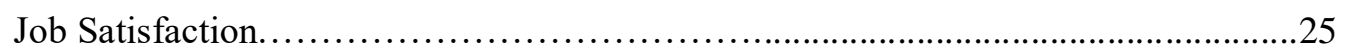

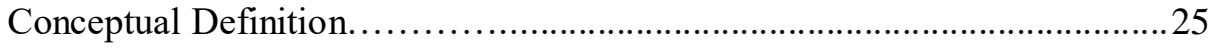

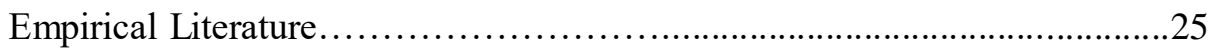

Work Environment...................................................27

Kanter's Theory of Structural Empowerment.............................22

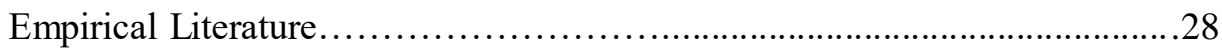

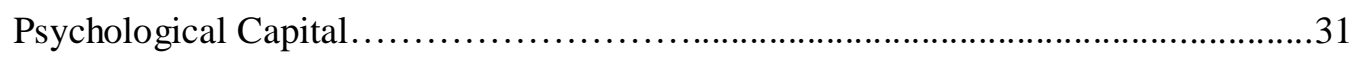


Conceptual Definition

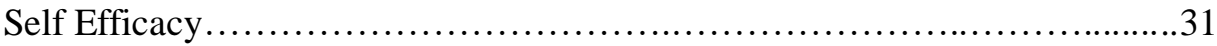

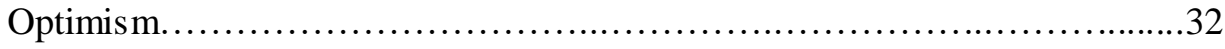

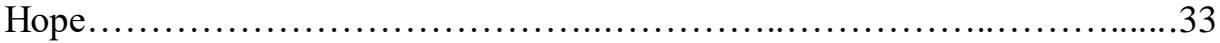

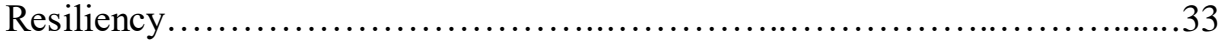

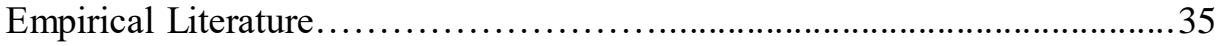

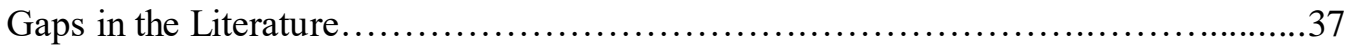

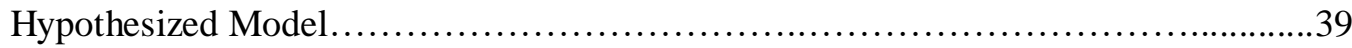

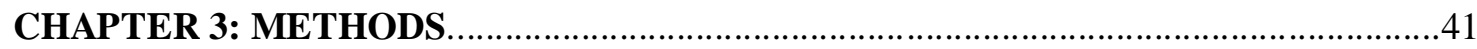

Research Questions and Hypotheses................................................41

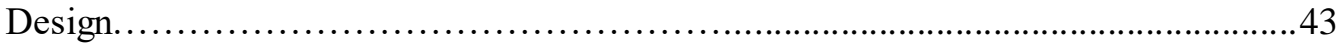

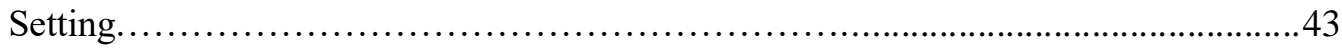

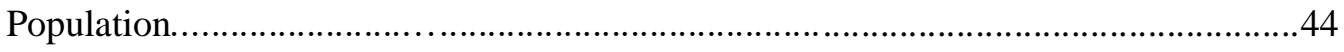

Sample

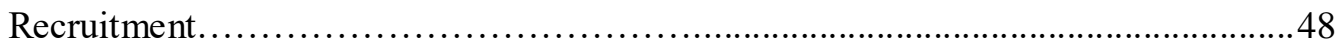

Data Collection.............................................................49

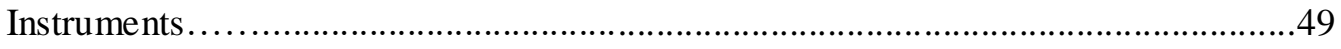

Job Satisfaction: Nurse Global Satisfaction Questionnaire.........................50

Work Environment: Conditions of Work Effectiveness

Questionnaire (CWEQ-II) .............................................50

Psychological Capital: Psychological Capital Questionnaire

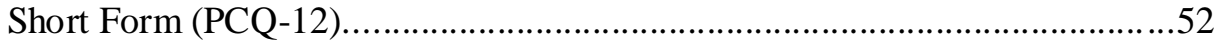




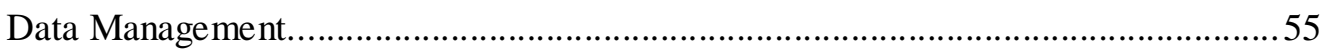

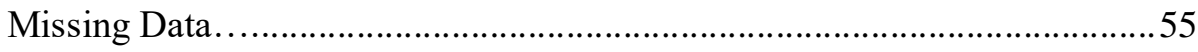

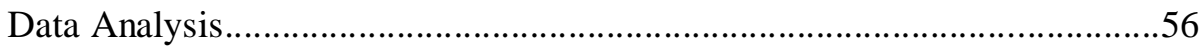

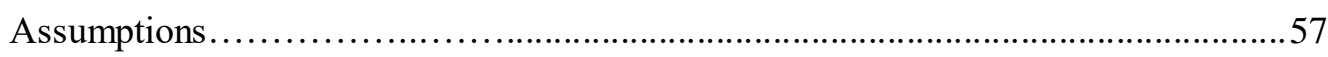

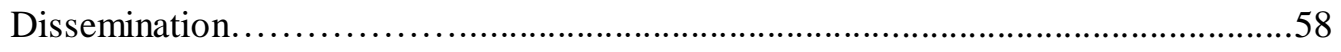

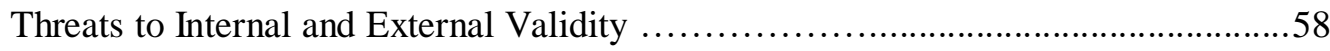

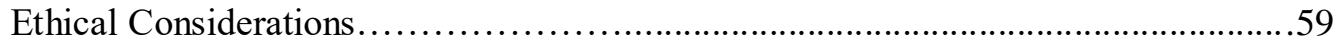

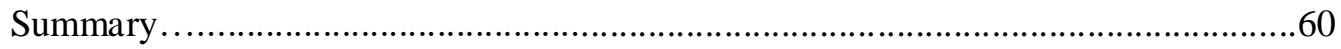

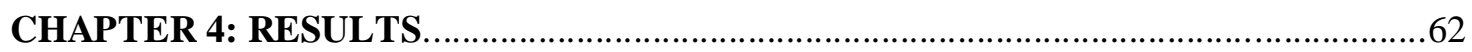

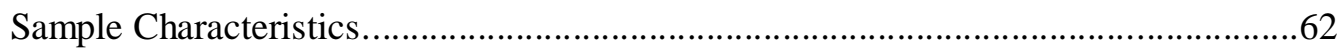

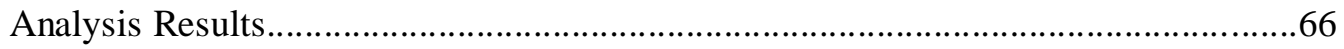

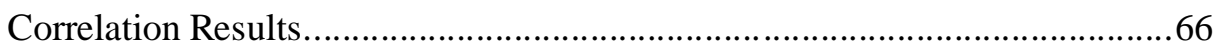

Regression Results-Research Question 1..............................................68

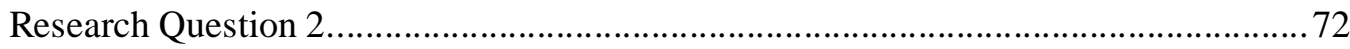

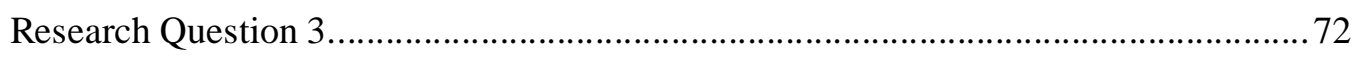

Research Question 4 Qualitative Analysis......................................................73

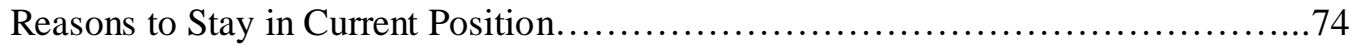

Reasons to Leave Current Position or Organization.............................75

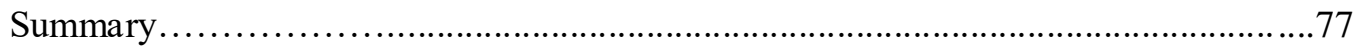




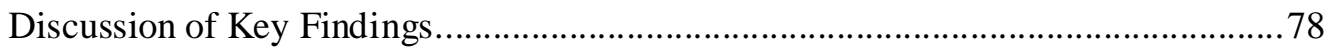

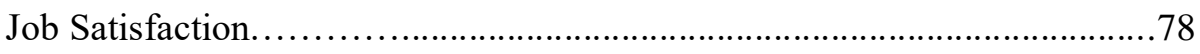

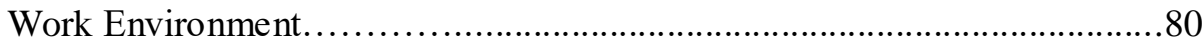

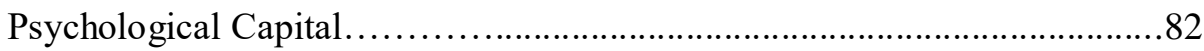

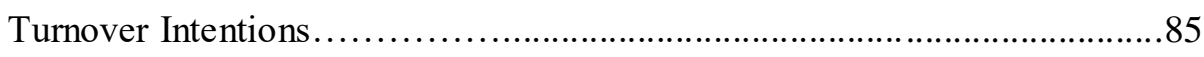

Overview of Theoretical Model ............................................ 86

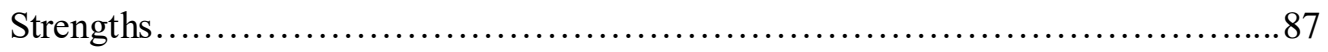

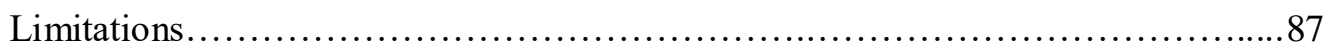

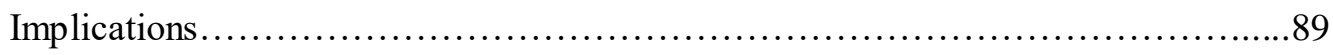

Implications for Practice......................................... 89

Implications for Education................................................................ 93

Implications for Policy................................................................... 94

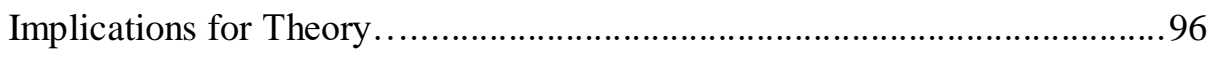

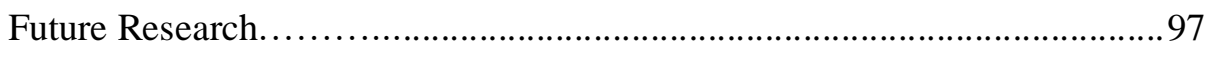

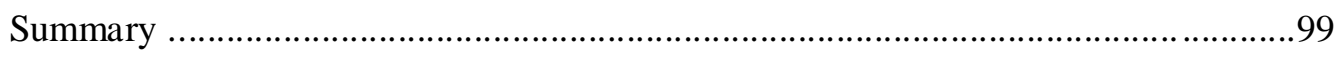

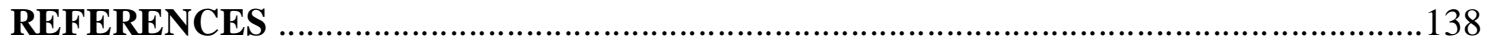




\section{LIST OF TABLES}

Table 1. Descriptive Characteristics of New Graduate Nurses.......................63

Table 2. Descriptive Results for Main Study Variables.............................65

Table 3. Correlation Matrix for Variables........................................66

Table 4. Subcategories Detailed Correlation Matrix...................................67

Table 5. Hierarchical Multiple Regression Analysis Summary.........................70

for Job Satisfaction, Work Environment (Empowerment),

Psychological Capital, Predicting Turnover Intentions from Position and Organization.

Table 6. Themes Derived from Participant Responses..............................73 


\section{LIST OF FIGURES}

Figure 1. Hypothesized Turnover Intention Model ............................................40

Figure 2. Model of Turnover Intentions from Position .................................. 71

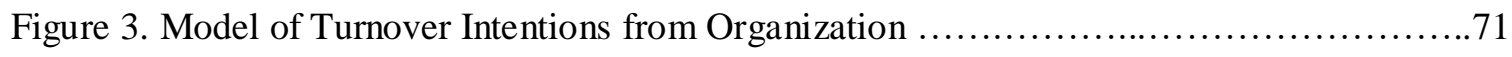




\section{LIST OF APPENDICIES}

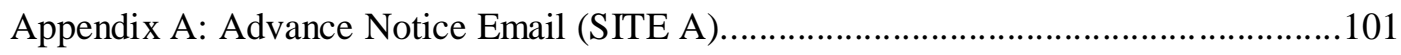

Appendix B: Invitation to Participate Email (SITE A)........................................ 102

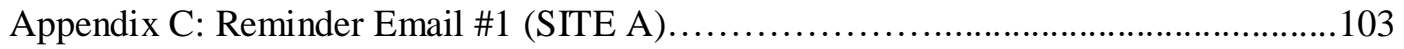

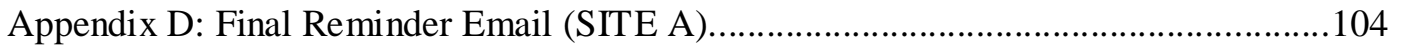

Appendix E: ObjectPlanet's Opinio Online Survey (SITE A) ....................... 105

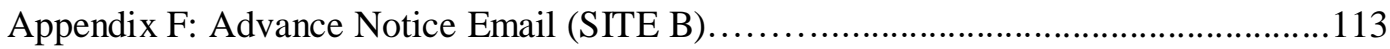

Appendix G: Invitation to Participate Email (SITE B).............................114

Appendix H: Reminder Email \#1 (SITE B) ................................... 115

Appendix I: Final Reminder Email (SITE B) .................................. 116

Appendix J: ObjectPlanet's Opinio Online Survey (SITE B).......................117

Appendix K: Letter of Information and Consent (SITE A)......................... 125

Appendix L: Letter of Information and Consent (SITE B)........................ 130

Appendix M: Ryerson REB Approval.......................................... 133

Appendix N: SITE A REB Approval........................................... 134

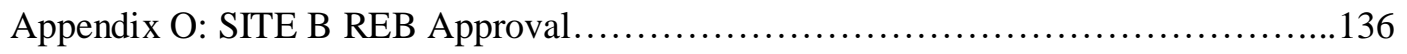




\section{Chapter 1: Introduction}

Nursing turnover is becoming a matter of increasing priority attributed to global nursing shortages, aging nurse and patient populations, and ever-changing complexity of demands in healthcare (O’Brien-Pallas et al., 2010). Although the turnover and retention of nurses have been studied extensively, little is known about the factors that influence turnover intentions of nurses (Anderson et al., 2009; Beecroft et al., 2008). Mindful of this gap in knowledge, the focus of this study explores the factors influencing turnover intentions among New Graduate Nurses (NGNs) employed in float pools. Further consideration and understanding of these factors are vital in promoting future retention and sustainability of the nursing workforce within healthcare organizations and the nursing profession itself (O'Brien-Pallas et al., 2010). In this chapter, the background and significance of turnover intentions are discussed including job satisfaction, work environment and psychological capital which have been selected to examine their influence on NGNs employed in the unique float pool role.

\section{Background}

\section{Nursing Turnover.}

Nursing turnover is costly for organizations, with replacement costs for a medical surgical nurse estimated to be between $\$ 42,000$ and $\$ 64,000$ for a specialty nurse (Hairr et al., 2014; O’Brien-Pallas et al., 2010). Direct costs are typically incurred during the initial recruitment and hiring process while indirect costs of turnover result from the combined effects of decreased productivity and staff morale in nursing (O'Brien-Pallas et al., 2010). Mindful of this, organizations need to be proactive in addressing and reducing turnover among the nursing workforce (Laschinger, 2012; Rudman et al., 2014). 
The ever-changing healthcare environment has required healthcare organizations to evolve and adapt to the shifting needs and acuity of today's patient population, all while in the face of critical nursing shortages. Upon examination of over 1600 hospital reports related to adverse patient events, the Joint Commission on Accreditation of Healthcare Organization (JCAHO, 2002) determined that $24 \%$ of adverse event cases resulted from nursing shortages. Although data collected from JCAHO is over a decade old, the issues of adverse nurse-patient events remains a concern today. More recently, the Canadian Institute for Health Information (CIHI, 2018) reported that in 2014 that the supply of nurses in Canada faced its first decline in two decades. Adequate and stable staffing is essential in order to promote and maintain highquality patient care, job satisfaction, decrease job stress and ultimately, address turnover of the nursing workforce (O’Brien-Pallas et al., 2010). In this regard, it is important to monitor nursing trends and maintain an understanding of the factors that can influence the supply of the nursing workforce.

Authors further suggest that differences in work-related attitudes such as work values and job satisfaction exist among generational groups of nurses, wherein younger nurses, such as those of the Millennial generation, are more likely to resign from their careers in comparison to older, Baby Boomer, nurses (Brewer et al., 2012; Keepnews et al., 2010; O’Brien-Pallas et al., 2006). These findings further illuminate the need for healthcare organizations who employ NGNs to be attentive in identifying and supporting nurses who may develop turnover intentions.

At the organizational level, appropriate countermeasures need to be in place to anticipate turnover intentions. It is recommended that unit-level managers strive to foster supportive work environments that recognize generational differences within the nursing workforce while encouraging staff from all generations toward common goals such as the delivery of safe, high 
quality patient care (Brewer et al., 2012; Keepnews et al., 2010). By examining and understanding these differences, increasingly successful retention strategies may be developed while improving work environments, particularly for NGNs integrating into the workplace.

\section{Turnover in New Graduate Nurses (NGNs).}

Each year, thousands of NGNs enter the professional practice setting, transitioning from the role of student to Registered Nurse $(\mathrm{RN})$. For the purpose of this study, new graduate nurses (NGNs) are defined as nurses with less than 3 years of working experience and a baccalaureate nursing degree (Boamah \& Laschinger, 2016; Pineau Stam et al., 2015). In 2014, approximately 12,000 NGNs graduated from schools of nursing in Canada alone (CIHI, 2018). As a result, NGNs are acknowledged as a primary source for a new supply of nurses in Canada (Regan et al., 2017). This is concerning as the present nursing workforce is aging with an estimated $40 \%$ of Canadian RNs between 50 and 60 years of age are approaching retirement (CIHI, 2011; Pineau Stam et al., 2015). In light of the impending nursing shortage and growing complexity of the population's health care needs, maintaining the supply of NGNs is critical to ensure the provision of high-quality patient care (Pineau Stam et al., 2015).

Turnover intentions of the nursing workforce are a global concern. Within the first five years of professional practice, Rudman et al. (2014) found that $27 \%$ of Swedish NGNs strongly intended to leave the nursing profession after one year, $45 \%$ after three years and $43 \%$ after five years of nursing employment in the acute care setting. These figures are comparable to findings from other international studies wherein an estimated 10-26\% of NGNs report turnover intentions from the profession (Flinkman, 2010; Lavoie-Tremblay et al., 2008). Meanwhile in the United States, studies revealed 18-35\% turnover rates among NGNs within the first year of professional employment were attributed to heightened levels of stress, burnout and difficult 
transition to practice (Beecroft et al., 2008; Laschinger et al., 2012; Kovner et al., 2009). In Canada, approximately $40 \%$ of NGNs left their first professional position within one-year post graduation as a result of inappropriate or inadequate staffing levels with reported turnover rates as high as $62 \%$ (Lavoie-Tremblay et al., 2008). In the province of Ontario alone, an estimated $62-66 \%$ of NGNs have experienced severe burnout as a result of transition to practice difficulties (Guay, Bishop \& Espin, 2016; Laschinger et al., 2009). The disequilibrium between staffing and patient workload further contributes to increased negative outcomes for both nurses and patients (Lavoie-Tremblay, 2008; O’Brien-Pallas et al., 2010). These factors among many others may in turn lead to increased turnover intentions, particularly within the first year of practice (Boamah \&Laschinger, 2015; Regan et al., 2017).

Conflict between the needs of NGNs and the realities of the professional practice work environment often create tension and turnover intentions in NGNs, thereby threatening an organization's ability to successfully retain these nurses (Chernomas et al., 2010). NGNs indicate that nursing staff commonly hold unrealistic or inconsistent expectations of the entry-level competencies of NGNs, particularly in regards to their capacity to care for high acuity patients (Lavoie-Tremblay, 2008; Regan et al., 2017). With a more comprehensive knowledge and understanding of the factors contributing to turnover intentions among NGNs, organizations can be proactive to address the factors related to actual turnover of nursing staff and retention may be improved in the future.

\section{New Graduate Guarantee (NGG).}

Studies have shown that a difficult transition to practice adversely impacts retention of NGNs (Duchscher, 2012; Guay, Bishop \& Espin, 2016; Laschinger et al., 2009; LavoieTremblay et al., 2008; O’Brien-Pallas et al., 2008). After the recession in 2007, the Ontario 
government developed the New Graduate Guarantee (NGG) as a way to support NGN's successful transition to practice (Health Force Ontario, 2011). By 2014, the NGG expanded eligibility criteria to include NGNs from other provinces and territories in Canada and internationally educated nurses who were newly registered in Canada (Health Force Ontario, 2011). As of 2017, the Ministry of Long-Term Care (the Ministry) implemented changes to ensure all participating NGNs transition into permanent full-time employment (Health Force Ontario, 2011). NGNs were considered eligible for the NGG if they were hired by their employer within 12 months post graduation. Additionally, the Ministry provides 20 weeks of funding for every NGN participating in the NGG which includes funding for 12 weeks for the NGN's transition to practice period as well as eight weeks of funding to reinvest in existing frontline nurses dedicated to their professional development (Health Force Ontario, 2011). Overall, the NGG offers an extended orientation period and pairing with an experienced $\mathrm{RN}$ preceptor to assist NGNs to learn responsibilities associated with their new professional role (Duchscher, 2012; Guay et al. 2016). In this way, the NGG may alleviate the predicted shortage of nurses and improve retention (Guays, Bishop \& Espin, 2016).

\section{New Graduate Nurses Employed in Float Pools and Nursing Resource Teams.}

In an attempt to manage staffing issues, many healthcare organizations utilize flexible resources such as nurses employed in float pools and nursing resource teams (Linzer, Tilley, Williamson, 2011; Larson et al., 2012). Fiscal constraints facing healthcare organizations in both Canada and the United States are the major indication for the utilization of float pool and resource team nursing. As a staffing strategy, float pools are credited as being cost-saving and efficient by reducing overtime and agency use (Dziuba-Ellis, 2006; Linzer et al., 2011). In the existing nursing literature (Dziuba-Ellis, 2006; Linzer, 2011) and within the selected institutions 
for this study, float pools are synonymously referred to as Nursing Resource Teams (NRTs). Float pool nurses are recognized as groupings of part-time or permanently employed RNs working in a variety of units within an organization in order to fill staffing needs and maintain safe and quality patient care (Linzer et al., 2011; Rainess et al., 2015; Roach, Tremblay \& Carter, 2011). Float pool nurses are also regarded as high-functioning and skilled practitioners who contribute a unique organizational perspective through their vast experience and observation of professional practice from one unit to another (Rainness et al., 2015). Through diverse patient assignments, float pool nurses have extensive opportunities to develop and refine clinical skills and competencies within a variety of specialty clinical areas (Lebenik \& Britt, 2015; Rainness et al., 2015). The variability of their role allows these nurses to advocate for their patients at the highest level through past and continuing interactions with inter-professional healthcare providers across the organization (Lebenik \& Britt 2015). NGNs employed in float pools are therefore a valuable asset to healthcare organizations as they advocate for best practice while connecting clinical concepts and patient care solutions across units and across the organization. These concepts and solutions include, but are not limited to, learning, demonstrating and promoting best practice guidelines and professional skills such as skin health and wound care, intravenous and nasogastric tube insertion, and falls prevention strategies (Lebanik \& Britt, 2015; Pineau Stam et al., 2015; Rainess et al., 2015). Therefore, this unique cohort of nurses is important for organizations to retain.

However, unlike the long-used float pools, Nursing Resource Teams (NRTs) have been considered as a more responsive approach to mitigating staffing needs where nurse expertise is considered prior to deployment (Dziuba-Ellis, 2006). The adaptability of working under a centralized nursing framework affords NRT nurses a diverse and continuous practice and allows 
them to work in a wide variety of medical and surgical specialties, including critical care settings. Although slight structural nuances between RNs in float pools and NRTs may differ, their present use within institutions is fundamentally the same. Therefore, they will be referred to as float pool nurses for the purpose of this research.

Interpretation of the literature related to float nursing must be taken with some caution. Previous literature surrounding float pools has regarded nurses as 'generalists', wherein nurses were deployed to assist with staffing needs to any given area within the hospital, regardless of experience or clinical expertise (Baumann, A., Hunsberger, M., \& Crea-Arsenio, 2011; DziubaEllis, 2006). Moreover, discussion of float nursing in earlier literature also appeared to offer two forms: mandatory re-assignment or 'floating' and float pool or resource team nursing. Although both forms suggested the deployment of nurses to areas of need within an organization, the most significant difference between these two forms of float nursing is that mandated floating forced nurses to float from their 'home' unit, regardless of their wishes to not be reassigned. The prior method of 'mandated' floating or reassignment of staff nurses to other areas of acute care outside their practice specialty was soon recognized to cause increased levels of stress, provoke anxiety and significantly decrease overall job satisfaction (Bates, 2013; Dziuba-Ellis, 2006; Good \& Bishop, 2011). In response, leaders in healthcare organizations were driven to utilize internal float pools or resource teams as a strategy to address critical staffing needs.

Historically, float pool nursing was reserved for the deployment of experienced nurses, and not typically recommended as the initial entry point for NGNs. However, in recent years, greater numbers of NGNs have been seen entering the workforce via float pools attributed to the recruitment and retention initiatives utilized by healthcare organizations (Dziuba-Ellis, 2006; Shinners et al., 2016). Moreover, in light of the most recent economic downturn experienced in 
2007, more staff nurses remained in their professional positions which resulted in a decrease in the number of available positions for NGNs (Staiger, Auerbach \& Buerhaus, 2012).

Concurrently, healthcare organizations were led to address staffing needs by acknowledging the availability and employment of NGNs into float pool roles (Bates, 2013; Baumann et al., 2011; Staiger et al., 2012). The flexibility of the float pool supports the healthcare organization's financial viability and promotes safer staffing at the point of care (Shinners, 2016). In order to ensure continued success of this staffing resource strategy, retention of nurses in the float pool role is imperative. In this role, however, nurses may experience significant stress when faced with the unpredictable process of floating in addition to the unfamiliarity of unit-specific patient diagnoses and treatment interventions, unit culture and routines, as well as the location of nursing care resources (Bates, 2013; Good \& Bishop, 2011; Lebanik \& Britt, 2015; Roach et al., 2011). The perceived challenges, fears and negative experiences that affect nurses employed in float pools are well documented. Research further acknowledges that NGNs may experience an additional degree of stress (Boamah \& Laschinger, 2016). As NGNs attempt to navigate opportunities to develop their confidence and competence during independent clinical practice, role stress and decreased job satisfaction are found to occur in relation to unsupportive work environments and unfair nurse-patient ratios (Boamah \& Laschinger, 2016; Pineau Stam et al., 2015). As much as 73\% of nurses who float have disclosed feelings of anxiety, resentment and discontent when floating (Bates 2013; DziubaEllis, 2006).

Successful floating experiences require a mutual understanding and responsibility from all stakeholders wherein institutions must move away from unit-focused towards organizationwide ways of thinking in order to support, retain and sustain NGNs working as float pool nurses 
(Shinners et al., 2016). Supporting a successful transition to professional practice is fundamental to retaining NGNs in the nursing workforce and ensuring healthcare needs of the population are addressed now, and in the future (Regan et al, 2017).

Furthermore, the increasing prevalence of acutely ill patients and the related care demands are closely linked to the deterioration of nurse's mental health status and subsequent turnover intentions (O’Brien-Pallas et al., 2010). Studies have suggested that NGNs who intend to leave the profession may experience considerable effort/reward disequilibrium accompanied by substantial psychological demands and stress (Lavoie-Tremblay et al., 2008; Rudman et al., 2014). These findings highlight a growing concern for NGN well-being and call for immediate attention and further inquiry into the interrelationship of job satisfaction and turnover intentions.

\section{Job Satisfaction}

Job satisfaction is widely recognized as one of the most significant and consistent predictors of intent to stay and voluntary turnover among nurses and also influences patient care quality and outcomes. (Brewer et al., 2012; Ileana Petrescu \& Simmons, 2008; Kovner et al., 2014; O’Brien-Pallas et al., 2010; Parker et al., 2014; Spetz 2010; Wang et al., 2012). Moreover, job satisfaction has been extensively linked to other major antecedents of turnover such as nursepatient workloads, negative work environments and cultures, in addition to varying degrees of organizational and collegial support (Parker et al., 2014). Job satisfaction has been found to be negatively correlated with turnover intentions and voluntary turnover itself (Brewer et al. 2012; O’Brien-Pallas, 2010). Increased job satisfaction has been correlated with a number of individual characteristics such as younger age, greater organizational commitment and fewer working hours (Hairr 2014; Spetz 2010). Workplace factors that have been positively correlated with job satisfaction include leadership support, recognition, promotional opportunities as well as status 
and salary within an organization (Spetz, 2010). Within the preliminary years of professional practice, it is acknowledged that job satisfaction of NGNs is largely dependent on the collective capacities among individuals, units and organizations to engage and support them towards fulfilling the responsibilities and expectations of a RN (Parker et al, 2014). In light of the substantial and growing evidence supporting the important influence of job satisfaction on nursing outcomes, it is imperative to further investigate job satisfaction as it relates to turnover intentions of NGNs.

\section{Work Environment.}

NGNs require a constructive learning environment that fosters and advances the development of competence and confidence as health practitioners (Chernomas et al., 2010). However, a poor work environment is negatively correlated with the global recruitment and retention of the nursing workforce (Lavoie-Tremblay, 2008). Kanter's (1977, 1993) theory of structural empowerment identifies four structural factors associated with the work environment that significantly impact employee work attitudes. These factors include access to information, access to support, resources necessary for job performance as well as learning and professional growth opportunities (Beecroft, 2008; Boamah \& Laschinger, 2016; Kanter 1977, 1993). When these structural factors are in place, nurses are more likely to remain committed to their healthcare organization (Boamah \& Laschinger, 2016). When these structural factors are not in place, work environments may not always be conducive to foster and support NGNs in

professional practice (Chernomas et al., 2010; Regan et al, 2017). In the practice setting, NGNs often encounter heavy workloads, inappropriate nurse-patient ratios, lack of support, incivility and bullying, and limited professional development or advancement opportunities (Flinkman \& Salantera, 2015; Parker et al., 2014; Wing et al., 2015). 
Moreover, positive work environments have been associated with greater nurse retention and job satisfaction through provision of adequate staffing and nursing resources, positive interprofessional relationships, and nurse's ability to contribute to hospital decision-making processes (Flinkman \& Salantera, 2015). Poor work environments leading to nursing turnover have been identified as an avoidable outcome, as healthcare organizations can engage in proactive and actionable change to influence and improve the work environment (Flinkman \& Salantera, 2015). Nurse leaders hold a critical position in fostering work environments that support NGN transition to practice and subsequently, the retention of NGNs in the workplace (Regan et al., 2017). It is important to engage in further inquiry to understand the relationship between the work environment and turnover intentions among NGNs.

\section{Psychological Capital.}

Recent research has acknowledged that intrapersonal resources and the use of positive human capacities are significantly related to behavioral and organizational outcomes such as job satisfaction, heightened workplace engagement, and decreased burnout (Brunetto et al., 2016; Pineau Stam et al., 2015; Laschinger et al., 2012). Psychological capital is recognized as a positive psychological state that includes the personal attributes of optimism, self-efficacy, resilience, and hope (Luthans, Aviolo, Avey \& Norman, 2007). While there is limited literature examining psychological capital within the context of nursing, authors have proposed that psychological capital may have protective qualities on NGN's attitudes and well-being during transition into profession practice (Boamah \& Laschinger, 2016; Brunetto et al., 2016; Laschinger et al, 2012). Further research is needed to determine the impact of psychological capital on turnover intentions over and above the contributions of job satisfaction and the quality of the work environment. 


\section{Problem Statement}

By the year 2020, the Canadian Nurses Association anticipates Canada will experience a shortage of 60, 000 nurses (Boamah \& Laschinger, 2016). In an attempt to counteract the growing shortage, the development of transition orientation programs employing NGN's into float pool nursing roles have gained greater prevalence. However, the transition of NGNs into professional practice is recognized as a vulnerable time wherein NGNs often formulate decisions related to their career intentions within a healthcare organization or the nursing profession itself (Boamah \& Laschinger, 2016; Lebanik \& Britt, 2015; Parker et al., 2014). It is acknowledged that NGNs continue to experience difficulties in their nursing work environment resulting in high levels of job dissatisfaction, burnout, and turnover intentions (Laschinger et al., 2012; Pineau Stam et al., 2015). Although float pools are commonly used as a recruitment and retention strategy for many organizations in Canada, experts consider float pool nurses difficult to retain (Dziuba-Ellis, 2006).

Within the first year of professional practice, an alarming $60 \%$ of employed NGNs in the acute care setting will leave their healthcare organization or transition to a career outside of nursing completely (Boamah \& Laschinger, 2016; Brunetto et al., 2016; Laschinger et al., 2012). This figure is three times greater than studies conducted in Sweden (Rudman et al., 2014), Finland (Flinkman \& Salantera, 2015) and Quebec (Lavoie-Tremblay et al., 2008) where findings suggest an estimated 10-26\% of NGNs reported intentions to leave the nursing profession within the first five years' post-graduation. On an international level, NGN turnover has the potential to further contribute to the significant nursing shortage currently faced by the profession and simultaneously threaten the quality of patient care (O'Brien-Pallas et al., 2010). 
Although turnover has been identified as an international human resource concern, with studies conducted in countries including but not limited to Taiwan (Chen et al., 2008), Japan (Suzuki et al., 2008), Italy (Camerino et al., 2008), Sweden (Josephson et al., 2008), Australia (Parker et al., 2014) and Canada (O'Brien-Pallas et al., 2010), the factors that influence the incidence of turnover intentions among NGNs are not well understood (Brewer et al., 2012). Consequently, the level of turnover intentions and subsequent voluntary turnover among NGNs, particularly in float pools remains relatively unknown. Despite the growing body of research exploring the factors of job satisfaction and work environment, little attention has been paid to the potential influence of intrapersonal resources such as psychological capital on nursing turnover. Given that NGNs are often hired into float pools for their first professional practice role, it is important to understand the contributors to turnover intentions for this unique cohort.

\section{Significance}

In light of the increasing nursing shortage, the unsustainable nature of turnover is cause for growing concern. Costs associated with retraining a specialty nurse have been estimated to be as high as $\$ 80,000$ USD (Burr, Stichler, \& Poeitler, 2011; Tellez, 2012). By retaining a single nurse, healthcare organizations may experience fiscal savings of approximately $\$ 140,000$ each year (Hairr, 2014). Further extrapolating this number to float pools within organizations across the nation has the potential to result in tremendous long-term savings (Burr et al., 2011; Hair, 2014). It is further suggested that when staffing changes of nurses on inpatient units occur, the effectiveness of interdisciplinary team-based relationships and subsequent patient care are negatively impacted (Beecroft, 2008). Thus, not only does retention of the nursing workforce have the potential for financial savings, it also significantly affects patient outcomes such as the incidence of medical errors and adverse patient events (Beecroft, 2008; Hairr, 2014). 
From a generational perspective, addressing concerns and needs of NGNs related to the work environment may present long-term solutions to the impending nursing shortage (LavoieTremblay, 2008). When nursing turnover occurs as a result of preventable work environment factors, nurse leaders play an active role in fostering positive work environments, which may further enhance job satisfaction and retention of NGNs working in float pools (Flinkman \& Salantera, 2015; Good \& Bishop, 2011; Laschinger, 2012; Tei-Tominaga, 2013). In this way, it is imperative for healthcare leaders to understand the factors that lead to turnover intentions and develop effective administrative strategies that directly invest in the quality of their work environment.

Overall, job satisfaction has been identified as a significant factor to reduce the incidence of turnover through enhancing intent to stay while decreasing job searching behaviour (Beecroft et al., 2008; Brewer et al., 2012). Managers must increase attention directed to the concerns of nurses that may further enhance job satisfaction, foster NGN intent to stay and ultimately minimize turnover (Brewer et al., 2012).

In addition to promoting efforts towards enhancing working environments and job satisfaction, further attention must be focused on developing NGNs psychological capacities and intrapersonal resources such as psychological capital. Psychological capital is acknowledged to be an important predictor of diverse organizational outcomes including increased levels of job satisfaction and work engagement (Boamah \& Laschinger, 2016; Laschinger et al., 2012; Luthans et al., 2007). Intrapersonal resources enable NGNs to cope with challenges encountered in the workplace and offer an actionable approach towards strengthening their abilities to optimise nursing practice (Boamah \& Laschinger, 2016; Luthans et al., 2007). Managers need to recognize and invest in the development of intrapersonal resources as they may play an 
influential role in empowering employee performance and engagement (Boamah \& Laschinger, 2016). In light of the immense challenges faced by the health care system today, it is imperative to foster positive psychological capital among NGNs in float pools in order for healthcare organizations to build a stronger workforce and improve retention of highly skilled NGNs.

By deepening our knowledge and understanding of each of the factors associated with turnover intentions including job satisfaction, work environment and psychological capital, actionable change is possible to ensure optimal nursing practice and patient care delivery. By doing so, NGNs may have greater success in transitioning into professional practice, improved retention rates within the profession are possible and can contribute to the sustainability of the overall nursing workforce in the future.

\section{Purpose of Study}

The purpose of this study is to explore and describe the relationship among job satisfaction, work environments and psychological capital and turnover intentions among new graduate nurses (NGNs) employed in float pools in acute care hospitals.

\section{Research Objectives}

Objective 1: To determine the extent to which job satisfaction, work environment and psychological capital predict turnover intentions among NGNs employed in float pools.

Objective 2: To identify and describe the inter-relationships that exist among job satisfaction, work environment and psychological capital and turnover intentions. 


\section{Chapter 2: Literature Review}

This chapter focuses on a review of existing literature to inform and guide this descriptive study of the factors influencing turnover intentions of NGNs employed in float pools. Through extensive searches, selected literature was critically analyzed and synthesized in order to gain a deeper understanding and identify gaps in knowledge related to this phenomenon. Theories from the fields of organizational behaviour and health human resources are examined to provide context for the study. Conceptual definitions and related empirical studies are reviewed for each study variable. The resulting hypothesized study model is introduced and discussed followed by the research questions to be answered.

\section{Literature Search Strategy}

Literature published within the last 10 years was generated and reviewed from databases including but not limited to ProQuest, Nurse \& Allied Health Database and CINAHL following an initial search with Google Scholar. The search was limited to English language, full text and peer-reviewed scholarly articles. Dissertations and thesis citations were reviewed for similar content, however, were not included for further research purposes. The Boolean operator AND was used to combine key search terms for a number of separate searches such as float pool AND new graduate nurse (2), job satisfaction AND new graduate nurse (619), work environment AND turnover intentions of new graduate nurse (227), psychological capital AND new graduate nurse (8) and turnover intentions AND new graduate nurse (246). Searches inclusive of all three search terms did not yield fruitful or relevant results. Therefore, there was little research found that was inclusive of all key terms. While extensive literature was found related to job satisfaction and new graduate nurses in general, there was a dearth of papers regarding NGNs employed in float pools who are of particular interest for this study. Only two papers were found exploring NGNs 
employed in float pools specifically. Both qualitative and quantitative studies were reviewed in addition to systematic reviews. Seminal work of key concepts was also included for review. A manual search of relevant articles from reference lists yielded the most fruitful literature for inclusion. Through the application of exclusion criteria, removal of duplicates, and additional title and abstract screening, 46 articles were selected as key resources for further review.

\section{Theoretical Framework: Positive Organizational Behavior and Health Human Resources}

This study is situated within the broader theoretical frame of positive organizational behaviour (POB) within the context of health human resources (HHR). These concepts and their implications on NGN turnover intentions are discussed in further depth.

\section{Positive Psychology.}

Historically, the discipline of psychology has been dominated by an exclusively pathological focus, resulting in a model of human beings that neglects the positive features that make life meaningful and fulfilling (Donaldson \& Ko, 2010; Seligman \& Csikszentmihalyi, 2000). While having a wide breadth of understanding of how individuals endure and survive conditions of adversity, psychologists possessed little knowledge about what truly makes life worth living and how individuals come to flourish under more temperate conditions.

Positive psychology was first introduced in 1998 as an initiative created by then president of the American Psychological Association, Martin Seligman (Duckworth, Steen \& Seligman, 2005). As an area of scientific study, positive psychology aims to examine the positive individual traits, experiences and the institutions that foster the development of strengths, well-being, resilience, and optimal functioning of human beings (Donald son \& Ko 2010; Duckworth, Steen \& Seligman, 2005). At the subjective level, Seligman \& Csikszentmihalyi (2000) further 
described the field as valuing the following subjective experiences: contentment, well-being, and satisfaction (in the past); optimism and hope (for the future); and happiness and flow (in the present). At the individual level, the focus in psychology shifted from preoccupation with repairing dysfunctional mental illness, towards positivity, drawing closer attention to the strengths (rather than weaknesses) of individuals and focused on how these strengths can develop and thrive (rather than how they can be maintained or fixed) (Luthans et al., 2008; Seligman \& Csikszentmihalyi, 2000).

Since the positive psychology movement, the positively focused orientation to research, scholarship and application has spread across a variety of professions and disciplines including but not limited to education, social and human services, public health and health care (Donaldson \& Ko, 2010; Muha \& Minion, 2010). This new orientation not only complements the traditional disease or problem-focused model of scholarship (Gayathri \& Karthikeyan, 2014), but offers an essential component to fully understand the array of present-day human experiences.

The aftermath of the most recent economic downturn resulted in a considerable amount of stress not only for healthcare organizations, but also for the employees that work within them. In order to contend with the looming shortage of RNs, healthcare leaders need to develop positive strategies to recruit and retain a new generation of nurses. Understanding how to transform the workplace into a positive culture that promotes teamwork, professionalism and camaraderie (Muha \& Manion, 2010) is one successful strategy hospitals could learn to implement in order to attract young nurses and maintain high levels of satisfaction and optimal functioning among them. In this way, a positive psychology lens may be effective in deepening our understanding of how organizations can recognize the influencing factors of turnover intentions of NGNs. By doing so, organizations may be able to mitigate these factors through the 
development of positive initiatives that build on and support the psychological capacities of NGNs, allowing them to flourish rather than falter in the ever-changing and sometimes toxic work environments of the acute health care setting.

\section{Positive Organizational Behavior (POB).}

Embedded within the field of organizational behaviour, positive organizational behaviour $(\mathrm{POB})$ is drawn from previous theoretical scholars and research pioneered by positive psychology as applied to the workplace (Luthans et al., 2008). Positive psychology can be applied to the work environment and how employees may improve their positive psychological resource capacities (Gayathri \& Karthikeyan, 2014). POB is largely defined as the study and application of positively oriented human strengths, resources and psychological capacities that can be measured, developed, and managed for effective performance improvement in today's workplace (Luthans, 2002a). POB has been positively correlated with strong organizational commitment, increased job satisfaction, and enhanced work performance (Lin \& Chang, 2015). In recent years, healthcare organizations have become concerned with improving ways to spontaneously elicit desired organizational behaviours in front-line nurses (Lin \& Chang, 2015). Thus, in order to gain greater understanding of these behaviours, this study aimed to identify the relationship among key concepts of job satisfaction, psychological capital and turnover intentions. $\mathrm{POB}$ has been recognized to encompass a positive approach with potential implications for performance management and health human resource (HHR) planning and development (Luthans et al., 2008). With this knowledge, this theory offers a positive foundation to enrich our understanding and possibly mitigate the reasons NGNs in float pools may intend to turnover from a position and/or organization. 


\section{Context of Health Human Resources (HHR).}

Further understanding of POB and the study of human strengths and resources has led to growing attention within the health human resource (HHR) field. The term HHR typically refers to individuals who provide healthcare services to the public that include physicians, allied health professionals and nurses (Baumann et al., 2016). Nurses comprise the largest healthcare profession in many countries including Canada and the United States, and play an integral role in the delivery of safe high-quality patient care services (Baumann et al., 2016). Government and public concern are growing as a result of reports of increasing shortages of health care providers, particularly nurses, across all jurisdictions in Canada (Baumann et al., 2016; Leiter, Price \& Laschinger, 2010; Wing et al., 2015). Canada's ability to adequately and effectively ensure the delivery of safe, accessible, high quality, patient-centered health service is highly dependent on the appropriate composition of health care providers with the right composition of skills, in the right place, at the right time (Baumann et al., 2016).

Although people are identified as the greatest asset to the Canadian health care system (Baumann et al., 2016), they are also the greatest cost. As evidenced by the Advisory Committee on Health Delivery and Human Resources (ACHDHR, 2007), between 60-80\% of every health care dollar is spent on HHR, excluding the cost of education and training of health care providers. Ensuring the retention of all nurses requires a more nuanced approach in re-inventing the planning and delivery of healthcare services in order to understand the needs of all unique groups, including NGNs employed in float pools.

Historically, the traditional approach to HHR planning in Canada has relied on the analysis of supply utilization trends and demographic change models that focus on the size and demographic composition of provider-to-patient population ratios to projected future populations 
(ACHDHR, 2007; O-Brien Pallas et al., 2007; Tomblin-Murphy et al., 2009). The supply of HHR-based services is attributed to the functioning of the quantity and availability of healthcare providers, workload and subsequent productivity. On the other hand, demand for HHR is highly dependent on factors such as population, disease prevalence and public expectations (Baumann et al., 2016; Health Canada, 2004).

A fundamental limitation in the traditional demographic approach to HHR planning was identified as the assumption that age and sex of patients solely account for the appropriate level of need for health care services (Birch et al., 2003; Tomblin-Murphy et al., 2009). The negative implications of this approach have been worsened by an inability to account for, anticipate and respond to ever-changing population and health system needs in addition to cycles of surplus and shortfalls of nurses, high turnover and attrition, as well as the destabilization of the health workforce (Baumann et al., 2016; Health Canada, 2004; O'Brien-Pallas et al., 2007). As a result of changing determinants of health, the focus has shifted to a systems-based design to address population health needs and lead to a more responsive health system (Health Canada, 2007). As a result, this new type of HHR planning provides an opportunity to identify the following: services needed, innovation in service delivery, the types of professionals required, and how to deploy them in order to maximize their scope of practice (Baumann et al., 2016; Health Canada, 2007). The overarching goal of this planning approach is to foster and maintain a health workforce that will support future health care renewal (Baumann et al., 2016). The maintenance and support of a health workforce is imperative to reduce turnover of the existing nursing workforce and counteract shortages in the future. Further understanding of the factors influencing turnover intentions of NGNs may offer greater insight into improving future organizational performance and the retention of nurses. 
The following section provides an overview of the conceptual definitions and related theory for the selected study concepts of turnover intentions, job satisfaction, work environment and psychological capital. A summary of empirical literature for each study concept is also discussed.

\section{Turnover Intentions}

\section{Conceptual Definition.}

Turnover intentions are defined as a withdrawal process characterized by an employee's (NGN's) decision to voluntarily leave their immediate workgroup and may further expand to leaving their organization or even to leave a profession (Galletta, et al., 2013; Laschinger et al., 2012; Mobley, 1977; Numminen et al., 2016). The literature suggests that turnover intentions are highly correlated with actual turnover and is therefore a useful concept to measure in order to develop and implement proactive strategies to mitigate the occurrence of actual turnover among NGNs. Mindful of this knowledge, this study took into consideration both types of turnover intention: from the position and from the organization.

\section{Empirical Literature.}

Overall, research examining nursing turnover offers insight into the complexity of the factors that influence nurses' decisions to leave their organization or profession (Rheaume Clement \& LeBel, 2011). NGNs seem to be particularly vulnerable to leaving the profession early in their careers (Flinkman \& Salantera, 2015; Rudman et al., 2014). Job satisfaction and intent to leave (turnover intentions) were identified as the strongest predictors of actual voluntary turnover, despite personal and organizational variables in place. (O-Brien-Pallas, 2010; Rheaume et al., 2011; Wang et al., 2012) 
According to a number of studies, antecedents to turnover intentions include job dissatisfaction, decreased organizational commitment, absenteeism, and cynicism (Brunetto et al., 2016; Laschinger et al., 2012; Numminen et al., 2017; Pineau Stam et al., 2015). However, the primary contributor to turnover among nurses is job dissatisfaction, where associations between turnover intentions and actual turnover are consistently well documented in the literature (Al-Hussami et al., 2014; Beecroft et al., 2008; Parker et al., 2014). In their study regarding job and work environment satisfaction in a hospital setting, Yu and Kang (2016) identified significant differences of turnover intentions among Korean NGNs. Here, turnover intentions were identified to be positively related to duration of orientation while negatively correlated with factors such as overall satisfaction with the job, work environment and obtaining employment at a desired hospital and department (Yu \& Kang, 2016). Similar studies identified that NGNs who did not receive their first choice of nursing unit accompanied by lower self confidence in professional practice were more likely to indicate turnover intentions (Beecroft et al., 2008; Numminen et al., 2017).

Moreover, structural empowerment has been identified as influential in reducing the development of burnout which can lead to turnover intent in Canadian NGNs (Boamah et al., 2017; Laschinger et al., 2013; Pineau Stam et al., 2015). In their longitudinal study of empowerment in Canadian nurses, Laschinger et al. (2004) suggested that perceived negative changes in structural empowerment directly affected changes in job satisfaction among nurses that, in turn, may lead to actual turnover.

Furthermore, differences in age among nurses has been shown to indirectly affect turnover (Brewer et al., 2012; Keepnews et al., 2010; Leiter et. al., 2010). Younger nurses, such as Millennials, are widely recognized in the literature as having greater turnover intentions than 
older nurses (Al-Hussami et al., 2014; Beecroft et al., 2008; Brewer et al., 2012; Kovner et al., 2009; O’Brien-Pallas et al., 2007). In comparison to more tenured nurses, studies also suggest that when NGNs are dissatisfied in the workplace, they are less invested in their positions and are therefore more inclined to leave (Beecroft et al., 2008).

In more than one study sample of NGN's in Ontario, researchers concluded that younger generations of nurses, including Millennials and Generation X nurses, may hold different expectations and socialization experiences than older generation nurses, such as Baby Boomers, which may contribute to the development of uncivil work environments and turnover intentions (Leiter et al., 2010; Wing et al., 2015). Leiter et al. (2010) further suggested that younger generations of nurses experience greater symptoms, both physically and emotionally, as a result of job stress. Ultimately, this leads to decreased job satisfaction, burnout and turnover. Boamah et al. (2017) also found that NGNs often reported difficulties finding a work-life balance and described increased levels of job stress exacerbated by heavy or unrealistic workloads and inadequate staffing.

Although a large body of research exists regarding nursing turnover and retention, there is a significant lack of exploration into the factors that lead to the turnover intentions among NGNs and particularly, those employed in float pools. Since float pool nurses are a unique cohort utilized to mitigate agency use and reduce costs to an organization, greater understanding is warranted to reap the benefit of this staffing strategy. 


\section{Job Satisfaction}

\section{Conceptual Definition.}

Although substantial literature exists surrounding job satisfaction among employees in general and within the nursing profession specifically, it appears there are many variations on the definition of job satisfaction (Coomber \& Barriball, 2007). Empirical studies have described job satisfaction as an overall attitude expressed by individuals regarding how well personal expectations correspond with work related outcomes (Coomber \& Barriball, 2007). Similarly, Lin \& Chang (2014) define job satisfaction as an attitude toward work as well as a positive emotion generated by work assessments and experiences. Within the current study, job satisfaction will correspond with the description presented by Coomber and Barriball.

\section{Empirical Literature.}

Among the many factors influencing turnover behaviour among professional nurses, researchers consistently highlight the importance of job satisfaction. Job satisfaction is the foremost indicator of an individual's likelihood to remain in a specific role within an organization and is an important factor related to nursing turnover (Brewer et al., 2012; Hairr et al., 2014 O'Brien-Pallas et al., 2010; Tellez, 2012; Wang et al., 2012). Job satisfaction has been identified to be significantly influenced by workload and working conditions and is strongly correlated with an employee's intent to stay as well as intent to leave (Wang et al., 2012). Research has acknowledged stressors for NGNs include a lack of confidence and experience, unrealistic patient loads, perceived lack of support, reliance on others and interactions with other healthcare team members (Morrow, 2009; Wing, Regan \& Laschinger, 2015). Mindful of this, NGNs must quickly learn to adapt to the demands of their new professional role and responsibilities, which may create feelings of emotional exhaustion, high anxiety, and low job 
satisfaction (Duchscher, 2012; Wing et al., 2015). This learning curve makes NGNs particularly vulnerable to early career burnout (Boamah \& Laschinger, 2016), poor personal and organizational outcomes (Laschinger, 2012) and increased turnover intentions (Boamah \& Laschinger, 2016). In their study of Canadian NGNs, Boamah et al., (2016) found that nurses who are more satisfied with their jobs demonstrate a greater likelihood to engage in organizational citizenship behaviours and hold higher levels of organizational commitment than those who are dissatisfied.

Furthermore, in a sample drawn from a population of NGNs working in acute care hospitals in Ontario, Peterson et al. (2011) discovered that several demographic and work characteristics were significant predictors of job satisfaction among NGNs. One significant predictor of NGN job satisfaction was found to relate to the clinical setting, where nurses working in either an ER or ICU reported less job dissatisfaction than nurses working on other specialty units (Peterson et al., 2011). This finding is consistent with findings from Kaddourah et al., (2013) who also found significantly greater job satisfaction among nurses working in critical care units than nurses working on medical- surgical units in Lebanon. Building on the notion of unit-based characteristics, both Laschinger (2008) and O-Brien Pallas (2010) identified that nurses on units with better leadership reported higher job satisfaction, which in turn, was then associated with reduced turnover. Results of this study were based on samples from 18 sites representative of 182 units in 41 hospitals across 10 Canadian provinces. In another Ontario based study aimed to describe the work-life experience of NGNs in the first two years of practice, Laschinger (2012) found empowerment, incivility and emotional exhaustion were all significant predictors of job satisfaction, particularly prominent in the first year of practice. 
Although there is considerable evidence connecting job satisfaction with turnover intentions of nurses, the evidence supporting this link among NGNs is scarce. In their study of Australian NGNs, Kenny, Reeve and Hall (2016) acknowledge the limited research on how well educational programs prepare NGNs for the workforce and the extent to which this preparation is related to turnover intentions and job satisfaction within the early years of professional practice. Moreover, using a sample of 204 Australian RNs, Kenny et al. (2016) found that intention to leave was associated with decreased satisfaction with the work environment including but not limited to inadequate staffing, lack of support, poor physical environment and limited professional development. This finding is consistent with other studies across California (Spetz, 2016) and Canada (Boamah et al., 2016; Laschinger, 2012; Purdyet al., 2010).

Although there is extensive evidence supporting the correlation between job satisfaction and nursing turnover (Kenny, Reeve \& Hall, 2016), little evidence exists investigating the concept of job satisfaction among NGNs, and even less among those employed to float pools. Further study is warranted to understand the impact of working in a float pool as a NGN on job satisfaction and turnover intentions.

\section{Work Environment}

Kanter's theory of structural empowerment was selected for this study as a way to conceptualize healthy work environments as it has previously been shown to be a significant predictor of organisational outcomes within nursing. Therefore, it offers a valuable framework for gaining deeper understanding of how empowering work environments may mitigate turnover intentions among NGNs employed in float pools in the hospital setting.

\section{Kanter's Theory of Structural Empowerment.}


Kanter's theory $(1977,1993)$ of structural empowerment suggests that structural factors within the work environment greatly impact the work attitudes and behaviours of employees. Kanter (1977) further described four organizational structures of empowerment: access to information, support, resources needed to do the job and opportunities to learn and grow. Access to information involves having formal and informal knowledge of organizational decisions and goals while possessing the technical knowledge and expertise required to accomplish one's work in meaningful ways. Access to support involves receiving guidance, feedback and emotional support from peers, superiors as well as subordinates. Access to resources includes the availability of appropriate equipment, supplies, materials and time necessary to achieve organizational goals. Opportunities for mobility and growth requires an individual to have access to challenges, rewards, and professional development opportunities that heighten their knowledge and skills. Kanter (1977) contends that productivity, motivation, commitment and job satisfaction are all further enhanced when opportunity is present within the workplace. Boamah \& Laschinger (2016) suggested that once the four factors of structural empowerment are in place, employees are more inclined to maintain organizational commitment, experience greater levels of trust in leadership management, and demonstrate higher accountability leading to improved work productivity, engagement and retention. According to this theory, when employees experience empowerment in the workplace, they are better able to accomplish their goals more efficiently and are then able to rise above challenges encountered within the organization (Boamah \& Laschinger, 2016; Kanter, 1993).

\section{Empirical Literature.}

The immediate work environment plays a significant role during the vulnerable period when NGNs first enter professional practice (Laschinger et al., 2009; Rheaume et al., 2011). 
Evidence has supported a significant connection between positive work environments and increased job satisfaction, work engagement and decreased turnover intentions respectively (Laschinger et al, 2010; Lavoie-Tremblay et al., 2011).

However, the work environment is often challenging for NGNs, leading to dissatisfaction with their surroundings and inter-professional relationships, which often contribute to low retention levels among this cohort (Rheaume et al., 2011). It is well-documented that nursing workplaces are infamous for strong and routinely stagnant practice traditions and unit cultures, which in turn, reduce receptiveness to novice NGN integration (Henderson, Ossenberg \& Tyler, 2015). For inexperienced NGN's, the practice environment has been described as emotionally and psychologically challenging (Wing, Regan \& Laschinger, 2015). In the beginning, many NGN's value support from more experienced nurses and often rely on them for guidance when making clinical decisions during new situations as well as socializing and acclimating to their new unit and organization (Lavoie-Tremblay et al., 2008; Wing et al., 2015).

Considering this, several researchers have described the transition stage for NGNs as a period of vulnerability and uncertainty, predisposing NGNs to increased levels of distress and workplace incivility, leading to turnover (Boamah \& Laschinger, 2016; Brunetto et al., 2016; Laschinger et al., 2012; Pineau Stam et al., 2015). By shifting the spotlight towards the importance of empowering structures in the workplace, healthcare leaders may more effectively promote healthy work environments for NGNs during a potentially stressful transition to practice (Wing et al., 2015).

Empowering work environments have also been identified in several studies as the strongest predictor of NGN job satisfaction (Pineau Stam et al., 2015). In one Canadian study of staff nurses in the acute care setting, Laschinger et al. (2009b) identified that empowerment, 
along with decreased levels of incivility and burnout, positively influenced job satisfaction, organizational commitment and turnover intentions. In combination with supportive practice environments and civil interpersonal relationships, structurally empowering workplaces led to lower levels of emotional exhaustion among NGNs (Laschinger et al., 2009a). Similarly, Smith et al. (2010) concluded that both collegial incivility and structural empowerment were important predictors of NGN organizational commitment. Furthermore, in their multi-level study examining nurses $(n=679)$ and patients $(n=1005)$ across 21 hospitals in Canada, Purdy et al. (2010) found that empowering structures significantly influenced group processes, team functioning, and positive collegial relationships Not only did these empowering workplaces positively impact psychological empowerment, but also in turn, directly affected job satisfaction, empowering behavior and patient care quality.

However, accessibility to structurally empowering workplaces is limited, often resulting in reduced quality of positive working experiences for nurses and increased risk of adverse patient outcomes (Laschinger \& Grau, 2012; Peterson et al., 2011; Pineau Stam et al., 2015). Studies further support the knowledge that work environments, along with other organizational working conditions, not only impact job satisfaction of nurses, but also retention (Hayes et al., 2012; Laschinger \& Grau, 2012; Laschinger et al., 2009; Mills et al., 2017). Indeed, studies have shown the nursing work environment can impact work-related outcomes including the key concepts of job satisfaction and turnover intentions. These studies confirm the critical value of empowering structures in the workplace to support NGNs, particularly in their first year of practice. However, little to no information was found to compare these findings with NGNs employed in float pools in particular. Therefore, it is necessary to determine how the work 
environment affects NGNs employed in the unique context of float pools, in order to prevent actual turnover among this vulnerable and valuable cohort.

\section{Psychological Capital}

\section{Conceptual Definition.}

Psychological Capital is a higher order construct recognized as the positive psychological state of development and motivational tendencies of an individual, indicated by the inclusion of four personal attributes: self-efficacy, hope, optimism, and resilience (Luthans, Aviolo, Youssef, 2007). When these four attributes are integrated together, psychological capital is further characterized by: (1) possessing confidence (self-efficacy) to take on and successfully execute specific tasks within a given context; (2) developing positive attributions (optimism) about succeeding in the present and in the future; (3) persevering towards goals and ability to redirect path to goals (hope) in order to successfully achieve them; (4) sustaining and bouncing back even beyond (resilience) from problems, adversity and uncertainties to achieve success (Boamah \& Laschinger, 2016; Luthans et al., 2007; Pineau Stam et al., 2015).

\section{Self-efficacy.}

Building on the original work of Bandura (1997), Stajkovic \& Luthans (1998) define selfefficacy as "an individual's confidence (or conviction) about his/her abilities to mobilize the motivation, cognitive resource, and courses of action needed to successfully execute a specific task within a given context” (p. 66). The relationship between self-efficacy and a variety of work-related performance dimensions is thoroughly established (Luthans \& Youssef, 2007). Self-efficacy has previously been positively correlated with work-related performance outcomes such as leadership, creativity, learning and career decision-making (Luthans \& Youssef, 2007). 
Frequently associated with confidence, self-efficacy is operationalized by challenging self-made goals and difficult tasks, self motivation towards mastery and goal accomplishment as well as perseverance in the face of adversity and obstacles (Luthans \& Youssef, 2007; Stajkovic \& Luthans, 1998). As a result, individuals with low self-efficacy are more vulnerable to despair, failure and self-doubt while individuals with heightened confidence possess the cognitive capacities towards achieving their personal goals (Bandura, 1997; Luthans \& Youseff, 2007) and engage in more proactive behavior more often (Saks \& Gruman, 2011). Mindful of this, it is important to nurture the development of self-efficacy in individuals through mastery experiences, training programs, providing supportive organizational culture and vicarious learning opportunities (Luthans et al., 2007). By supporting and enhancing confidence in NGNs employed in float pools, work-related outcomes such as job satisfaction may be improved and lead to reduced turnover intentions in this cohort.

\section{Optimism.}

Optimism is understood as the concept of having positive outcome expectancies and making positive attributions for events (Luthans, 2002a). Optimism within employees is associated with organizational outcomes such as retention and improved work performance (Saks \& Gruman, 2011). Similar to hope and self-efficacy, optimism is created, developed and motivated by an individual's ability to achieve valuable personal goals (Saks \& Gruman, 2011). Moreover, optimism is often associated with a wide variety of positive outcomes such as psychological and physical health, coping, well-being and recovery (Saks \& Gruman, 2011). Particularly relevant to $\mathrm{POB}$, is its positive relationship with performance in a number of life domains including the workplace (Luthans \& Youssef, 2007). The positive outcomes that stem 
from harnessing optimism in individuals may be particularly useful to understanding the nature of the relationship between optimism and turnover intentions of NGNs.

\section{Hope.}

Adopted from Snyder, Irving and Anderson (1991), hope is recognized as "a positive motivational state that is based on an interactively derived sense of successful agency and pathways (planning to meet goals)" (p.287). Since nurses are in short supply and the shortage is anticipated to worsen, the motivational component of hope within psychological capital is important to understand in relation to the key concepts of job satisfaction, work environment and turnover intentions.

\section{Resiliency.}

Traditionally, the concept of resiliency is viewed as a proactive approach that focuses on a capacity that is state-like and measurable and can be learned and fostered in even the most ordinary individuals (Luthans \& Youssef, 2007; Saks \& Gruman, 2011). Resilience is defined by Luthans (2002a) as "the capacity to rebound or bounce back from adversity, conflict, failure, or even positive events, progress.” (p. 702). The concept of resilience and its influence towards enabling nurses to cope with the challenges of caring for patients in today's healthcare environment is of growing interest (Laschinger \& Grau, 2012; Mills et al., 2017).

Moreover, POB offers an enriched perspective to the concept of resilience by focusing on opportunities for learning, development and personal growth through a proactive "bouncing back and beyond" approach (Luthans \& Youssef, 2007) from adversities. This approach engages an individual's adaptive mechanisms that are flexible and creative in nature that work toward the achievement of organizationally and personally significant goals (Luthans \& Youssef, 2007). 
According to the literature, the proactive approach of resilience has been commonly supported as a strong predictor of work-related outcomes and has demonstrated promise to future workplace development and management (Luthans et al., 2008; Luthans \& Youssef, 2007; In recent literature, resilience has been found to play a pivotal role in enhancing job satisfaction while mitigating turnover intentions of NGNs (Hudgins, 2016). Studies further reveal that through experiencing a stressful event and subsequently overcoming it with resilience, individuals were able to emerge stronger, improved performance, and became more self efficient and confident overall (Hudgins, 2016). Most recently, Yu \& Lee (2018) found that NGNs may have less intention to turnover if they possess a high degree of resilience, despite dissatisfaction with their work environment.

Each of these four qualities of psychological capital have been studied independently, linking them to organizational and behavioural outcomes (Luthans et al., 2007; Brunetto et al., 2016). However, research has suggested that the effect of psychological capital as a whole, particularly related to work-related outcomes- is greater than the impact of each component separately (Luthans et al., 2008; Saks \& Gruman, 2011). Originating from the paradigm of POB, psychological capacities and positive human strengths are believed to be state-like characteristics, such as human emotions and moods, that are susceptible to change, development and improvements based on varying situations and contexts (Brunetto et al., 2016; Luthans et al., 2007; Pineau Stam et al., 2015).

Growing evidence has demonstrated that a meaningful relationship exists between psychological capital and desirable behaviours of employees, affective organizational commitment, job satisfaction, and work performance (Luthans et al., 2007; Luthans et al., 2008). Preliminary research suggests that in the context of work-related attitudes, psychological capital 
provides added value to both social and human capital (Luthans \& Youssef, 2007). In addition, the concept of psychological capital has been linked to nurse well-being and mental health (Brunetto et al., 2016; Luthans et al., 2007). For the purpose of this study, the conceptual definition of psychological capital will correspond with the definition proposed by Luthans et al. (2007), as described in this section, as this definition is widely recognized throughout existing literature. By utilizing this set of internal psychological resources, individuals may better strive for and achieve their personal and professional goals.

\section{Empirical Literature.}

Numerous studies have investigated the relationship between psychological capital and desirable employee attitudes, including but not limited to job satisfaction and organizational commitment (Avey et al., 2011; Luthans et al., 2008; Luthans et al. 2007; Newman et al., 2014). For example, Brunetto et al. (2016) identified that psychological capital accounted for $45 \%$ of the variance in job satisfaction among nurses and $44 \%$ variance of nurse's intention to quit. Further research has established that psychological capital positively influences employee's intentions to stay as well as work engagement towards organizational missions and values (Newman et al., 2014). Studies also identify that inadequate staffing levels prevent nurses from establishing empowering work conditions and from cultivating intrapersonal strengths, leading to job dissatisfaction and consequently increased transition intentions (Pineau Stam et al., 2015). However, employees who harness higher levels of psychological capital were found to possess greater empowerment which subsequently reduced their intentions to leave (Avey et al., 2009). Studies have also linked the positive influence of psychological capital to employee well-being over time (Avey et al., 2010; Newman et al., 2014). Studies further suggest personal resources may have protective factors that mitigate negative behavioural and organizational outcomes such 
as employee cynicism and turnover intentions (Avey et al. 2011; Luthans et al., 2007; Newman et al., 2014; Van Bogaert et al., 2017).

In their meta-analysis of existing psychological capital literature, Avey et al. (2011) tested several moderators including U.S. based versus non-U.S. based samples, student versus working adult, and manufacturing versus service samples. Through understanding and examining the role of these potential moderators and their relationship with psychological capital, they were able to find statistically significant correlations. Desirable employee work attitudes of commitment, satisfaction and psychological well-being were found to be positively correlated with psychological capital (Avey et al., 2011). In addition, a significantly negative correlation was found between psychological capital and undesirable employee attitudes such as stress and anxiety, cynicism, and turnover intentions (Avey et al., 2011). Together, these results and the amassed evidence surrounding psychological capital, are indicative that psychological capital may significantly and strongly impact both the strength and direction of desirable employee attitudes in order to effectively meet goals for human resource functioning in today's organizational climate. More specifically, psychological capital has been shown to have a considerable impact on service work (Avey et al., 2011), such as the nursing profession, where social interactions that require the expression of a positive affect are heavily relied upon as an emotional norm.

Relatively few studies have been conducted in examining the role of psychological capital on NGN turnover intentions, particularly in regards to those employed in float pool nursing positions. The majority of psychological capital research related to nursing is primarily focused on job performance and does not explore work-related nursing outcomes, particularly in relation to nurse retention and turnover (Brunetto et al.,2016; Sun et al., 2012). The use of 
personal resources such as psychological capital is a critical and under-researched factor that may mitigate burnout, influence work engagement and decrease transition intentions. In order to respond to the anticipated nursing shortage, further research is encouraged to delve into the influences of the personal resources of nurses in relation to nursing outcomes. With increased awareness of the potential benefits of psychological capital, NGNs may harness the tools to better understand their emotions and subsequent stress or behaviour (Brunetto et al., 2016). In turn, this may result in beneficial improvements to nurses' well-being and successful professional retention strategies in the future.

Although research identifies the significant role of psychological capital and work environment on NGN's decision making regarding staying or leaving their job, Rheaume et al. (2011) suggest approximately $76 \%$ of the variance of turnover intentions remains largely unknown. Together, these studies provide strong evidence that acknowledge the importance of understanding the factors that influence NGNs turnover intentions, such as psychological capital in relation to preventing burnout and increasing retention-rates for healthcare organizations and the profession.

\section{Gaps in the Literature}

A methodological critique of rigour was conducted for the selected literature. Only peerreviewed articles and those published in journals were considered for inclusion in this review to ensure quality. Using the CASP checklist, critical appraisal of the literature was undertaken in order to assess internal and external validity. Claydon (2015) recommends utilizing critical appraisal checklists in order to check that methodological steps required in research have not been omitted in the study being examined. Using a checklist such as CASP also provided a logical, reliable, and valid step-by-step process to assess literature. The rigour of studies was also 
assessed through identification and comparison of each study design with study outcomes. Some articles included also utilized qualitative methods such as semi structured interviews to further glean understanding of the NGN experience or nurses experience of the other variables (job satisfaction, work environment and turnover intentions). Many of the studies utilized a quantitative design including descriptive, predictive, cross-sectional or non-experimental methods. One longitudinal and time-lagged study was also included. With the understanding that cross-sectional studies may not be representative of a phenomenon over time, it is acknowledged that longitudinal studies are better positioned to infer causal relationships while providing a stronger test of hypothesized relationships (Laschinger et al., 2004). Overall, the studies included within this review utilized valid and reliable research instruments that demonstrated satisfactory Cronbach's alpha reliabilities and construct validity. Overall, the methodological empirical evidence reported within the selected literature supported the research objectives.

The literature reviewed highlights the key study variables related to turnover intentions among NGNs employed in float pools. However, several limitations were identified in this review. The primary limitation is the paucity of recent available Canadian literature focused on psychological capital and float pool NGNs context specifically. No single study was found inclusive of all study variables (job satisfaction, work environment and psychological capital) exploring the factors influencing turnover intentions in the context of NGNs in float pools. Here, external validity was assessed by reviewing whether the results of each study could be generalized to the characteristics of the population and setting of interest in this research study. However, the majority of the reviewed literature discussed the experiences and empirical findings of staff nurses or NGNs employed in surgery, ICU and general medicine units. This 
further acknowledged the need for greater knowledge and understanding of the uniqueness and impact of being employed in the float pool nursing role.

Furthermore, studies were almost identical in their demographic descriptions, with predominantly female (89-95\%), new graduate nurses (NGNs); defined as nurses with less than 3 years of working experience and a baccalaureate nursing degree (Boamah \& Laschinger, 2016; Pineau Stam et al., 2015). The paucity of literature available not only addressing psychological capital among nurses, but also on the cohort of NGNs in float pools specifically, make it difficult to draw conclusions related to the influencing factors of turnover intentions of this unique population. Further research reflecting the factors affecting nursing outcomes of this population in the Canadian healthcare system may reveal a variety of factors that may differ from international studies. Results from this study may address gaps identified in the current literature.

\section{Hypothesized Model}

Based on the review of theoretical literature, the hypothesized relationships to be tested in this study are depicted in Figure 1 and address the first research question: How do job satisfaction, work environment and psychological capital predict turnover intentions among NGNs employed in float pools? It is hypothesized that job satisfaction (H1), work environment (H2) and psychological capital (H3) would be negatively related to turnover intentions. In light of the extensive literature supporting the impact of job satisfaction on turnover, job satisfaction was entered into the model first. Work environment was placed second as previous evidence also suggests the important contribution of the work environment to turnover intentions.

Psychological capital was entered last to determine if the new concept would make an additional contribution to our understanding of turnover intentions over and above job satisfaction and work environment. 
The second research question to be answered is: What is the inter-relationship between job satisfaction, work environment and psychological capital? Based on the literature review, it was hypothesized that there would be direct positive relationships between job satisfaction and work environment (H4a), work environment and psychological capital (H4b), and psychological capital and job satisfaction $(\mathrm{H} 4 \mathrm{c})$. The additional research questions to be answered are as follows:

R3: What is the degree of turnover intentions among NGNs employed in float pools in an acute care hospital setting?

R4: How do NGNs employed in float pools describe their reasons for staying or leaving their current position or organization?

\section{Hypothesized Model Figure 1.}

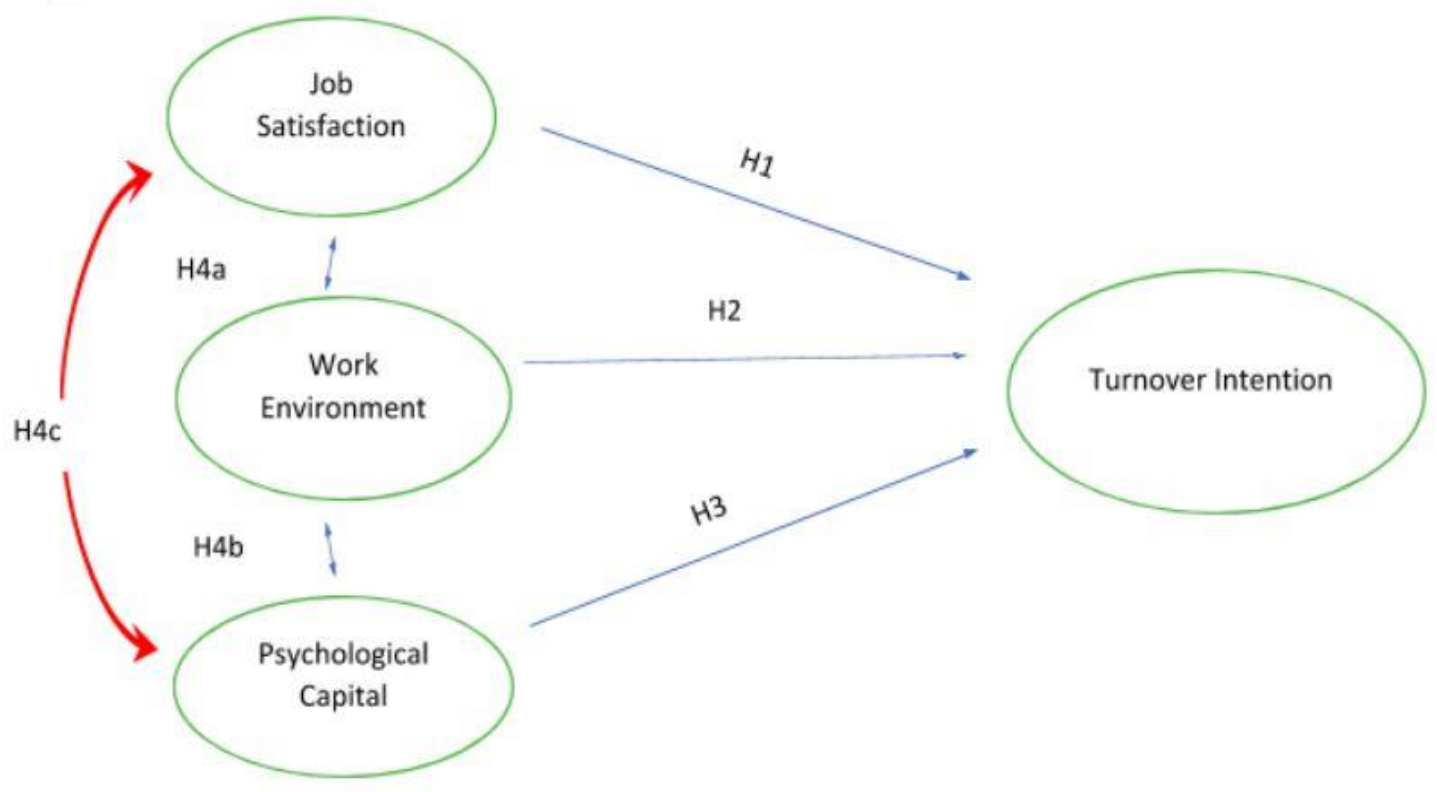




\section{Chapter 3: Methods}

The purpose of this study was to explore and describe the relationship among job satisfaction, work environment and psychological capital (resiliency, efficacy, hope and optimism) and turnover intentions among new graduate nurses (NGNs) employed in float pools in the acute care hospital setting. In this chapter is a description and discussion of the research methodology including sampling, data collection, data management and analysis that were utilized in this study. The chapter concludes with methodological assumptions, threats to validity and ethical considerations pertaining to this study.

To address the purpose of the study, the following research questions and hypotheses were established:

Research Question 1: How do job satisfaction, work environment and psychological capital predict turnover intentions among NGNs employed in float pools?

Hypothesis 1: There will be a negative relationship between job satisfaction and turnover intentions.

Hypothesis 2: There will be a negative relationship between work environment and turnover intentions.

Hypothesis 3: There will be a negative relationship between psychological capital and turnover intentions.

Research Question 2: What is the inter-relationship between job satisfaction, work environment and psychological capital. 
Hypothesis 4(a): There will be a direct positive relationship between job satisfaction and work environment.

Hypothesis 4(b): There will be a direct positive relationship between work environment and psychological capital.

Hypothesis 4(c): There will be a direct positive relationship between psychological capital and job satisfaction.

Research Question 3: What is the degree of turnover intentions among NGNs employed in float pools in an acute care hospital setting?

Research Question 4: How do NGNs employed in float pools describe their reasons for staying or leaving their current position or organization?

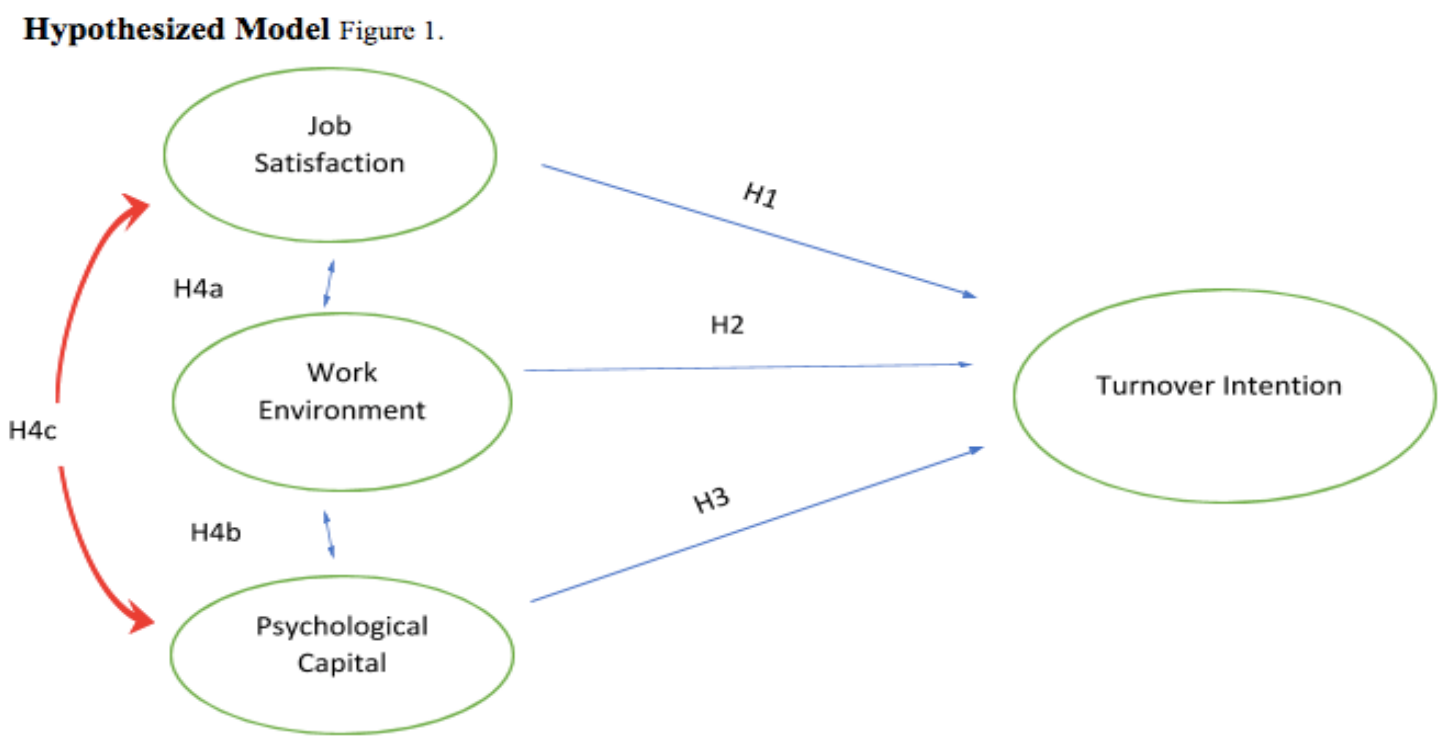




\section{Design}

In this quantitative study, the relationships among the predictor variables (job satisfaction, work environment and psychological capital) and the outcome variable (turnover intentions) were examined. A descriptive cross-sectional, correlational non-experimental design was adopted. The design allowed the researcher to observe multiple variables at a given point in time using an online survey methodology. The design was useful to describe, examine and differentiate associations among and between two or more identified study variables (Sousa, Driessnack \& Mendes, 2007). Rather than manipulating the independent variables, a correlational design allowed the researcher to observe data for patterns of responses while using statistical procedures to determine the direction and strength of the relationships as they naturally existed. In light of the limited amount of research regarding the experience of NGNs, specifically those employed in float pools, a descriptive correlational study was most suitable as it offered the ability to describe the identified variables and provided deeper insight into the relationships that exist both among and between them.

\section{Setting}

The study was conducted at two large quaternary multi-site academic adult acute care hospitals (Site A and Site B) located in the Greater Toronto Area. The selected hospitals both provide acute care services such as general medicine, general surgery, intensive care and emergency. In 2017, Site A reached almost 60,000 patient visits, with a 433 inpatient bed capacity and is widely recognized as a leading facility in organ transplants, cardiac care, and treatment of patients with complex health needs. Site B has been reported 1.2 million patient visits annually, holds 1325 inpatient beds including bassinets, and specializes in trauma care. 
Both sites utilize float pool nurses, otherwise known as Nursing Resource Team (NRT) nurses, comprised primarily of NGNs in order to meet internal staffing needs.

\section{Population}

At the selected acute care quaternary hospitals, the nursing float pools are comprised of both male and female new graduate nurses (NGNs) trained to work on a variety of different units in order to address staffing replacement needs throughout the organization. Float pool nurses are also referred to as "Nursing Resource Team" nurses within both organizations.

At Site A, The New Graduate Guarantee (NGG) is the primary source of new employees entering the nursing float pool while Site B no longer utilizes the NGG for hiring purposes and instead, relies on external hiring processes. The NGG was discontinued at Site B in 2016 for a multitude of reasons. These included an inability to guarantee full-time positions to new graduate nurses, organizational changes that resulted in a hiring freeze since 2017 and the closure of one inpatient surgical unit.

Once hired into the float pool, NGNs are provided with a generalized, comprehensive, and individualized orientation dependent on their 'hiring pool' or 'cluster'. Through funding from the NGG, Site A offers a minimum of 12 weeks preceptored bedside mentorship and an additional two-weeks of corporate orientation to assist NGNs in their transition to practice. NGNs are hired into three 'clusters': 1. medical-surgical, (as well as further opportunities in other specialty areas such as in-patient psychiatry, hemodialysis and multi-organ transplant) 2 . intensive care unit and 3. emergency. At present, there are 54 Registered Nurses (RN), many of them NGNs, that actively employed in the medical-surgical cluster, 19 in the intensive care unit, and three in emergency. Although NGNs entering these pools are new to the nursing profession, within a year, many have been offered access to unique clinical experiences not typically 
available to novice nurses such as Medical Imaging, the Medical Day Unit and the Family \& Community Medicine clinic.

Site B offers a shortened orientation that consists of a one-week corporate orientation and theory development in addition to 10-14 days of bedside preceptorship with an experienced mentor. Presently, NGNs have the option of being recruited into one of two hiring pools; Acute Care Nursing Resource Team (ACNRT) and the Critical Care Nursing Resource Team (CCNRT). However, due to the recent hiring freeze across the organization, the float pool manager has only been able to hire NGNs into the ACNRT. Currently, there are 136 Registered Nurses employed in the ACNRT and 19 Registered Nurses in the CCNRT for a total of 155 cross-trained nurses in the nursing resource team float pool overall. Upon hiring, NGNs are oriented to a program. These programs consist of general internal medicine (nephrology, respirology and stroke), trauma (orthopedic, neurological and general) and surgical oncology. Once NGNs are competent in one program, they are then cross-trained to another program after the probationary period. As a result, these nurses can be mobilized to over 40 units across the institution's three campuses.

At both hospital sites, the nursing float pools are consistently utilized as a strategy to reduce agency use, minimize recruitment costs, and improve the quality of care delivered organization wide. As these nurses rotate through various clinical areas, they gain an extensive breadth of knowledge, skill and experience, and develop a strong sense of adaptability and flexibility. In turn, this provides float pool nurses with a distinct advantage to fast-track their careers within the organization as well as the healthcare industry on a broader scale Site B website). As a result, their versatility to work with a variety of nursing teams is developed in order to provide safe, competent, patient-centered care. 


\section{Sample}

The participants for this study were selected via convenience sampling. Due to an inability to obtain the required sample size from Site A, ethics approval was sought from Site B for additional recruitment purposes. As a result, a convenience sampling method was selected by the researcher to facilitate data collection in a short period of time. The researcher had personal knowledge and prior experience in one of the float pools and was known by the organization's leadership for the nursing float pool and research departments. Convenience sampling has been recognized as a type of nonprobability or non-random sampling that is useful when the researcher has easy access and geographical proximity to members of the population that meet specific criteria (Etikan, Musa \& Alkassim, 2015). As an alternative to random sampling, the total population of all currently employed NGNs in the float pool at the two selected sites $(\mathrm{N}=231)$ were offered the opportunity to participate in the online survey. Inclusion criteria consisted of being employed as a float pool nurse for greater than three months (where NGNs are too new to experience the impact of the study concepts on turnover intentions) and less than three years as a Registered Nurse (as per the definition of NGNs used in this study), age greater than 21 years, and the completion of a baccalaureate degree. Although random sampling strategies are recognized as the gold standard in research (Van Hoeven et al., 2015), random sampling of participants was not the most feasible or optimal choice for this study. In this case, by surveying the entire population of the float pool at both sites, a similar advantage of random sampling of ensuring participant representativeness was achieved.

The inclusion criteria were validated by asking participants to record the number of years that they were in the profession and in their current position. Participants were excluded from the sample if inclusion criteria were not met. The years in profession and years in position were 
increased to five years in order to reduce the loss of participants and increase the sample size. This decision was justified by previous studies that noted $10-26 \%$ of nurses intended to leave their position or organization within the first five years suggesting that the experiences of turnover for new graduates extended to this time frame (Lavoie-Tremblay, 2008). By utilizing narrow inclusion criteria, this study sought to create a homogeneous sample inclusive of participants who were alike to one another in one or more respects (Gray et al., 2017). In turn, it was anticipated that generalizations could be made to similar homogenous populations of NGNs employed in nursing float pools in other acute care hospital settings.

Furthermore, in order to minimize the probability of Type II Error and reduce threats to external validity, the prospective sample size of 231 NGNs provided adequate data significance for the study, as medium to large sample sizes are required to yield stable estimates while ensuring sample representativeness to the study population (Gray et al., 2017; Laschinger et al., 2012). In order to increase the opportunity to achieve adequate sample size, the total population of current float pool nurses at each site $(\mathrm{N}=76)$ and $(\mathrm{N}=155)$ were sampled.

An a-priori power analysis was conducted to determine an adequate sample size appropriate to identify significant relationships and differences within the study (Gray et al., 2017). For a hypothesized moderate effect size, with three predictor variables, at a power of 0.80 , using an alpha level of .05 , a minimum sample size of 64 was determined to be sufficient for the analysis (Cohen, 1988; Soper, 2006). The selection of an adequately large sample allowed for true relationships amongst the variables to be revealed, which were anticipated to decrease the threat of inadequate statistical conclusion validity (Gray et al., 2017). 


\section{Recruitment}

With research ethics board (REB) approval and institutional authorization, access to the Nursing Resource Team (NRT) float pool was achieved. A modified version of the Dillman (2000) method for email prompting and survey distribution was utilized to increase response rates. Overall, four emails were sent one to two weeks apart for six weeks via the nurse manager of the nursing float pool at both sites. It was identified by each nurse manager that email correspondence was the strongest and most accessible method of communication for nurses in the float pool. The nurse manager was utilized solely to access and disseminate study information to the email list of RNs in the float pool. The nurse manager remained unaware of which nurses participated and was not involved in data analysis.

The first email message was an advanced notice of the study and contained a personalized message, the letter of information consent form and a description of the study and incentive (see Appendix A, F, K and L). The second email sent one week later contained a personalized message of invitation, a description of the study, the hyperlink to the Opinio online survey, and incentive information (see Appendix B and G). A reminder email followed two weeks later (see Appendix $\mathrm{C}$ and $\mathrm{H}$ ) and a final follow-up email was sent after two weeks in case of non-response (see Appendix D and I). All emails included information pertinent to the description of the study, inclusion criteria, incentive information and informed consent form. The recruitment incentive was an opportunity to win a $\$ 100$ gift certificate for a spa treatment to encourage self-care practices (for which the odds of winning were 1 in 231 chances via a random draw). 


\section{Data Collection}

The survey was completed online using ObjectPlanet's Opinio survey (see Appendix E and J). Opinio is a user friendly full featured web application designed for creating, managing and publishing online surveys, collecting data from respondents and offers powerful reporting and analysis of collected data (ObjectPlanet Inc, 2017). A Ryerson server housed the online survey. Sending surveys via email was determined to be advantageous in that participants could complete the surveys at their leisure and their responses were automatically submitted upon completion (Gray et al., 2017). Secondly, the online survey provided easy accessibility for participants and a reduced time commitment as the survey was expected to take less than 15 minutes to complete.

\section{Instruments}

The demographic questionnaire, which included the open-ended questions, was developed by the student investigator to provide a descriptive profile of the NGN sample. Questions included information related to participant's gender, age, specialty unit, highest level of education, employment status, years of work experience as an RN and in the float pool, and the length of stay in their current role. The three open-ended questions sought to build on the quantitative results by asking participants to identify reasons to stay or leave their current position/organization, and what type of new position they might seek and why. All other measures were standardized questionnaires with acceptable psychometric properties and demonstrated construct validity (Boamah \& Laschinger, 2016; Laschinger \& Grau, 2012). Permissions for the use of the instruments were granted from the original authors unless the instrument was readily available in the public domain. Each instrument is described in detail in 
the next paragraphs. Overall, the questionnaire was comprised of 47 items and required less than 15 minutes to complete.

\section{Job Satisfaction: Nurse Global Satisfaction Questionnaire.}

The independent variable (IV) job satisfaction was measured by the Nurse Global Satisfaction Questionnaire that consisted of three items using a five-point Likert scale. The instrument was modified from Hackman and Oldham's (1975) Job Diagnostic Survey (Laschinger \& Havens, 1996).

The three items were related to overall satisfaction with the current job, with co-workers and the work environment. Responses ranged from 1 (Strongly Disagree) to 5 (Strongly Agree), with higher scores demonstrating greater job satisfaction and lower scores demonstrating decreased job satisfaction. Adequate reliability and validity for this scale has been established in other studies of hospital-based nurse populations with a Cronbach's alpha ranging between .77 to .85 (Laschinger et al, .2004; Laschinger, 2009; Purdy et al., 2010). A mean score was calculated from the three items.

\section{Work Environment: Conditions of Work Effectiveness Questionnaire (CWEQ-II).}

The independent variable (IV) quality of the work environment was measured with the Conditions of Work Effectiveness Questionnaire (CWEQ-II) (Laschinger, Finegan, Shamian \& Wilk, 2004). The CWEQ-II was designed to measure NGNs perceptions of access to empowerment structures in their workplace (Pineau Stam et al., 2015). Items were derived from Kanter's original ethnographic study of work empowerment and modified by Chandler (1986) for use in a nursing population and have since been strongly associated with nursing work conditions and patient outcomes (Laschinger, 2008; Purdy et al., 2010). The instrument has also been 
shown to discriminate between levels of empowerment among nurses holding progressive leadership roles (Laschinger \& Wong, 2007; Laschinger, 2004). In addition, this instrument has been utilized extensively in nursing research since 2000 and has consistently demonstrated validity and reliability. The CWEQ-II is further recognized as a modification of the original version based on confirmatory factor analyses (Laschinger et al., 2000), however, is considerably shorter and directed to towards application in research studies (Laschinger, 2012). The subscales of the CWEQ-II measuring formal and informal powers were not used in this study.

The CWEQ-II measures 12 items distributed into the four core components of structural empowerment (perceived access to opportunity, information, support and resources) with three items for each subscale. According to Kanter (1977) the subscales are defined are as follows:

1. "Access to opportunity refers to the possibility for movement and growth within the organization and also the opportunity to improve skills and knowledge.

2. Access to resources refers to an individual's ability to acquire the financial materials, time, supplies and materials necessary to perform required work.

3. Access to information relates to the informal and formal knowledge that is required to be effective in the workplace.

4. Access to support suggests receiving guidance and feedback from peers, superiors and subordinates." (Wing, Regan \& Laschinger, 2015, p.633)

Items were rated on a five-point Likert scale ranging from 1 (none) to 5 (a lot), with higher scores representing higher levels of each dimension of empowerment and lower scores representing lower levels of each dimension (Laschinger et al., 2001). A subscale mean score was obtained by summing and averaging the items. To produce an individual's total level of structural empowerment, the scores on each item were summed. Therefore, the range of the scores for empowerment were between 12-60. Overall empowerment levels were interpreted by the investigator as low with scores ranging between 12-27, moderate between $28-43$ and high between 44-60 to yield categories of approximately the same range. 
Furthermore, a global empowerment (GE) measure was added to the questionnaire as a validation index (Laschinger, 2012). The GE score was obtained by summing and averaging the two global empowerment items at the end of the CWEQ-II. Scores range between one and five, with higher scores representative of stronger perceptions of working in an empowered work environment (Laschinger, 2012).

According to Laschinger, Finegan, Shamian, \& Casier (2000), the Cronbach's alpha reliability coefficients for the CWEQ-II were .81 (opportunity), .81 (information), .89 (support) and .84 (resources), demonstrating consistent internal reliability across the subscales. Additional reliability tests among multiple samples and studies showed Cronbach's alpha coefficients across the four subscales to range from .70 to .95 (Laschinger et al., 2009; Laschinger et al., 2013; Lautizi et al., 2009; Wong \& Laschinger, 2013). Construct validity was determined acceptable via confirmatory factor analysis (Laschinger, Finegan, Shamian \& Wilk, 2004).

\section{Psychological Capital: Psychological Capital Questionnaire Short Form (PCQ-12).}

The independent variable psychological capital was measured using the Psychological Capital Questionnaire Self-Rater Short Form (PCQ-12) developed by Luthans, Avolio \& Avey (2007). The PCQ-12 is the reduced version of the original 24-item Psychological Capital Questionnaire (Luthans, 2007). The researcher requested and received permission to use the questionnaire for this study (Luthans, F., Personal Communication, September 25, 2017). In previous studies, this scale has been tested on RNs and NGNs in particular, making it an appropriate choice to further understand this phenomenon. Since its emergence, the construct of psychological capital has been assessed using the original PCQ in over 14 countries and languages, along with the adapted short-rater scale in order to match target population needs (Lorenz, Beer, Putz \& Heinitz, 2016). Furthermore, discriminant validity of the PCQ has been 
confirmed by correlations with the Big Five personality factors and core self evaluations in other research (Antunes, Caetano \& Cunha, 2017; Luthans et al., 2007). Acceptable construct validity was further demonstrated using confirmatory factor analysis to support the higher-order factor of psychological capital overall (Luthans et al., 2007).

The PCQ-12 is a 12-item scale for each of the four components of psychological capital: hope, efficacy, optimism and resilience. The PCQ-12 included three items for efficacy, four items for hope (two agentic capacity, two pathways thinking), two items for optimism and three items for resilience. Each item was measured on a six-point Likert scale $(1=$ strongly disagree to $6=$ strongly agree), with higher scores representing higher levels of each dimension of psychological capital and lower scores representing lower levels of each dimension. Each of the four PCQ-12 subscales scores was calculated by taking the mean of all items in the subscale. The overall psychological capital score was then calculated by taking the mean of all items in the PCQ-12 (range 1-6). Internal consistency, estimated through the Cronbach's alpha coefficients, were adequate and similar across published studies using the PCQ 24 item scale and ranged between .68 and .87 (Azanza, Domínguez, Moriano, \& Molero, 2014; León-Pérez, Antino, \& LeónRubio, 2016; Luthans et al., 2007; Luthans, Avey, Clapp-Smith, \& Li, 2008). Moreover, the PCQ-12 has an overall reliability rating ranging from .87 to .93 in previous studies, (Avey et al., 2010; Combs, Milosevic, Jeung \& Griffith, 2012; Luthans et al., 2007; Norman, Aviolo \& Luthans, 2010). The Cronbach's alphas for each dimension of the PCQ-12 were within acceptable ranges (Dawkins, Martin, Scott \& Sanderson, 2013). Despite two subscales of optimism ( $\alpha=0.63-0.69)$ and resiliency ( $\alpha=0.63-0.66)$ having reliability ratings consistently below acceptable limits, the overall reliability of the PCQ-12 was above acceptable standards (Luthans et al., 2007). 


\section{Turnover Intentions: Intent to Stay Instrument.}

The dependent variable (DV) of turnover intentions was measured and adapted from Price's (1997) Intent to Stay instrument further adapted from Kim, Price, Mueller and Watson (1996). This instrument measures an individual's intentions to remain employed at an institution.

The 5-point Likert-type scale instrument was adapted to include four questions for each subscale measuring turnover intentions from position and from the organization using the following questions: 1.I would like to leave my present position/organization; 2. I plan to leave my present position/organization as soon as possible; 3.I plan to stay with my present position/organization as long as possible; 4. Under no circumstances will I leave my present position/organization. The responses for each subscale (position and organization) were scored from 1 (strongly disagree) to 5 (strongly agree). Reverse scoring was used for the negative items (items 1 and 2) within the questionnaire. Scores ranged from 4 to 20. The higher the score, the more likely the nurse intends to stay in the position or organization. Scores were interpreted by the researcher as low (4-9), moderate (10-15), and high (16-20) where each category had a similar range of five points. Cronbach's alpha for the Price and Mueller intent to stay measure have ranged from .85 to .90 (Kim, Price, Mueller, \& Watson, 1996) indicating that the tool is internally reliable. The Intent to Stay instrument has been previously tested on a sample of salaried physicians from a tertiarycare center (Kim, Price, Mueller \& Watson, 1996) in addition to a primarily female sample of RNs in private hospitals, (Price \& Mueller, 1986a) and RNs working within a university hospital (Price \& Mueller 1990). This instrument was considered appropriate to use with the sample of NGNs in this study considering the previous research conducted on similar populations. However, it was noted that there is limited recently published information on validity for this intent to stay instrument. 


\section{Data Management}

All study data and documents were stored in electronic files on a secure password protected Ryerson shared drive. Any electronic files containing personally identifiable information were stored on this drive, accessible only by the student investigator and not shared with any members of the research team until data were anonymized. Participant information, such as the participant email address voluntarily provided for the incentive, was kept in a secure folder separate from the data files on the drive. The full research committee was given access to de-identified data on as needed basis necessary for analysis activities.

\section{Missing Data.}

In order to avoid missing data, the investigator incorporated reminder notations embedded within the study survey to encourage participants to review that they have responded appropriately to each question before completion and final submission. However, participants were free to skip any or all questions. In situations where the participant opened the survey but did not respond to any questions, the case was deleted from the SPSS data file which was the default option (Tabachnick \& Fidell, 2007). Across all remaining cases, there was only one item from one instrument that was left unanswered therefore there were no substantive problems related to missing data. Four submitted surveys from Site A were noted to have double entry responses. In order to manage this, the researcher attempted to observe the pattern of responses on each subscale in order to accept the appropriate value. However, since the researcher was unable to verify the answer, an analysis was run with both responses. Since the results were not impacted, the first answer was used in the analysis. 


\section{Data Analysis.}

Manual data entry was performed. Data were double entered, checked and verified by a second reviewer. Data cleaning was performed by checking raw data collected for errors in data recording and to potentially eliminate impossible points of data so that statistical analyses could be performed using IBM SPSS Statistics Version 25. Descriptive statistics were utilized in order to describe the characteristics of the sample and variable distribution. The demographic questionnaire involved primarily categorical data (gender, employment status, level of education) and were reported using descriptive statistics (frequencies). Age and years of experience were interval level data and reported using measures of central tendency such as mean, median and range values as well as standard deviation. Although the values of each standardized questionnaire were ordinal-level data, the summed scores were analyzed at the interval-level, allowing for greater parametric statistical analysis (Gray et al., 2017). Descriptive statistics (mean, standard deviation and range) were reported for each scale and subscale.

Content analysis was undertaken in order to analyze the qualitative data elicited from open-ended questions. These questions were related to possible turnover intentions of NGNs from their current position and organization. Using a conventional content analysis approach, codes and themes were identified. Conventional content analysis is an appropriate method, as it is typically utilized when existing literature regarding a specific phenomenon is limited (Hsiu \& Shannon, 2005). With this method, categories and codes flow naturally from the data, which avoid imposition of preconceived categories. First, data from the text was read word for word by highlighting exact words that appeared to capture key concepts in order to derive the initial codes (Hsiu \& Shannon, 2005). Next, labels for codes were drawn directly from the text and were then sorted into different categories based on the varying codes identified (Hsiu \& Shannon, 2005). 
Finally, the categories that emerged were utilized to then group codes into meaningful clusters. As a result, qualitative aspects were included to support the quantitative findings and contribute to a richer understanding of turnover intentions of NGNs employed in float pools.

Initial bivariate relationships between variables were tested using Pearson's $r$ correlation statistics. The multivariate study hypotheses were tested further using hierarchical regression analyses. Multiple regression involved the use of interval or ratio level data. Multiple regression analysis offered an extension of simple linear regression where more than one independent (predictor) variables were entered into the analysis (Gray et al., 2017). The goal was to determine the accuracy with which one could predict the value of a dependent variable (turnover intentions) based on the values of one or more independent (predictor) variables (job satisfaction, work environment and psychological capital). The order of entry included job satisfaction first, then work environment and psychological capital in subsequent blocks. Job satisfaction was entered first as we understand it as the foremost important contributor to turnover as evidence by the literature. Work environment was entered second as it was also shown to be a significant predictor of turnover intentions in the literature. Psychological capital was entered last as it was a new concept to test in our understanding of turnover intentions in the nursing context. Therefore, the hierarchical approach was utilized as it enabled the researcher to identify if the variables of work environment and psychological capital made an additional contribution to the prediction of the turnover intentions over and above job satisfaction (Leech, Barrett \& Morgan, 2008).

\section{Assumptions}

Several assumptions existed in this study. The chosen methodology contained the assumption that the participants would have readily available internet access to complete the survey. It was also assumed that individuals who achieved Registered Nurse licensure would be 
able to read and comprehend the language used in the online survey. Additionally, it was assumed that when entering responses, participants would be trustworthy and honest. Having the ability to complete the survey anonymously and in a place and time of their preference, was anticipated to optimize the likelihood of receiving honest survey responses.

\section{Dissemination}

Findings from this study will be disseminated through the development of a research report, presentations at nursing research conferences and a publication directed to nurses, healthcare professionals, and policy-makers at the organizational level. Findings from this study will also be shared with the institution and with members of the nursing float pool through sharing of the published manuscript. By sharing study findings, knowledge of this phenomenon may encourage replication in future studies, and lend to further research opportunities related to improving retention of the nursing workforce.

\section{Threats to Internal and External Validity}

Threats to internal validity included the possible failure to measure the effect or control for extraneous variables that could influence job satisfaction, work environment, psychological capital and turnover intentions of NGNs. Some of these environmental factors could have been hiring freezes in the organization at the time of the study, changes in patient volumes and acuity and other unmeasured factors. To manage this possibility, current workplace issues at the time of data collection were discussed with the managers of the float pools and considered when interpreting the data. Threats were also documented in a logbook.

Threats to external validity may have also included potential selection bias and unique characteristics of the population that may not be generalizable to a greater population. Selection bias may have occurred through self-selection or voluntary participation by individuals for the 
study (Institute for Work and Health, 2015). Individuals who chose to join the study may share different or unique characteristics than non-participants and therefore, may have affected the outcomes of the study (Gray et al., 2017). Individuals who volunteered for the study may possess different characteristics than the average individual in the population of interest. Moreover, individuals who did not respond to email prompted requests to be studied generally have different baseline characteristics than responders. In order to mitigate selection bias stemming from a convenience sampling method, the researcher offered the opportunity to participate in the study to the entire float pool population at both sites. Demographic characteristics of the final sample were compared to other samples of new graduate nurses reported in the literature to assess for similarities and differences.

It is acknowledged that use of self-report instruments raises concerns regarding common method variance (Brunetto, 2016; Laschinger, Finegan, Shamian \& Wilk, 2001). However, previous research has suggested that common method variance may be more problematic with poorly designed or single item scales than well designed and validated multi-item scales (Laschinger et al., 2001). Given the demonstrated validity and reliability of the selected measures used in this study, common method variance concerns should be lessened. Methods for controlling bias included use of qualitative open-ended questions to confirm and validate quantitative scores.

\section{Ethical Considerations}

The proposed study received Research Ethics Board (REB) approval from Ryerson University and both of the selected hospital institutions (see Appendix M, N \& O). The rights of privacy and confidentiality were ensured for all participants in the study (Streubert \& Carpenter, 2011). To ensure privacy, participants were able to complete the online survey in the privacy of their own 
home or any place and time of their preference. To ensure anonymity, the researcher was unable to connect completed surveys to specific participants. Any study data collected including demographics such as age, gender and years in profession, were coded and did not contain names or email addresses that assisted in successfully identifying individual participants. If personal emails were voluntarily provided for the incentive draw at the end of the study, the emails were only accessible to the student researcher in a separate file on a secure shared drive to ensure participant confidentiality. Internet addresses were not collected after survey completion. All study files were maintained on a secure shared drive as an electronic document and deleted after the prescribed retention period appointed by the institutions and university. Moreover, participant rights to self-determination were protected through full disclosure and provision of adequate information pertaining to the study. This was contained in the letter of information and informed consent form based on the REB guidelines from each site. Each participant received a copy of the consent via work email for their own records. The consent to participate was provided in advance as an attachment to the recruitment emails. Confirmation of consent was implied through completion and submission of the online survey.

\section{Summary}

In this chapter, the methods for this quantitative non-experimental cross-sectional correlational study were described. The purpose of this study was to describe the factors influencing turnover intentions of NGNs employed in float pools through the exploration of relationships among the variables of job satisfaction, work environment and psychological capital (resiliency, efficacy, hope, and optimism) on turnover intentions. The research question and hypotheses focused on the possible predictive relationships among the selected variables. A convenience sampling method was employed to facilitate data collection in a short duration of 
time. In order to mitigate bias of using this method, the entire population of nurses employed in the float pool at two academic adult acute care hospitals were offered the opportunity to complete the web-based survey. Further recruitment was sought from a secondary site in order to improve sample size and response rates. The survey contained a brief demographic survey and four psychometrically sound and validated questionnaires (Nurse Global Satisfaction Scale, CWEQ-II, PCQ-12 and Intent to Stay questionnaire) to measure each study variable. Three openended qualitative questions related to turnover intentions were included to validate and elaborate upon the quantitative scores. The final survey included 47 items that required less than 15 minutes to complete. Data cleaning was performed by the student investigator and verified by the thesis supervisor using SPSS Statistics Version 25. Descriptive statistics were then utilized to describe the sample characteristics and study variables. Content analysis was conducted to identify themes from the qualitative open-ended questions. Some of the study hypotheses were tested using hierarchical multiple linear regression. Research ethics approval was received from both the university and institutional sites prior to study implementation. Concerns related to ethical considerations, threats to validity and study limitations were described and addressed along with mitigation strategies in order to increase the rigor of this research study. 


\section{Chapter 4: Results}

The purpose of this study was to explore and describe the relationships among job satisfaction, work environment and psychological capital (resiliency, efficacy, hope and optimism) and turnover intentions among new graduate nurses (NGNs) employed in float pools in an acute care hospital setting. This chapter begins with a description of the demographic characteristics of the float pool nurses who completed the online survey followed by descriptive results for the main study variables. Qualitative data from participant responses to the openended questions from the online survey are then analyzed. The chapter concludes with a presentation of the results of the statistical analyses required to answer each of the research questions.

\section{Sample Characteristics}

The participants of the study were NGN RNs $(n=56)$ employed in the float pool at two urban acute care academic hospitals (site A and site B) in Southern Ontario. Overall, 67 RNs completed the survey inclusive of both sites with a $29 \%$ survey response rate. There were 11 cases that did not meet inclusion criteria and were excluded from the sample, leaving 56 RNs in the final sample. The removed cases included six nurses who were employed for over five years as an $\mathrm{RN}$ in the float pool (and hence not new graduates) and five cases had less than three months experience (and were too new to experience the impact of the study concepts on turnover intentions). The demographics of the participants are presented below in Table 1.

The majority of the participants were female $(\mathrm{n}=43,76.4 \%)$ and $92.9 \%$ were employed full time at the time of the study. The age of participants ranged between 22-46 years of age, with a mean of 27.9 years. The length of time in the profession and role ranged from three months to five years, with a mean of two years. After data was collected and analyzed, inclusion 
criteria for years in position and years $\mathrm{RN}$ were increased to include up to five years to reduce further decrease in sample size and loss of fruitful participant responses. This decision was supported by previous researchers who suggested 10-26\% of nurses will intend to turnover after five years (Lavoie-Tremblay, 2008). Thirty-two percent $(n=18)$ of the participants had been employed in the float pool for less than one year.

Table 1. Descriptive Characteristics of New Graduate Nurses $(n=56)$

\begin{tabular}{|c|c|c|c|}
\hline \multicolumn{4}{|l|}{ Variable } \\
\hline & $\bar{X}$ & $S D$ & $R A N G E$ \\
\hline Age (Years) & 28.0 & 5.1 & $22-46$ \\
\hline Years RN & 2.0 & 1.4 & $0.3-5$ \\
\hline \multirow[t]{2}{*}{ Years Current Position } & 1.7 & 1.3 & $0.3-5$ \\
\hline & $n$ & $\%$ & \\
\hline \multicolumn{4}{|l|}{ Gender } \\
\hline Male & 12 & 21.8 & \\
\hline Female & 43 & 76.4 & \\
\hline No answer & 1 & 1.8 & \\
\hline \multicolumn{4}{|l|}{ Highest Level of Education } \\
\hline Bachelor's Degree & 53 & 94.6 & \\
\hline Master's Degree & 3 & 5.4 & \\
\hline \multicolumn{4}{|l|}{ Current Employment Status } \\
\hline Full time & 52 & 92.9 & \\
\hline Part time & 3 & 5.4 & \\
\hline Casual & 1 & 1.8 & \\
\hline \multicolumn{4}{|l|}{ Hiring Float Pool Cluster } \\
\hline Medical Surgical & 50 & 89.2 & \\
\hline Critical Care/Emergency & 6 & 10.7 & \\
\hline
\end{tabular}

Note. $\bar{X}=$ mean $; S D=$ standard deviation 
The descriptive results for the study variables are summarized in Table 2 on the next page. Overall, NGNs demonstrated moderate levels of job satisfaction $(\bar{X}=3.5$, range $1-5)$. It should be noted that the Empowerment Mean was calculated as a summated score. Overall, NGN's demonstrated a high level of Empowerment (41.5, range 12-60) and Opportunity $(\bar{X}=4.57$, range $1-5)$. On the contrary, it was noted that the lowest subscales of the empowerment dimension were support $(\bar{X}=3.02$, range 1-5) and resources $(\bar{X}=2.90$, range 1-5). NGNs showed high levels of psychological capital $(\bar{X}=4.56$, range $1-6)$. Of the four subscales of psychological capital, NGNs demonstrated highest scores in resilience $(\bar{X}=4.85$, range $=1-5)$ and lowest scores in efficacy ( $\bar{X}=4.11$, range $1-5)$. Finally, NGNs demonstrated moderate levels of turnover intention from their position $(\bar{X}=11.54$, range 4-20), yet low levels of turnover intention from the organization $(\bar{X}=8.69$, range $4-20)$. 
Table 2. Descriptive Results for Main Study Variables

\begin{tabular}{lllll}
\hline Variable & $\begin{array}{l}\text { Score } \\
\text { Range }\end{array}$ & $\bar{X}$ & SD & Cronbach's alpha \\
\hline Job Satisfaction & $1-5$ & 3.53 & .82 & .86 \\
Empowerment & $12-60$ & 41.48 & 6.32 & .83 \\
Opportunity & $1-5$ & 4.57 & .47 & .67 \\
Information & $1-5$ & 3.33 & .81 & .83 \\
Support & $1-5$ & 3.02 & .91 & .79 \\
Resources & $1-5$ & 2.90 & .73 & .72 \\
Global Empowerment & $1-5$ & 3.39 & .87 & .78 \\
Psychological Capital & $1-6$ & 4.56 & .72 & .91 \\
Efficacy & $1-6$ & 4.11 & 1.03 & .87 \\
Hope & $1-6$ & 4.58 & .70 & .82 \\
Resilience & $1-6$ & 4.85 & .82 & .80 \\
Optimism & $1-6$ & 4.79 & .94 & .80 \\
Turnover Intentions & & & & \\
Turnover Position & $4-20$ & 11.54 & 3.92 & .78 \\
Turnover Organization & $4-20$ & 8.69 & 3.86 & .78 \\
\hline Note. $\bar{X}=$ mean; SD= standard deviation & & \\
& & & & \\
\hline
\end{tabular}

All survey instruments demonstrated high reliability and internal consistency $(\alpha=.78-.91)$, as shown by the Cronbach's alpha values listed in Table 2. Low reliabilities were noted in the subscale of opportunity $(\alpha=.67)$ and resources $(\alpha=.72)$. The psychological capital instrument demonstrated the highest overall reliability $(\alpha=.91)$. The turnover intentions instrument demonstrated acceptable reliabilities as well $(\alpha=.78)$. 


\section{Analysis Results}

\section{Correlation Results.}

Bivariate correlation results for individual variables are presented in Table 3. Job satisfaction was found to have a moderate positive and statistically significant relationship with work environment (empowerment) $(\mathrm{r}=.563, \mathrm{p}<.05)$ as well as psychological capital $(\mathrm{r}=.470$, $\mathrm{p}<.01)$. Results also revealed a moderate negative and statistically significant correlation between job satisfaction and turnover intention from position $(\mathrm{r}=-.531, \mathrm{p}<.01)$ and organization $(\mathrm{r}=-.504, \mathrm{p}<.01)$. The work environment was found to be moderately correlated $(\mathrm{r}=.417, \mathrm{p}<.01)$ to psychological capital in a positive and statistically significant way while demonstrating a weak negative correlation to turnover from position $(\mathrm{r}=-.376, \mathrm{p}<.01)$ as well as a weak correlation to turnover from organization $(r=-.341, \mathrm{p}<.05)$.

Table 3. Correlation Matrix for Individual Variables

\begin{tabular}{|c|c|c|c|c|c|}
\hline Variable & 1. JS & 2. EM & 3. PC & 4. TP & 5. TO \\
\hline 1.Job Satisfaction & -- & & & & \\
\hline 2. Empowerment & $.563 *$ & -- & & & \\
\hline 3. Psychological Capital & $.470 * *$ & $.417 * *$ & -- & & \\
\hline 4. Turnover Position & $-.531 * *$ & $-.376 * *$ & $-.267 *$ & -- & \\
\hline 5. Turnover Organization & $-.504 * *$ & $-.341 *$ & $-.433 * *$ & $.635^{* *}$ & -- \\
\hline
\end{tabular}


Psychological capital was found to have a weak negative relationship to turnover intention from position $(\mathrm{r}=-.267, \mathrm{p}<.05)$, yet a moderate negative relationship to turnover intention from organization $(\mathrm{r}=-.433, \mathrm{p}<.01)$. Lastly, turnover from position showed a strong positive relationship to turnover from organization $(\mathrm{r}=.635, \mathrm{p}<.01)$.

A more detailed depiction of correlation results for variable subdimensions are presented below in Table 4.

Table 4. Subcategories Detailed Correlation Matrix

\begin{tabular}{|c|c|c|c|c|c|c|c|c|c|c|c|c|c|c|c|}
\hline \multicolumn{2}{|c|}{ Variable } & 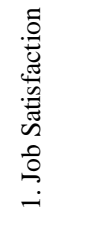 & 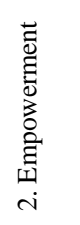 & 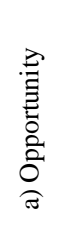 & 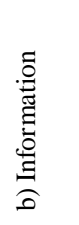 & 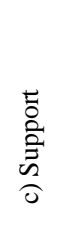 & 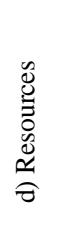 & 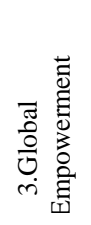 & 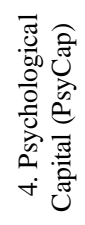 & 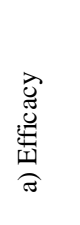 & 芒 & 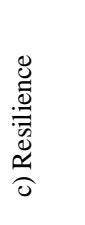 & 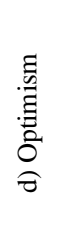 & 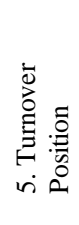 & 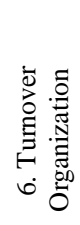 \\
\hline \multicolumn{2}{|c|}{ 1Job Satisfaction } & -- & & & & & & & & & & & & & \\
\hline \multicolumn{2}{|c|}{ 2. Empowerment } & $.56 * *$ & -- & & & & & & & & & & & & \\
\hline a) & Opportunity & .25 & $.47 * *$ & -- & & & & & & & & & & & \\
\hline b) & Information & $.53^{* *}$ & $.78 * *$ & $.32 *$ & -- & & & & & & & & & & \\
\hline c) & Support & $.33^{*}$ & $.78^{* *}$ & .15 & $.42^{* *}$ & -- & & & & & & & & & \\
\hline d) & Resources & $.45^{* *}$ & $.74 * *$ & .16 & $.42^{* *}$ & $.45^{* *}$ & -- & & & & & & & & \\
\hline \multicolumn{2}{|c|}{$\begin{array}{l}\text { 3. Global } \\
\text { Empowerment }\end{array}$} & $.64 * *$ & $.55^{* *}$ & .06 & $.39 * *$ & $.49 * *$ & $.50 * *$ & -- & & & & & & & \\
\hline \multicolumn{2}{|c|}{ 4.Psychological Capital } & $.48 * *$ & $.41 * *$ & .06 & $.52^{* *}$ & .22 & $.30^{*}$ & $.55^{* *}$ & -- & & & & & & \\
\hline a) & Efficacy & $.41 * *$ & $.40^{* *}$ & .04 & $.50^{* *}$ & .25 & $.27 *$ & $.43 * *$ & $.89^{* *}$ & -- & & & & & \\
\hline b) & Hope & $.45^{* *}$ & $.37 * *$ & .15 & $.48^{* *}$ & .15 & .24 & $.41^{* *}$ & $.86^{* *}$ & $.71 * *$ & -- & & & & \\
\hline c) & Resilience & $.37 * *$ & $.34 *$ & .07 & $.37^{* *}$ & .22 & .26 & $.49 * *$ & $.83^{* *}$ & $.63 * *$ & $.58^{* *}$ & -- & & & \\
\hline & Optimism & $.34 * *$ & .24 & -.13 & $.38^{* *}$ & .15 & .23 & $.53 * *$ & $.74 * *$ & $.51 * *$ & $.51 * *$ & $.57 * *$ & -- & & \\
\hline \multicolumn{2}{|c|}{ 5.Turnover Position } & $.53^{* *}$ & $\begin{array}{l}-.38 \\
* *\end{array}$ & -.24 & $.45^{* *}$ & -.20 & -.18 & $\begin{array}{l}-.39 \\
* *\end{array}$ & $-.27 *$ & -.17 & $-.28^{*}$ & -.21 & -.26 & -- & \\
\hline \multicolumn{2}{|c|}{ 6.Turnover Organization } & $\begin{array}{l}- \\
.51 * *\end{array}$ & $-.34 *$ & -.04 & $\begin{array}{l}-.45 \\
* *\end{array}$ & -.17 & -.24 & $\begin{array}{l}-.36 \\
* *\end{array}$ & $\begin{array}{l}-.44 \\
* *\end{array}$ & $-.32 *$ & $\begin{array}{l}-.39 \\
* *\end{array}$ & $\begin{array}{l}-.41 \\
* *\end{array}$ & $\begin{array}{l}-.34 \\
* *\end{array}$ & $\begin{array}{l}.63 \\
* *\end{array}$ & -- \\
\hline
\end{tabular}

Note: *. Correlation is significant at the $* p<.05$ (two-tailed)

**. Correlation is significant at the $p<.01$ level (two-tailed) 
Based on the correlational analyses, the first three hypotheses were supported by the data. For Hypothesis 1, job satisfaction was found to be statistically significant with a moderate negative correlation to turnover from position as reported via Pearson's $r(r=-.53, p<.01)$ as well as turnover from organization $(\mathrm{r}=-.51, \mathrm{p}<.01)$. For Hypothesis 2 , the work environment was negatively correlated with turnover intentions from position $(\mathrm{r}=-.38, \mathrm{p}<.01)$ and from organization $(r=-.34, \mathrm{p}<.01)$. For Hypothesis 3, psychological capital was weakly and negatively correlated to turnover intentions from position $(r=-.27, \mathrm{p}<.05)$ and turnover from organization $(\mathrm{r}=-.44, \mathrm{p}<.01)$

\section{Regression Results - Research Question 1.}

In order to investigate how job satisfaction, work environment and psychological capital predict turnover intentions, multivariate analysis using hierarchical multiple linear regression was conducted. As suggested by Leech, Barrett and Morgan (2008), the hierarchical approach was an appropriate method to use as the researcher had an a priori idea as to how the predictor variables (job satisfaction, work environment, psychological capital) fit together to predict the dependent variable (turnover intentions).

The standardized beta weights, presented in Table 5, suggest that job satisfaction contributed the most to turnover intentions to both position $(\beta=-.46, \mathrm{p}<.01)$ and organization $(\beta=-.38, \mathrm{p}<.01)$ when all predictors were considered.

Although a statistically significant relationship was found in the bivariate correlations of work environment and turnover intentions, regression analysis demonstrated that work environment (empowerment) was not found to be a statistically significant contributor to turnover intentions from position and from the organization when job satisfaction was included in the regression analysis $(\beta=-.12, \beta=-.03$ respectively $)$. 
Finally, although psychological capital revealed statistically significant correlations to turnover intentions, once entered into the regression model, psychological capital was not found to be a statistically significant contributor to turnover intentions from position and from the organization when job satisfaction was included in the analysis ( $\beta=.002, \beta=-.25$ respectively).

In relation to turnover from position, the adjusted $\mathrm{R}$ squared value was .25 . This indicates that all variables combined contributed to $25 \%$ of the variance in turnover intentions from position. Similarly, when using all variables simultaneously to determine turnover intentions from the organization, the adjusted R squared value was .27, explaining $27 \%$ of the variance in turnover intentions from the organization. Although the measures of work environment (empowerment) and psychological capital were significantly correlated with each other (as shown in Figures 1 and 2), neither contributed in a significant way to our understanding of turnover intentions in this model, as represented by the minimal R square change. 
Table 5. Hierarchical Multiple Regression Analysis Summary for Job Satisfaction, Work Environment (Empowerment), psychological capital, Predicting Turnover Intentions from Position and Organization. $(N=56)$

\begin{tabular}{|c|c|c|c|c|c|c|}
\hline Dependent Variable & Independent Variable & $\mathrm{b}$ & SEB & B & $\begin{array}{l}\text { Adjusted } \\
\mathbf{R}^{2}\end{array}$ & $\mathbf{R}^{2 \Delta}$ \\
\hline \multirow[t]{3}{*}{ Turnover Position } & $\begin{array}{l}\text { Step } 1 \\
\text {-Job Satisfaction }\end{array}$ & -2.53 & .55 & $-.53 * * *$ & $.27 * * *$ & .28 \\
\hline & $\begin{array}{l}\text { Step } 2 \\
\text {-Job Satisfaction } \\
\text {-Work Environment } \\
\text { (Empowerment) }\end{array}$ & $\begin{array}{l}-2.21 \\
-.075\end{array}$ & $\begin{array}{l}.67 \\
.09\end{array}$ & $\begin{array}{l}-.46^{* *} \\
-.12\end{array}$ & .26 & .01 \\
\hline & $\begin{array}{l}\text { Step } 3 \\
\text {-Job Satisfaction } \\
\text {-Work Environment } \\
\text { (Empowerment) } \\
\text {-Psychological Capital }\end{array}$ & $\begin{array}{l}-2.21 \\
-.08 \\
.01\end{array}$ & $\begin{array}{l}.71 \\
.09 \\
.75\end{array}$ & $\begin{array}{l}-.46 * * \\
-.12 \\
.002\end{array}$ & .25 & .00 \\
\hline \multirow[t]{3}{*}{ Organization } & $\begin{array}{l}\text { Step } 1 \\
\text {-Job Satisfaction }\end{array}$ & -2.40 & .55 & $-.51 * * *$ & $.25 * * *$ & .26 \\
\hline & $\begin{array}{l}\text { Step } 2 \\
\text {-Job Satisfaction } \\
\text {-Work Environment } \\
\text { (Empowerment) }\end{array}$ & $\begin{array}{l}-2.18 \\
-.05\end{array}$ & $\begin{array}{l}.67 \\
.09\end{array}$ & $\begin{array}{l}-.46^{* * *} \\
-.08\end{array}$ & .24 & .01 \\
\hline & $\begin{array}{l}\text { Step } 3 \\
\text {-Job Satisfaction } \\
\text {-Work Environment } \\
\text { (Empowerment) } \\
\text {-Psychological Capital }\end{array}$ & $\begin{array}{l}-1.77 \\
-.02 \\
-1.33\end{array}$ & $\begin{array}{l}.69 \\
.09 \\
.72\end{array}$ & $\begin{array}{l}-. .38 * \\
-.03 \\
-.25\end{array}$ & .27 & .05 \\
\hline
\end{tabular}

Note: $* p<.05, * * p<.01, * * * p<.001 ; b=$ unstandardized beta; SEB= standard error; $\beta=$ standardized beta; Adjusted $R^{2}=$ Adjusted $R$ square $; R^{24}=R$ square change 
Figures 2 and 3 represent the resulting models for turnover intentions to position and organization respectively.

Figure 2. Model of Turnover Intentions from Position

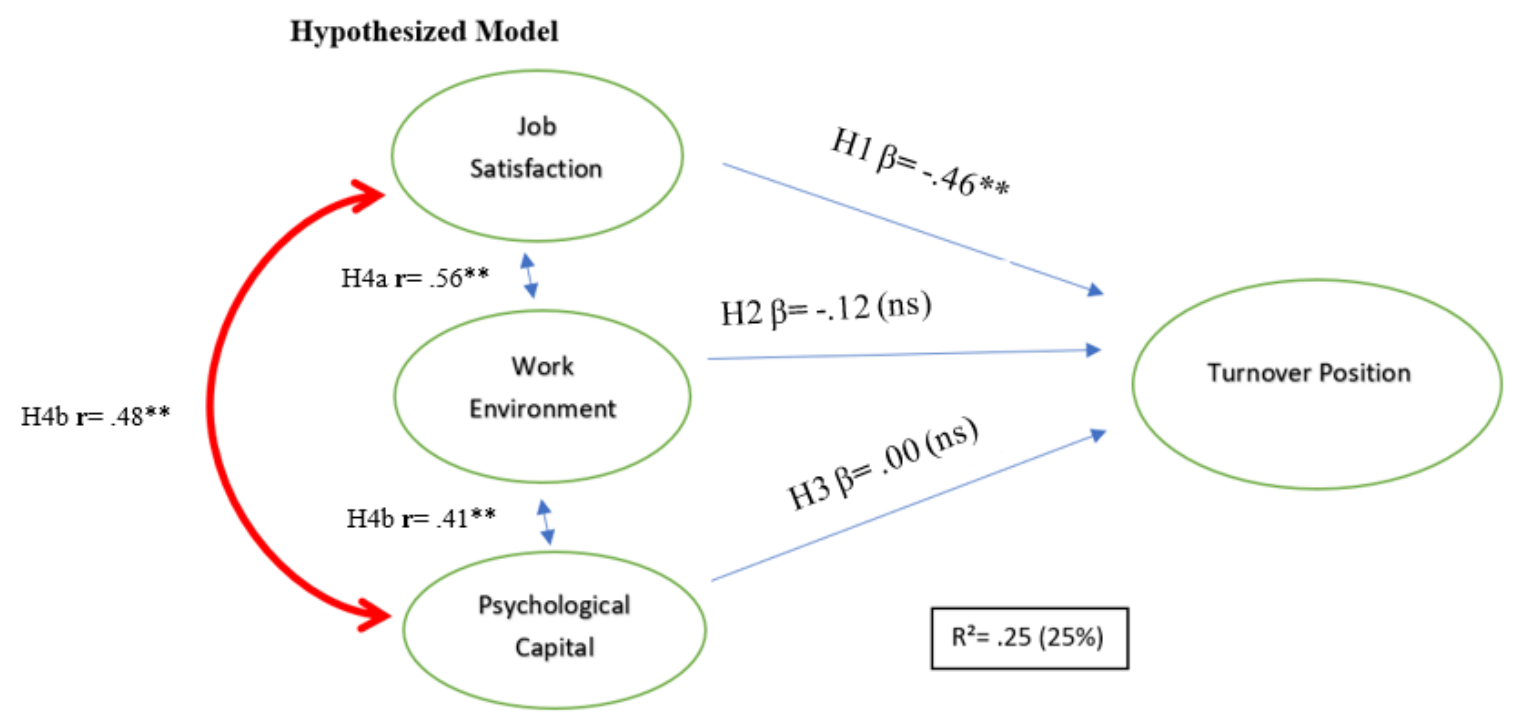

Figure 3. Model of Turnover Intentions from Organization

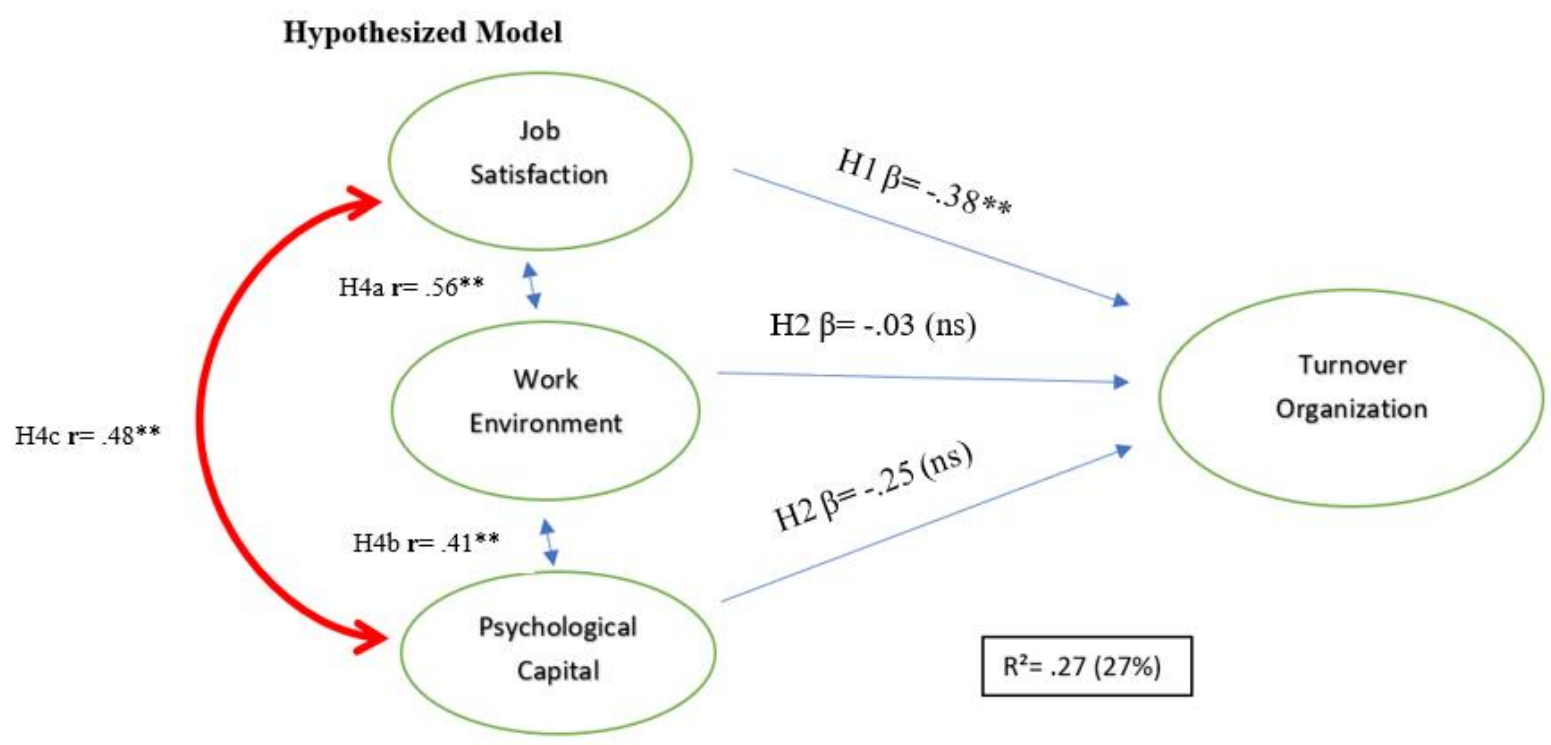




\section{Research Question 2}

To determine the inter-relationship between job satisfaction, work environment and psychological capital, three hypotheses were tested. Hypothesis 4(a) suggested that there will be direct positive relationships between job satisfaction and work environment. The hypothesis was supported by a moderate positive correlation between job satisfaction and work environment ( $\mathrm{r}=$ $.56, \mathrm{p}<.01)$. For Hypothesis $4(\mathrm{~b})$, testing if there was a direct positive relationship between work environment and psychological capital, the data supported by a statistically significant and moderate positive correlation between work environment and psychological capital $(\mathrm{r}=.41$, $\mathrm{p}<.01)$. For Hypothesis 4(c), examining if there would be a direct positive relationship between psychological capital and job satisfaction, the hypothesis was supported by a statistically significant and moderate positive correlation between psychological capital and job satisfaction $(\mathrm{r}=.48, \mathrm{p}<.01)$.

\section{Research Question 3}

What is the degree of turnover intentions among NGNs employed in float pools in an acute care hospital setting? Using a frequency distribution, the degree of turnover intention from position was calculated. Approximately one third of NGNs $32.1 \%(n=18)$ demonstrated low turnover intention, $41 \%(\mathrm{n}=23)$ reported moderate turnover intention, while $26.8 \%(\mathrm{n}=15)$ showed high turnover intention from current position within the acute care hospital setting. It was found that almost two thirds of NGNs $(64 \%, \mathrm{n}=36)$ demonstrated low turnover intention from the organization. Approximately $27 \%(\mathrm{n}=15)$ of NGNs revealed moderate turnover intention while only $9 \%(\mathrm{n}=5)$ reported high turnover intention from the organization. 


\section{Research Question 4 - Qualitative Analysis}

Three open-ended questions were included at the end of the survey in order to assess aspects of participant turnover intentions not otherwise captured by the quantitative data.

Responses were read word for word then organized into grouping/categories of similar responses and further clustered into themes that were generated from the text-based data extracted from the following three open-ended questions:

1. Identify your reasons for staying in your current position

2. What would be reasons to leave your current position or organization?

3. If you have thought about leaving the position or organization, what new position would you be seeking and why?

Table 6 includes a summary of the six themes identified as contributing to both reasons to stay and reasons to leave. These themes included: learning opportunities, working relationships, benefits, unit politics, proximity to workplace and uncertainty. It was noted that the absence or negative experience of these shared themes provided reasons to leave in the float pool role while the presence or positive experience of these themes contributed to reasons to stay.

Table 6. Themes derived from participant responses.

\begin{tabular}{cc}
\hline Reasons to Stay & Reasons to Leave \\
Learning Opportunities & Learning Opportunities \\
Working Relationships & Working Relationships \\
Benefits & Benefits \\
Proximity to Workplace & Proximity to Workplace \\
Unit Politics & Unit Politics \\
Uncertainty & Uncertainty \\
& Value Alignment \\
& Higher Education \\
\hline
\end{tabular}




\section{Reasons for Staying in Current Position.}

Six themes were identified as reasons to stay in their current position in the nursing float pool. Within the theme of learning opportunities, participants stated that they enjoyed the ability to gain clinical experience in a wide variety of clinical areas as well as opportunities for growth into non-bedside roles. The following are excerpts from three NGN's employed in the float pool provide support for the quantitative findings. "I am a new graduate and feel that NRT is the best position for me. It provides me with many different experiences by giving me an opportunity to meet different people and exposes me to new skills" (NGN \#9).

Great learning opportunities, such as exposure to different populations, conditions, and skills. I have been able to learn and become more competent with many nursing skills that I may not have if I were in one unit. For example, a nurse working in GIM rarely works with pre/post op patients (NGN \#31).

I love the diversity that ACNRT offers. I love being trained to new places and having the opportunity to experience different areas of nursing. I am trained to go to 13 different units and I love the challenge and excitement of that (NGN \#48).

Participants described important contributors of positive working relationships as enjoying meeting new people, having fun with fellow NRT colleagues as well as support from the department and leaders. As one NGN explained, "I enjoy floating to different units, see a variety of patient demographics, procedures, team members and how to work in different work cultures" (NGN \#11).

Benefits of working as a float pool nurse were described as being able to work in a fulltime role when full time positions within the organization were not available, good benefits including pension, accessible online work schedule, flexibility, easy to gain seniority quickly and greater independence. This was demonstrated in the following responses: "The seniority within NRT moves quickly, joining any ICU would mean possibly years until I'm senior enough to take 
time off in the summer as I need" (NGN \#12). "I enjoy the variety of skills and location, no unit politics and more independence, no micromanaging as well as opportunities to try new things" (NGN \#24). Proximity to workplace was also found to be an important consideration as one NGN shared: "I enjoy the proximity of my workplace to my living situation" (NGN \#21). Furthermore, ability to avoid unit politics was also an important contributor as one NGN stated, "I enjoy the variety of my position and you stay away from unit politics" (NGN \#45). Another NGN shared, "I enjoy learning new things and enjoy the change. Staying with NRT allows me to stay away from unit politics and be objective with my nursing care" (NGN \#54). Finally, uncertainty of career trajectory was found to influence reasons to stay for many as two NGNs shared the following: "I just started at this position and I'm still finding my way" (NGN\#14). "I am beginning my nursing practice and not sure where I want to specialize" (NGN \#10).

\section{Reasons to Leave Current Position or Organization}

In contrast, the six themes previously identified were also noted to influence reasons to leave if these work factors were not present or NGNs had negative experiences in the workplace. First, a lack of learning opportunities was noted to be a concern as one NGN noted:

Limitations on flexibility or opportunity to engage in nursing research/quality improvement as a staff nurse. Increasingly fast paced environment with growing demands and diminishing support systems (i.e. experienced RNs moving on to other units \& RN cuts), coupled with overworked nursing staff decreases enjoyment of being an RN. Feeling that I often can't fully care for and connect with patients as I was trained to because of constant competing demands (NGN\#25).

Furthermore, NGN's described how the presence of negative working relationships significantly impacted their roles. As one NGN noted: Sometimes NRT nurses get the 'short end of the stick' when assigned heavier patient loads, sometimes other [staff] nurses on units don't seem to like helping us, sometimes we get short notice changes in the unit assigned to us (NGN 
\#24). Other participants shared similar feelings of lacking a sense of belonging and difficulty building rapport with unit staff in the following excerpts: "Float pool nurses are often treated unfairly for example, are given heavier assignments by either more patients and/or difficult patients. This unfortunately makes shifts harder and leads to burnout" (NGN \#36). "Poor team dynamics. Being bullied" (NGN \#34).

I want to have a base unit (home), it can be difficult and challenging having different patients everyday and working with different people as they have different values, work ethics and it can be hard to develop a sense of trust and team work if you are not working with the same nurses (NGN \#21).

Moreover, NGN's also described their feelings of stress related to lack of resources and support as a float pool nurse in the following excerpts: "The workload issues on certain units, heavier assignments for NRT staff. Need more of receptive culture in welcoming NRT on units. The work environment in some units is not conducive to one's learning or experience" (NGN \#55).

I experience stress of not knowing where you are going to be placed; not knowing who you will be working with that day; Sometimes feeling less valued on the unit; Being given heavier assignments - being "dumped" on; Always having different patient assignments can be stressful and lack of continuity can feel unsafe at times; Not really having a home unit/home team can make me feel like I am missing out on a positive experience (NGN \#41).

Moreover, many NGN's shared they may choose to leave in order to seek further education such as a masters degree. "I would leave for further opportunities within the organization that can increase my skill set or leadership quality and/or graduation from graduate school and entering a field that would be suitable for graduate studies" (NGN \#53).

Lastly, some NGN's described how a perceived misalignment between their personal or professional values with those of the organization contributed to their intentions for leaving. "I would be looking to work in an organization that truly works by principles of patient safety first, and has a mission and tools in place to actually implement and achieve these principles" (NGN \#12). 


\section{Summary}

Hierarchical multiple linear regression was conducted in order to analyze the relationships between predictor variables (job satisfaction, work environment and psychological capital and the dependent variable of turnover intentions. All survey instruments demonstrated high reliability in this study. Although strong correlations were found between the independent and dependent variables, job satisfaction was determined to be the only significant predictor of turnover intentions from position $\left(\beta-.46^{* *}, \mathrm{p}<.01\right)$ and organization $\left(\beta-.38^{* *}, \mathrm{p}<.01\right)$. The variables of work environment and psychological capital were not statistically significant contributors to the model. However, approximately $25 \%$ of variance in turnover intentions from position and $27 \%$ of turnover intentions from organization were explained by the three predictor variables in this model. Qualitative analysis of participant responses to open ended questions was conducted to further assist with interpretation of the relationships. Six themes were extracted from the text as contributing to both reasons to stay and reasons to leave. These themes included: learning opportunities, working relationships, benefits, unit politics, proximity to workplace and uncertainty. Two additional themes of value misalignment and seeking higher education were found to influence NGN's reasons to leave. Based on these results, a discussion of the key findings, implications, and recommendations for future research surrounding this phenomenon is continued in Chapter 5. 


\section{Chapter 5: Discussion}

The purpose of this study was to explore and describe factors influencing turnover intentions among new graduate nurses (NGNs) employed in float pools in the acute care hospital setting. In this study, a theoretical model was tested. The theoretical model consisted of the dependent variable of turnover intentions, considering turnover from both position and organization, as well as three independent variables including job satisfaction, work environment and psychological capital. Although many studies have examined NGNs transition to practice as well as each study variable independently, no study to date has investigated all of these concepts together and in the context of NGNs employed specifically in float pools.

A descriptive cross-sectional, correlational non-experimental design was utilized to achieve the aims of this study. Data were collected from 56 NGN's from two urban acute care academic hospital sites in Ontario, Canada over a four-month period from May-September 2018. Overall, four of the six research hypotheses were supported. Of the tested relationships, job satisfaction was the most significant and direct predictor of turnover intentions.

In this chapter, a detailed discussion of the findings specific to the factors influencing turnover intentions among NGNs employed in float pools will be presented. Implications for nursing practice, education, policy and research will follow. The chapter ends with a discussion of study strengths, limitations and final conclusions.

\section{Discussion of Key Findings}

\section{Job Satisfaction.}

As hypothesized, job satisfaction had a strong negative correlation with turnover from position as well as turnover from the organization. Job satisfaction explained the most significant 
amount of variance in turnover intentions of NGNs in the model. Additionally, most NGNs in the sample reported moderate levels of job satisfaction at work in their role within the float pool.

The important role of job satisfaction for NGNs employed in float pools is consistent with previous research where job satisfaction was found to be the foremost indicator of a nurse's likelihood to remain in a role within an organization and is an important factor influencing turnover in the nursing profession (Brewer et al., 2012; Hairr et al., 2014; Hayes et al., 2012; O’Brien-Pallas et al., 2010; Tellez, 2012; Wang et al., 2012). Specifically, job satisfaction was negatively correlated with turnover intentions as reported in earlier studies that also found job satisfaction to be related to voluntary turnover itself (Brewer et al., 2012; O'Brien-Pallas, 2010). Kenny, Reeve and Hall (2016) found that job dissatisfaction with the work environment among NGNs also comprised one of the factors predicting the intent to leave. Furthermore, job satisfaction has been extensively associated with other significant antecedents of turnover including nurse-patient workloads, negative work environments and cultures, as well as varying degrees of organizational and collegial support (Parker et al., 2014). The qualitative themes in this study further corroborated these findings where instances of inappropriate patient workloads, uncivil working relationships, and lack of support by unit staff or management contributed to decreased satisfaction in the work environment, potentially contributing to turnover intentions.

Moreover, a strong positive correlation was identified between job satisfaction and work environment. Workplace factors have been positively correlated with job satisfaction including leadership support, recognition, promotional opportunities and also status and salary within an organization (Spetz, 2010). Within the preliminary years of professional practice, it is recognized that job satisfaction of NGNs is greatly dependent on the collective capacities among individuals, units and organizations to engage and support them towards fulfilling the responsibilities and 
expectations of an RN (Parker et al, 2014). Additionally, in one Ontario based study aimed to understand the work-life experience of NGNs, Laschinger (2012) acknowledged that empowerment, incivility and emotional exhaustion were significant predictors of job satisfaction, particularly within the first year of professional practice. Mindful of this research, it is possible that the quality of the work environment may be an antecedent of job satisfaction that, in turn, influences turnover. This alternate theoretical model may better explain the relationships among job satisfaction, work environment and turnover intentions for NGNs employed in float pools.

\section{Work Environment (Empowerment).}

Work environment, as measured from an empowerment perspective, was found to be negatively correlated with turnover intentions from both position and organization as predicted with bivariate correlations; however, the results were not statistically significant in the regression model.

Overall, participants in this study demonstrated high levels of empowerment. Similar to a previous survey of Canadian NGNs (Rheaume et al., 2011), the NGNs in this study felt empowered in their current role in the float pool. This may be attributed to their ability to thrive in new experiences and conquer new skills i.e. having access to opportunity to learn and grow (Kanter, 1977). This finding contradicts previous findings from studies where NGNs have been described as feeling insecure, fearful, and overwhelmed in the face of increased responsibility and novel tasks (Duchscher, 2012; Guay et al.,2016). There are several possible reasons for these differences. While many individuals would dislike the idea of temporary placement, NGNs working in the float pool enjoy the variety of their clinical role and the benefits and challenges that come with exposure to new situations that make them more adaptable and marketable nurses (Larson et al., 2012; Linzer et al., 2011). In fact, it is this variability, the openness to engage in 
learning new practices in patient care and the feeling of independence is what often attracts NGNs to the float pool (Lebanik \& Britt, 2015; Shinners et al., 2016; Straw, 2018).

NGNs also demonstrated high scores in the sub dimension of opportunity. This finding was further validated by the narrative comments. Reasons to stay in the float pool were attributed to a plethora of learning opportunities and professional development in a variety of clinical specialties and patient populations. Wing et al. (2015) also found that gaining knowledge through new opportunities allowed NGNs to build confidence and clinical competence in their professional practice. These findings suggest that increased opportunities in the workplace may contribute to an individual's desire to stay within a position rather than leave.

The two lowest mean score subscales of the empowerment dimension were support and resources. The NGNs in this study reported that they often felt unsupported on the unit when given heavier or more challenging patient assignments than unit staff, treated as 'outsiders' by unwelcoming unit cultures, and not being able to find supplies or resources needed to provide care effectively and efficiently, all leading to potential burnout. Similarly, Wing et al. (2015) reported lowest mean scores of access to support in their sample of NGNs, acknowledging that NGNs found value through support from peers and regular clinical guidance and feedback from other health professionals in the work setting. This finding was also consistent with previous findings (Laschinger \& Grau, 2012; Pineau Stam, 2015) where NGNs reported experiencing workplace incivility and where limited access to empowering workplace structures was found to reduce the quality of nursing work experiences. These findings suggest important steps are required in order to eliminate these subtle forms of hostility from healthcare work environments, which have been voiced as a contributing theme (negative working relationships) to turnover intentions of NGNs employed in the float pool in this sample. 


\section{Psychological Capital.}

After controlling for job satisfaction, psychological capital was not found to be a statistically significant contributor to turnover intentions from position or organization. Overall, NGNs demonstrated high levels of psychological capital. Of the four subscales of psychological capital, NGN participants in this study demonstrated lowest scores in efficacy and the highest scores in resilience. It is understood that while individuals with heightened confidence possess greater cognitive capacities towards achieving their personal goals (Bandura, 1997; Luthans \& Youseff, 2007), individuals who possess low self-efficacy are more vulnerable to despair, failure and self-doubt. In this way, the NGNs participants who demonstrated low self-confidence (efficacy) may be more susceptible to despair, failure and self-doubt which may put them at greater risk of leaving their position. Previous literature has also recognized stressors for NGNs included lack of confidence and experience, perceived lack of support, reliance on others and interactions with other healthcare team members (Morrow, 2009; Wing, Regan \& Laschinger, 2015). Similarly, NGNs in this study reported feeling uncertain in new situations, required orientation to new units for resources and unit specific protocols and relied on staff nurses more often when unfamiliar with unit expectations or cultures.

NGNs may not have felt they had the capability to mobilize their cognitive resources and act in ways to execute a given task effectively and successfully in their role. This is not surprising as many NGNs reported lacking confidence as it was their first professional role and they were still navigating through skills and experiences. According to Laschinger \& Grau (2013), nurses with more positive psychological capital have enhanced awareness of their job suitability and experience less emotional exhaustion than those with lower levels of psychological capital. This is congruent with the qualitative findings from this study where 
NGNs working in the float pool reported that they enjoyed the benefits and experiences that were associated with their role overall.

Participants also revealed high levels of resilience. According to the literature, the proactive approach of resilience has been frequently identified as a strong predictor of workrelated outcomes and has shown promise to future workplace development and management (Luthans et al., 2006; Luthans \& Youssef, 2007; Luthans et al, 2010). In this current study, NGNs discussed feeling resilient in 'bouncing back' from barriers or challenges experienced in their nursing role within the float pool. They demonstrated their resilience by considering such adversity as learning opportunities that allowed them to grow professionally and personally as new nurses. According to Luthans \& Youssef (2007), this resilient approach engages an individual's adaptive mechanisms that are flexible and creative in nature and contribute toward the achievement of organizationally and personally significant goals. Nurses who work in float pools have often been described as having the unique characteristic of flexibility and adaptability in any given environment, which makes them high-functioning and diverse healthcare providers, and an incredible asset for organizations. Most recently, in a cross-sectional study investigating the impact of resilience on turnover in NGNs, Yu \& Lee (2018) emphasized the significance of resilience on NGNs' turnover intentions, suggesting that their turnover intentions can be altered, based on how they overcome their dissatisfactory job environments or if they possess a high degree of resilience. As a result, resilience contributes to the promotion of an NGNs' control of negative emotions and has been found to play an important part in the promotion of job satisfaction (Yu \& Lee, 2018; Hudgins, 2016).

In the current study, psychological capital did not significantly predict turnover intentions of the NGNs employed in float pools when job satisfaction and work environment were 
considered in the model despite a moderate negative correlation to turnover intentions from their position as well as turnover from the organization when considered alone. Overall psychological capital has been previously shown to be related to both desirable and undesirable employee behaviours in numerous studies. Based on a meta-analysis conducted by Avey et al. (2011), significant positive relationships were found between psychological capital and job satisfaction as well as organizational commitment. Significant negative associations between psychological capital and undesirable attitudes included cynicism, turnover intentions and job stress/anxiety. Laschinger et al. (2016) have also suggested that psychological capital may have protective effects for NGNs by assisting them to cope with job demands and reduce possible burnout. Bandura's (1997) theory of self efficacy suggests that employees often utilize their psychological capital in times of stress as a method to stay motivated and develop proactive strategies for overcoming adversity and obstacles encountered at work.

In this study, there was a moderately positive correlation between psychological capital and job satisfaction. This positive relationship is consistent with the work of Pineau Stam et al. (2015) in their secondary analysis of NGNs from a larger study and Luthans et al., (2007a) who discovered a significant relationship between psychological capital and job satisfaction for employees of business and manufacturing industries. Therefore, psychological capital could also be an antecedent of job satisfaction that, in turn, influences turnover.

Although psychological capital is described as an individual resource, it is significantly related to external factors including both contextual and interpersonal in nature. Therefore, in order to develop psychological capital, research has shown that a positive and supportive work environment is essential, particularly for NGNs in order for them to accumulate more positive experiences that can therefore develop psychological capital (Laschinger \& Grau, 2013; Luthans 
et al, 2008; Pineau et al., 2015). In the current study, the concepts of work environment and psychological capital were found to be moderately positively correlated. This finding suggests that individuals with an enhanced overall sense of well-being may have more job satisfaction related to their work environment, may be better equipped to achieve their personal and professional goals in an ever-changing environment, and may protect against negative behavioural and organizational outcomes such as turnover intentions (Avey et al., 2011; Luthans et al., 2007; Newman et al., 2014).

\section{Turnover Intentions.}

This study found that approximately one third of NGNs in the float pool were at risk of leaving their position, which could be interpreted as a warning sign to the organization. Previous studies have identified that approximately $24 \%$ of new nurses intended to leave their position within two years (Kovner et al., 2007, Peterson et al., 2011). The most common reasons for NGNs employed in float pools to intend to leave were lack of learning opportunities, negative working relationships and the desire to seek higher education.

Mindful of the demographics of the sample of NGNs in this study, where the age of participants ranged from 22-46 years with a mean of 27.9 years of age, the younger generation of nurses may be more inclined to leave a position to further develop their own professional aspirations including acquiring graduate degrees and advanced practice nursing roles. Previous studies have shown that younger nurses may want to pursue further qualifications while older nurses are typically more committed to their organization (Hayes et al., 2015).

Almost two thirds of NGNs demonstrated low turnover intentions from the organization. This finding is positive news for organizations as they have an opportunity to develop strategies to retain NGNs more effectively. 
In a large pan-Canadian study investigating the impact and key determinants of turnover, O’Brien-Pallas et al. (2010) identified important reasons to leave based on broad nursing samples from 18 healthcare sites representing 182 units in 41 hospitals across 10 provinces. Reasons included, lack of team support (poor working relationships with managers, other nurses and physicians), professional effectiveness (inability to deliver care according to clinical competency), low job satisfaction and employer support (salary and support for ongoing professional development) (O’Brien-Pallas et al., 2010). However, similarities existed in their voiced concerns related to the themes of working relationships and need for increased support and resources while floating. Unlike O'Brien-Pallas' study, the sample of NGNs in this study demonstrated moderately high levels of job satisfaction in their role which contributed to lower levels of turnover intent overall.

\section{Overview of Theoretical Model}

Turnover intentions from. position and the organization were examined to determine the influence of job satisfaction, work environment (empowerment) and psychological capital. Based on the hierarchical regression results, there was a statistically significant and direct negative effect of job satisfaction on turnover intentions related to both position and organization. Although the measures of work environment (empowerment) and psychological capital were significantly correlated with one another and to job satisfaction, neither contributed substantially to our understanding of the factors influencing turnover intentions of this cohort using the proposed study model. Overall, job satisfaction was the most critical factor influencing turnover intentions of NGNs employed in float pools in the acute care setting. 


\section{Strengths}

This study is the first of its kind to investigate the factors influencing turnover intentions among NGNs employed in float pools which includes job satisfaction, work environment (empowerment) and psychological capital. An additional strength of this study was the use of open-ended qualitative questions within the survey. The qualitative responses from participants strengthened our understanding of the quantitative results by offering further explanations as to why or how job satisfaction, work environment and psychological capital impacted their turnover intentions.

Although work environment and psychological capital were significantly correlated with turnover in previous nursing research (Boamah \& Laschinger, 2016; Pineau Stam et al., 2015; Read \& Laschinger, 2017; Rheaume et al., 2011), they did not contribute any additional variability in turnover intentions over and above the influence of job satisfaction in this study. The uniqueness of this cohort working in float pools as compared to staff RNs might have accounted for this finding. NGNs stated they enjoyed the benefits of avoiding unit politics, engaging in learning opportunities and ability to leave unwelcoming unit environments after each shift. The flexibility and ability to walk away from unpleasant work environments or unit level conflict might contribute to higher satisfaction of NGNs in the float pool. Further research to determine the influence of the work environment and psychological capital on NGN float pool nurses could help to understand these relationships.

\section{Limitations}

A limitation of this study included recruitment of participants to achieve the desired sample size. Due to the unforeseen turnover within the float pool prior to data collection at one organization, the available sample had decreased to less than half the expected pool of potential 
participants. Turnover intention of this cohort may have been higher, however more than half of the NGNs in the float pool had already left prior to the data collection phase. This may have been attributed to contextual issues within the workplace, including management concerns, unmanageable workloads and an influx of job openings on other more desirable specialty units. To overcome insufficient sample size, further recruitment was sought from a secondary site with a larger total population. However, the overall sample size $(n=56)$ did not meet minimum sample size $(n=64)$ requirements for this study. As a result, there is also the possibility of type II error due to lack of power to reveal statistically significant relationships, which may account for the insignificant findings in this study.

Findings may not be generalizable to the greater population of NGNs at either site or in other Canadian healthcare institutions that utilize nursing float pools as a result of small sample size. In the future, a study of a larger scale would allow for a larger sample size to support and compare findings from this study. That said, the latest 2017 Canadian Health Institute for Health Information (CIHI, 2018) report of nursing workforce characteristics reveals similarities of the study sample to overall population of nurses in Canada.

The demographic data from this study revealed a mean age of 27.9 years for NGNs employed in the float pool which is similar to national data where $15.8 \%$ of Registered Nurses providing direct care are under 30 years of age (CIHI, 2018). The study sample demographics therefore represents the overall population of Canadian nurses to some degree and may enable a limited generalization of the study findings.

The findings of the study must be interpreted with caution as a correlational design was used which cannot infer causality. Future research using a longitudinal design could potentially offer improved assessment of changes over time and glean a greater understanding of the 
relationships among the variables of job satisfaction, work environment, and psychological capital to turnover intentions among NGNs in float pools.

Although the non-probability sample was selected via convenience sampling, the entire population of NGNs employed in the float pool at each site were offered the opportunity to participate in the research study (given they met eligibility criteria) as an alternative to random sampling. Selection bias may have occurred through self-selection or voluntary participation by individuals for the study (Institute for Work and Health, 2015). Individuals who chose to join the study may share different or unique characteristics than non-participants in regards to intentions to leave their position or organization. Therefore, the outcomes of the study may have been affected.

Lastly, generalizability of the results may be impacted by the low survey response rate despite using the Dillman (2000) method and offering an incentive. Recent research has shown that survey response rates are declining among healthcare professionals (Cook et al., 2009), possibly as a result of increased workloads and time constraints (VanGeest and Johnson, 2011). This poses a challenge for potential participants to find time to respond to invitations to participate in research.

\section{Implications.}

\section{Implications for Practice.}

As a result of the most significant finding from this study, it is imperative for organizations to provide further support to adopt, continue, and restore efforts to enhance job satisfaction of NGNs in acute healthcare settings. There is a need to enhance support and resources in the work environment for NGNs employed in the float pool given that work environments are strongly associated with job satisfaction. These findings have implications for 
nurse educators, management and point of care leadership such as unit nursing staff in the creation of welcoming work cultures and relationships. There is a need for a collective and collaborative effort to improve support at the social, educational, informational, and organizational level for NGNs in order to retain them. Given that one third of NGNs in this study were at a high risk of turnover, the cost of turnover has the potential to be detrimental to the organization. Furthermore, new data analysis from the 2017 CIHI report (CIHI, 2018) revealed that declining numbers of NGNs in combination with the growing outflow of late career nurses has led to a reduction in growth of employed regulated nurses in Canada. This further supports the importance for organizations to address the concerns revealed in this study in order to successfully retain NGNs.

This study has raised awareness of the concerns and needs of NGNs in the float pool that relate to their reasons to stay and leave. Nurse leaders as well as point of care staff play a crucial role in ensuring that NGNs experience high quality and empowering work environments that offer the availability of the necessary resources to perform quality nursing care. In this study, the NGN self-reports of hostility, incivility, and lacking a sense of belonging further suggest that leaders at the organizational level need to act to strengthen civility and respect in the workplace to mitigate hostile work environments. In particular, NGNs reported feeling more vulnerable to uncivil behaviour due to their status in the float pool where they are perceived as less capable or competent by others. This finding is aligned with Wing Regan \& Laschinger's (2015) findings where NGNs were targeted by nursing staff due to their perceived lower status within the organization. As Lavoie-Tremblay (2008) previously found, the current generation of NGNs expects to hold positions that provide recognition, advancement and social support while feeling perceived as valued members within their organization. Given the link between professional 
development and turnover intentions, nurse leaders within organizations should also provide opportunities for NGNs to discuss their career ambitions and to consider professional development initiatives that would help them achieve their career goals within the existing organization (O’Brien-Pallas, 2010).

Nurses could benefit from empowering working conditions where strategies are implemented such as zero tolerance policies for workplace bullying, regular unit meetings with point of care staff to improve professional relationships and overcome unit conflicts, and where it is an expectation for all interdisciplinary team members to engage in respectful interactions (Laschinger et al., 2012; Laschinger et al., 2016). These strategies, among many others, may have the potential to be effective in enhancing empowering work environments, workplace civility and may contribute to improved job satisfaction for NGNs in the float pool across organizations.

In light of NGNs reporting difficulties finding support during challenging situations and lack of visibility of leadership for this cohort, future strategies may include formal and/or informal weekly drop-in support sessions for NGNs before or after their shift where emotional and social support could be provided ideally by the manager, other NGNs or more experienced nurses in the float pool. It is also recommended that NGNs develop a relationship with a mentor post orientation to further assist with emotional or social support in the clinical setting. With additional support provided early in their career, perhaps NGNs may feel better equipped and familiar with units and organizations, contributing to greater success in transition. It is also recommended that nursing staff on inpatient units be provided with more information and education surrounding the value and clinical capabilities of NGNs working in float pools in order to better support their sense of belonging and collegiality. 
Lastly, open communication with leadership, preceptors or mentors should be promoted regarding the challenges NGNs experience while floating such as caring for critically ill patients, feeling overwhelmed by patient assignments and workload, uncertainty with unfamiliar populations or units, and stressful or uncivil work environments. This increased awareness and open dialogue may promote practice change in the future at the unit level and result in the cultivation of a more supportive work environment.

On a positive note, approximately two thirds of NGNs employed in the float pool in this study were not at risk of turnover intentions. The NGNs in this sample reported moderate satisfaction in their current role. Many NGNs described the broad learning experiences and opportunities that come with being a float pool nurse where they have the unique ability to provide care for a variety of patient populations across multiple specialties, an advantage that would not be possible on a single unit. Many NGNs also reported satisfaction with the benefits of being employed in the float pool including flexibility, scheduling, avoiding unit politics, full time status, and ability to acquire seniority at a faster rate than on a specialty unit. Not only does the flexibility of the float pool promote satisfaction in NGNs, it also supports the healthcare organization's financial viability and further promotes safe staffing at the point of care (Shinners, 2016).

Through diverse patient assignments, float pool nurses have extensive opportunities to develop and refine their clinical skills and competencies through exposure to a variety of specialty clinical areas (Lebenik \& Britt, 2015; Rainness et al., 2015). In this way, float pool nurses have the potential to become high-functioning and skilled practitioners who contribute a unique organizational perspective through their vast experience and observation of professional practice from one unit to another (Rainness et al., 2015). 


\section{Implications for Education.}

In baccalaureate nursing programs, nursing students are exposed to an array of clinical experiences rather than one specialty area in an attempt to prepare them as generalist practitioners. This broad exposure may make NGNs more adaptable and flexible to float pool nursing. However, having NGNs employed in float pools as their initial entry to practice role has previously been widely discouraged and instead, exposure to a consistent practice environment has been recommended for NGNs (Dziuba-Ellis, 2006). With the ever-changing healthcare climate and staffing concerns of today, it is a real possibility for NGNs to be employed in float pools at the entry to practice level.

Career counseling for nursing students may be a possible strategy to prepare students to openly consider a variety of employment options, including a nursing resource team or float pool (Price, 2015). In consideration of the unique needs and career aspirations of the Millennial generation nurses, which frequently include a need for change and growth (Hayes et al., 2012, nursing resource team or float pool nursing may be an appealing option that offers variety, flexibility, and choice and could be presented as a nursing specialty in the final year of nursing practicum.

Given that psychological capital is related to job satisfaction, it is important to promote psychological capital as it is amenable to change and can be developed (Luthans et al., 2008, 2010). There have been numerous successful interventions where psychological capital has increased in nurses who have participated in online modules as well as training interventions designed to develop these intrapersonal resources (Luthans et al., 2008, 2010). An example of one existing program is the Psychological Capital Intervention (PCI) (Luthans, Youssef, \& Avolio, 2007). In order to develop hope, participants are guided to establish realistic 
work-related goals that also hold personal meaning. Optimism is then developed through the creation of paths to the goals and plans to deal with obstacles that may arise. Efficacy is developed through vicarious learning via group processes and through the mastering of tasks to achieve established goals. Finally, resilience is developed through the exploration and usage of the individual's personal assets including talents, social networks and skills. This type of training intervention or online module may be useful to incorporate in nursing programs (undergraduate and continuing education offerings) in order to foster the intrapersonal resources of NGNs prior to entry to practice.

With this in mind, it is suggested that NGN's clinical competency and psychological capital be cultivated early on through the provision of positive reinforcement for success, discussion of situations and outcomes with reliable and trusted preceptors and/or mentors, and discussion of realistic goals (Pineau Stam et al., 2015). By offering supportive learning experiences and effective role modeling with a positive vision of professional nursing, psychological capital can be strengthened in NGNs early on and may better prepare them to effectively transition into professional practice. Noting the significant associations found in this study between both work environment and psychological capital and job satisfaction, these recommendations may improve the overall job satisfaction of NGNs, lead to improved retention and decreased turnover intentions in the future.

\section{Implications for Policy.}

With the provincial government promising to open approximately 15,000 long term care beds over the next five years (Personal Communication. Hepburn, B, May 23, 2018) and no verbalized plan to support additional staffing, the ability to recruit and retain the NGNs in the workforce and the continued utilization of float pool nurses remains vital. Health Human 
Resource (HHR) planners continue to strategize solutions to address nursing shortages across all jurisdictions in Canada. As Canadian healthcare organizations continue to face fiscal constraints, the utilization of nursing float pools and resource teams are credited as one cost saving and efficient staffing strategy (Dziuba-Ellis, 2006; Linzer et al., 2011). Despite recent literature discouraging the hiring of NGNs into the float pools as the initial entry point to professional nursing practice, greater numbers of NGNs have been entering the workforce via float pools due to recruitment and retention initiatives, such as the New Grad Guarantee (NGG) (Dziuba-Ellis, 2006; Shinners et al., 2016). The importance of continued sustainable funding for NGNs transitioning to practice, including the New Grad Guarantee (NGG), cannot be understated. If financial cuts are made to the orientation and training funding for NGNs, turnover could be negatively impacted, leading to further nursing shortages.

At the organizational level, it may be worthwhile for administrators to invest in resources that foster positive working cultures and collegial relationships in order to improve retention and recruitment of NGNs within the organization (Wing et al., 2015). High turnover and low retention of frontline NGNs may cause substantial financial losses and reduce a healthcare organizations' ability to provide efficient patient care services (Hayes et al., 2012). The cost of replacing a medical surgical nurse has been estimated to be between $\$ 42,000$ and $\$ 64,000$ per specialty nurse (O'Brien-Pallas et al., 2010). For this sample, 30\% of NGNs with high turnover intentions could result in potential turnover costs of approximately $\$ 798,000$ across the two organizations for only one year. While these direct costs may represent a significant loss, even more detrimental to an organization is the indirect cost related to decreased productivity of a new employee and the overall group, as well as reduced staff morale (O’Brien-Pallas, 2010). As a 
result of the loss of productivity associated with acquiring new employees, the cost of turnover has potential to be substantially higher than is currently accounted for.

There is a need for organizations to consider strategies that mitigate nurse turnover rates and improve retention in order to ensure consistent care delivery, prevent loss of valuable clinical expertise and reduce costs of potential turnover. Institutions need to move away from unit-focused approaches and invest in organization-wide ways of thinking to better support, retain and sustain NGNs working as float pool nurses (Shinners et al., 2016). Supporting a successful transition to professional practice is fundamental to successfully retaining NGNs in the nursing workforce and ensuring healthcare needs of the population are addressed now, and in the future (Regan et al., 2017).

\section{Implications for Theory.}

The utilization of a positive psychology lens, specifically Positive Organizational Behavior (POB), may be effective in enhancing our understanding of how organizations can recognize the factors influencing turnover intentions of NGNs. In this way, organizations may be able to mitigate these factors through the development of positive initiatives that build on and support the psychological capacities of NGNs, allowing them to flourish in today's dynamic healthcare environment. Utilizing the POB approach has potential implications for performance management and health human resource (HHR) planning and development (Luthans et al., 2008). This may be significant for leaders in healthcare organizations to develop strategies to spontaneously elicit desired organizational behaviours from front-line nurses and contribute to further retention of NGNs (Lin \& Chang, 2015). POB theory offers the potential to uncover better ways to transform the workplace into a positive culture that fosters teamwork, professionalism and camaraderie (Muha \& Manion, 2010) and has potential to maintain 
increased levels of job satisfaction. This is certainly important for NGNs in float pools given their concerns about unit politics, negative working relationships and the need for increased support in the workplace. Ensuring the retention of NGNs employed in float pools may require a more nuanced approach in the planning and delivery of healthcare services and further understanding of the needs of NGN's working in the current healthcare environment.

While psychological capital has been previously linked to turnover intentions, it did not demonstrate a significant effect in this study after controlling for job satisfaction. Similarly, Kanter's theory of empowerment has previously been shown to be significantly associated with turnover intention of NGNs. Kanter's theory of structural empowerment was selected for this study as it offers a valuable framework for understanding how structures of the work environment (access to information, support, resources needed to do the job and opportunities to learn and grow) impact work attitudes and behaviours and has previously been shown to be a significant predictor of organisational outcomes within the nursing profession (Kanter, 1977, 1993; Boamah \& Laschinger, 2016; Laschinger, 2012). However, findings revealed an empowering work environment did not contribute significantly to turnover intentions over and above job satisfaction in this study. Although empowerment did not contribute to the overall variance to turnover intentions, findings further revealed NGNs in this study demonstrated low levels of support and resources in their role. The fact that NGNs were lacking two of the four structures needed for an empowering work environment may have contributed to the low significance to the overall model. 


\section{Future Research.}

While approximately $25-27 \%$ of turnover intentions of a sample of NGNs employed in float pools is now understood as a result of this study, $73-74 \%$ of the variance of turnover intentions remains unexplained by the current model. Further investigation into other factors is required to gain a deeper understanding of NGNs working in the float pool role such as the influence of teamwork and interprofessional collaboration on retention and turnover of this cohort. The concepts of teamwork and interprofessional collaboration were noted in the identified theme of working relationships among the NGNs in this sample as well as previous literature (Laschinger et al., 2010; Purdy et al., 2010). To gain further knowledge and understanding of the factors influencing turnover intentions among NGNs, findings from this study must be validated in a larger sample from a broader Canadian sample of NGNs employed in float pools.

Considering the high correlations found among job satisfaction, work environment and psychological capital, an alternate model to the one proposed in this study could be formulated where work environment and psychological capital could be tested as antecedents to job satisfaction. Future research may consider testing this revised model by using a path analysis, which is an extension of multiple regression (Tabachnick \& Fidell, 2007) to predict the magnitude and significance of these hypothesized relationships.

Other areas of future study to consider include: a comparison of the transition experience of NGN working in the float pool and NGNs working on a single unit; exploring the impact and utilization of float pool NGNs on patient experiences and outcomes and gathering the perceptions of nurse managers, staff nurses, charge nurses, nurse educators as well as other interdisciplinary team members on the value of working with NGNs employed in float pools. 
These comparisons would assist to isolate the impact of working in a float pool role has on NGNs in the current healthcare climate.

Lastly, as the upcoming generation of nurses are expected to fill the gaps left by retiring Baby Boomers and the looming nursing shortage, it is important to understand the specific and unique characteristics of the younger generational cohort of nurses and how work environment may contribute to turnover rates of NGNs. There is a growing literature examining nursing turnover from the generational perspective, recognizing that recruitment and retention plans should consider generational needs (Hayes et al., 2012). Leiter et al. (2010) reported that a notable extent of the distress experienced by Generation X nurses in their study was reflected by conflict of values with the dominating culture of the Baby Boomers in the workplace. It is imperative to direct focus of future nursing research on the experiences of the younger generations of nurses in comparison to older generations in the workplace and customize retention and recruitment strategies accordingly.

\section{Summary}

Study findings add further insights into our understanding of factors influencing turnover intentions among NGNs employed in float pools in the urban acute care setting in Ontario.

Overall, NGNs in this study demonstrated moderate levels of satisfaction with their jobs, high levels of psychological capital and were moderately empowered in their work environment. Intentions of nurses to leave their position and organization were low but not insignificant as one third were at risk of leaving under current conditions. Strong positive associations were found between job satisfaction, work environment and psychological capital, yet job satisfaction was the only statistically significant predictor of turnover intentions in a regression model overall. 
Approximately one quarter of the variance of turnover intentions was explained using the current model.

Findings from this study highlight the need to further increase support and resources to NGNs in this unique role and to develop strategies to enhance job satisfaction and thereby retention of this cohort. Unique insights into the advantages and challenges for NGNs working in a nursing float pool that contributed to turnover intentions were the availability of learning opportunities, working relationships, benefits, unit politics, proximity to the workplace and uncertainty as well as value alignment and seeking higher education. Nurse leaders and point of care staff play an essential role in ensuring that NGNs are exposed to high quality and empowering work environments that offer the availability of the necessary resources and support to provide quality nursing care. Further development of organizational strategies to improve job satisfaction, reduce nurse turnover and improve retention rates are imperative to optimize consistent care delivery, prevent the loss of valuable clinical expertise and reduce costs of potential turnover in the future. The understanding gained from this study provides valuable insight into the employment situations of NGNs in this role and how organizations may better meet the health human resource needs for the healthcare environment of today. Future research may consider testing an alternate model with work environment and psychological capital as antecedents to job satisfaction. The results of the examination of the potential financial cost of nursing turnover of NGNs employed in float pools provide further evidence that warrants continued emphasis on retention strategies and the creation of empowering work environments that increase job satisfaction of NGNs in the workplace. 
Appendix A: Advance Notice (SITE A)

\title{
FACTORS INFLUENCING TURNOVER INTENTIONS OF NEW GRADUATE NURSES EMPLOYED IN FLOAT POOLS: RECRUITMENT EMAIL LETTER/ADVANCE NOTICE
}

\author{
Ryerson University
}

To all New Graduate Nurses working in the

Float Pool,

\section{This message is being sent as an advance notice of my upcoming study.}

My name is Sarah McDermid-Flabbi and I am a Masters in Nursing (MN) student at Ryerson University. I am currently conducting a study for my master's thesis which will be overseen by my thesis advisor, Dr. Nancy Purdy. The purpose of this study is to explore and describe some of the factors such as job satisfaction, work environment and positive psychological resources that impact turnover intentions among new graduate nurses (NGNs) employed in float pools at the

Participation in the study is voluntary and involves completing a short web-based survey provided to you via your email. The survey will take no longer than 15 minutes and can be completed at a private location of your choice. These questions will include demographic data and your perceptions of job satisfaction, the work environment, positive psychological resources and turnover intentions.

I am currently seeking volunteers to participate in this study.

In recognition of your support in this research study, participants who complete the survey will have a chance to win a $\$ 100.00$

spa gift card.

You will receive another email in a week providing the link to the study, letter of information and consent form for participating in a research study for your reference.

Please do not hesitate to contact me by email at $ـ \quad$ should you have any questions about the study.

Thank you in advance for your participation in this research.

Regards,

Sarah McDermid-Flabbi, RN, BScN, MN student,

Daphne Cockwell School of Nursing, Ryerson University

Version date: $15-03-2018$ 


\section{Appendix B: Invitation to Participate (SITE A)}

TO: Float Pool RNs (sent to the Nurse Manager who will forward as general distribution to float pool nurses)

FROM: Sarah McDermid-Flabbi, RN, BScN, MN student, Student Investigator

SUBJECT: Invitation to Participate- Nursing Research Study- Factors Influencing Turnover Intentions

(Date)

To all New Graduate Nurses working in the Float Pool, Within the last week, you were sent an advanced notice of this study. New graduate nurses employed in the float pool have been asked to participate in a research study examining factors influencing turnover intentions. Your perspectives and experiences are vital to the development of strategies and policies that have the potential to improve retention rates within the nursing profession and optimize nursing care delivery. Further details pertaining to the study are found in the attached letter of information and consent form.

Participation in the study involves completing an online survey that should take no more than 15 minutes to complete. Please find attached the consent form to participate in a research study for your reference.

Please contact the student investigator by email at should you have any questions about the study or have misplaced this information.

If you agree to participate, please use the link to the online survey listed below.

\section{Link to study survey:}

https://survey.ryerson.ca:443/s?s=6578

The survey needs to be completed at one time and you will not be able to return to the survey at a later date. Please be sure to answer each question completely.

In recognition of your support in this research study, participants who complete the survey will have a chance to win a $\$ 100.00$ spa gift card.

Thank you for your support.

Sarah McDermid-Flabbi, RN, BScN, MN Student, Daphne Cockwell School of Nursing, Ryerson University

Version date: $15-03-2018$ 


\section{Appendix C: Reminder Email \#1 (SITE A)}

TO: Float Pool RNs (sent to the Nurse Manager who will forward as general distribution to float pool nurses)

FROM: Sarah McDermid-Flabbi, RN, BScN, MN Student, Student Investigator

SUBJECT: Reminder 1-Nursing Research Study- Factors Influencing Turnover Intentions

(Date)

To all New Graduate Nurses working in the $\quad$ Float Pool,

Mindful of your busy schedules, you may not have had the opportunity to complete the web-based survey for the study titled "Factors Influencing Turnover Intentions of New Graduate Nurses Employed in Float Pools". Your perspectives and experiences related to job satisfaction, the work environment, positive psychological resources and turnover intentions are very important. The results of the study will be used to inform strategies to improve the workplace and thereby retention rates within the nursing profession to optimize nursing care delivery.

Participation in the study is voluntary and involves completing an online survey that should take no more than 15 minutes. If you agree to participate, please visit the website listed below.

Please find attached the consent form to participate in a research study for your reference. Please contact the student investigator by email at should you have any questions about the study or have misplaced this information.

\section{Link to study survey:}

https://survey.ryerson.ca:443/s?s=6578

The survey must be completed at one time and you will not be able to return to the survey at a later date. Please be sure to answer each question completely.

In recognition of your support in this research study, participants who complete the survey will have a chance to win a $\$ 100.00$ spa gift card.

Thank you for your participation.

Sarah McDermid-Flabbi, RN, BScN, MN Student

Daphne Cockwell School of Nursing, Ryerson University

Version date: $15-03-2018$ 


\section{Appendix D: Final Reminder Email (SITE A)}

TO: Float Pool RNs (sent to the Nurse Manager who will forward as general distribution to float pool nurses)

FROM: Sarah McDermid-Flabbi, RN, BScN, MN Student, Student Investigator

SUBJECT: Final Reminder -Nursing Research Study- Factors Influencing Turnover Intentions

(Date)

To all New Graduate Nurses working in the

Float Pool,

Mindful of your busy schedules, you may not have had the opportunity to complete the web-based survey for the study titled "Factors Influencing Turnover Intentions of New Graduate Nurses Employed in Float Pools". Your perspectives and experiences related to job satisfaction, the work environment, positive psychological resources and turnover intentions are very important. The results of the study will be used to inform strategies to improve the workplace and thereby retention rates within the nursing profession to optimize nursing care delivery.

Participation in the study is voluntary and involves completing an online survey that should take no more than 15 minutes. Please find attached the consent form to participate in a research study for your reference.

Please contact the student investigator by email at have any questions about the study or have misplaced this information.

If you agree to participate, please visit the website listed below.

\section{Link to study survey:}

https://survey.ryerson.ca:443/s?s=6578

The survey needs to be completed at one time and you will not be able to return to the survey at a later date. Please be sure to answer each question completely.

In recognition of your support in this research study, participants who complete the survey will have a chance to win a $\$ 100.00$ spa gift card.

\section{This is the final reminder to participate in the study.}

Thank you for your participation.

Sarah McDermid-Flabbi, RN, BScN, MN Student

Daphne Cockwell School of Nursing, Ryerson University

Version date: $15-03-2018$ 


\title{
Appendix E: ObjectPlanet's Opinio Online Survey (SITE A)
}

\section{Factors Influencing Turnover Intentions}

\author{
Introduction
}

\author{
WHAT YOU ARE REING ASKED TO DOA
}

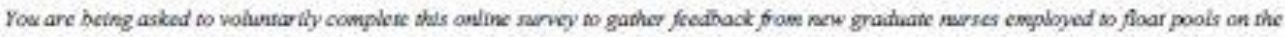

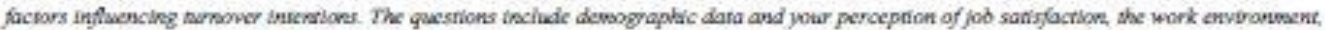

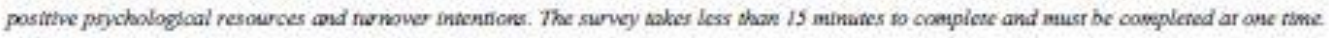
All guestions mus be answered before clicidng "finish"

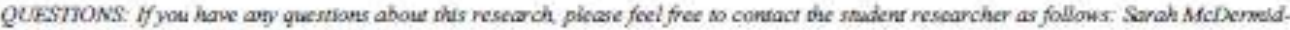
Fiabbi:

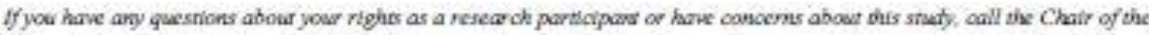

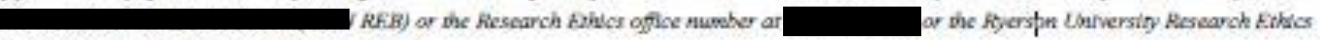
Boardar

CONFIRMATION OF AGRFFMENT

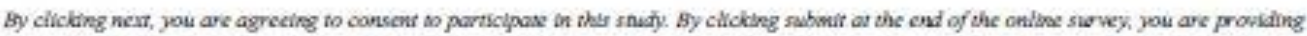
consenr for your participation. Your consent indicares you have rad she informarion in the agreement (scrit previously by cuall) and have heen

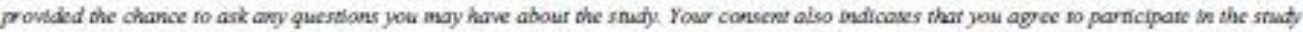

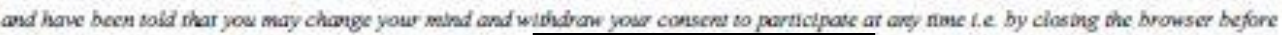

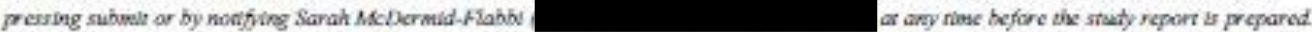

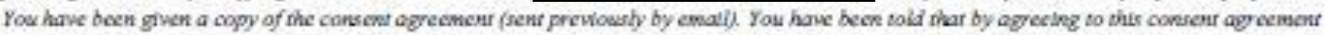
you are nar giving up any of your legal righss.

Thank you.

\section{Demographics}

Q1: Gender

Male

Femole

Other

Prefer not to answer

Q2: Age in years

Q3: Current Employment Status

$\bigcirc$ Full Time $\bigcirc$ Part Time $\bigcirc$ Casial 
Q4: How many years have you been a Registered Nurse (RI)?

Q5: How long have you been a nurse in your current position?

Q6: Which nursing float pool cluster are you hired into?

Medical-Surgical $\bigcirc$ Emergency O Intensive Care

Q7: Highest level of education.

College Diploma $\bigcirc$ Bachelors $\bigcirc$ Masters $O$ Other

If you have chosen "other", plense specify:

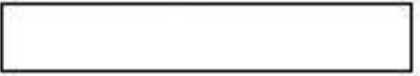

Q8: Please Respond to the following open ended questions:

Please identify your reasons to stay in your current position.

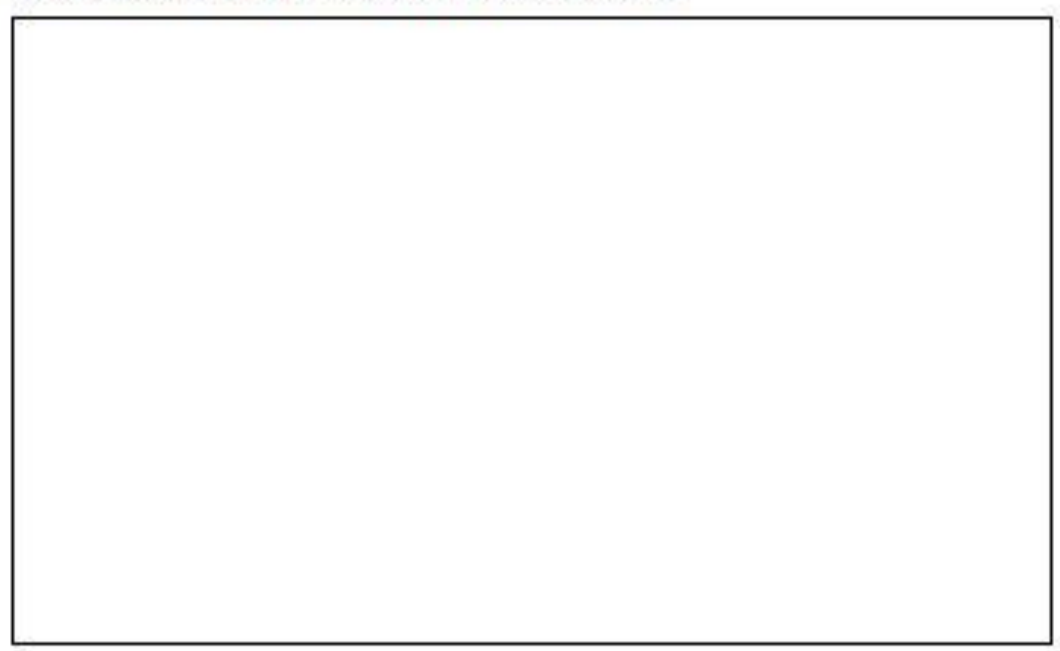


Q9: What would be reasous to leave your current position or organization?

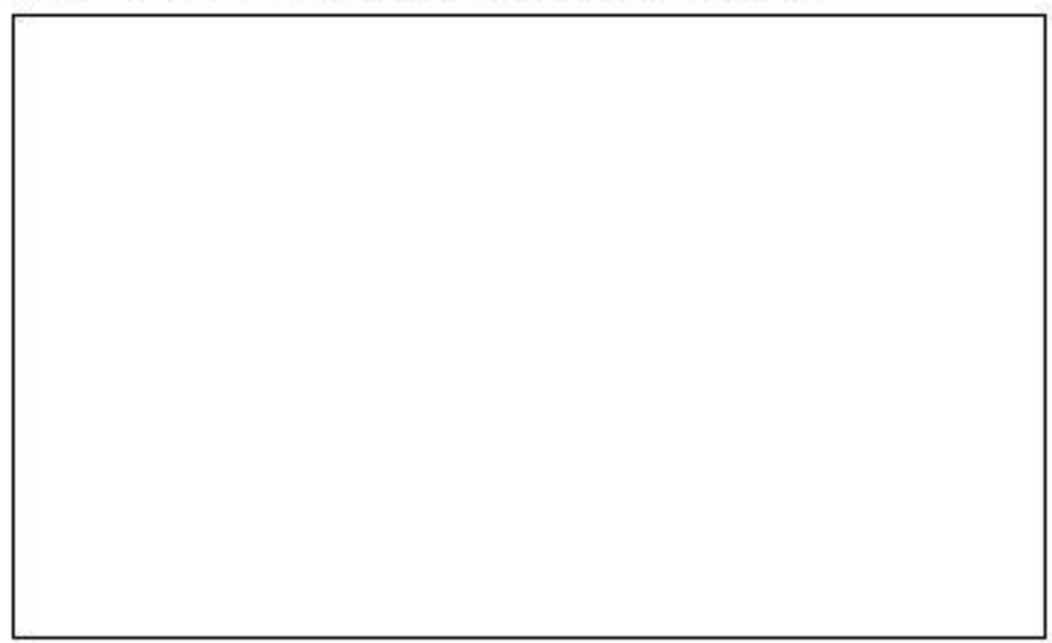

Q10: If you have thought about leaving the position or organization, what new position are you seeling and why? (If applicable)

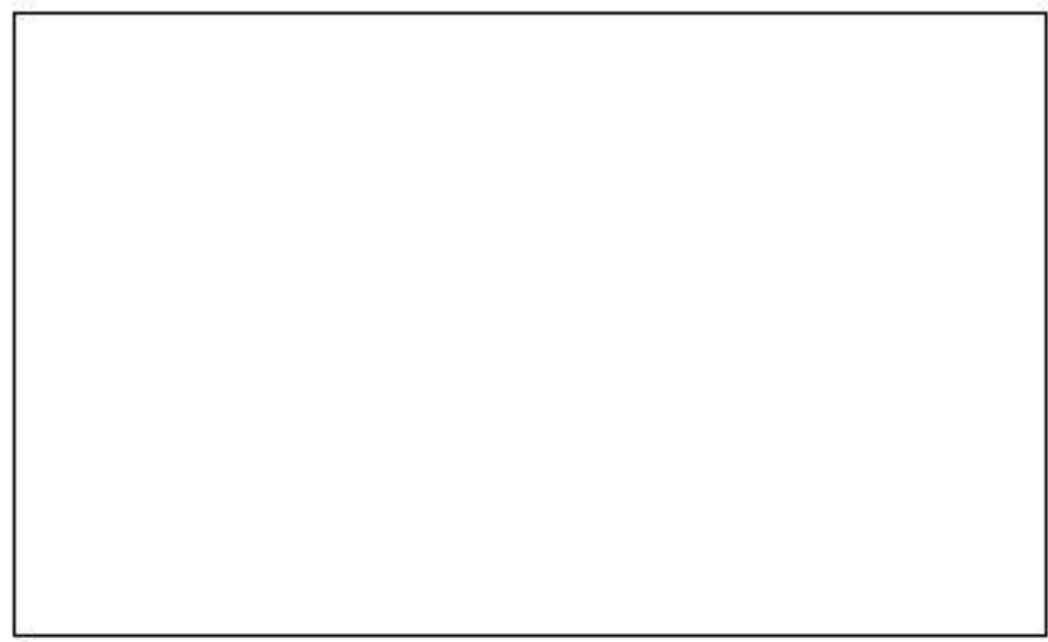

Job Satisfaction

Page 3 of 8 
Q11: Please indicate the extent to which you agree or disagree with each statement.

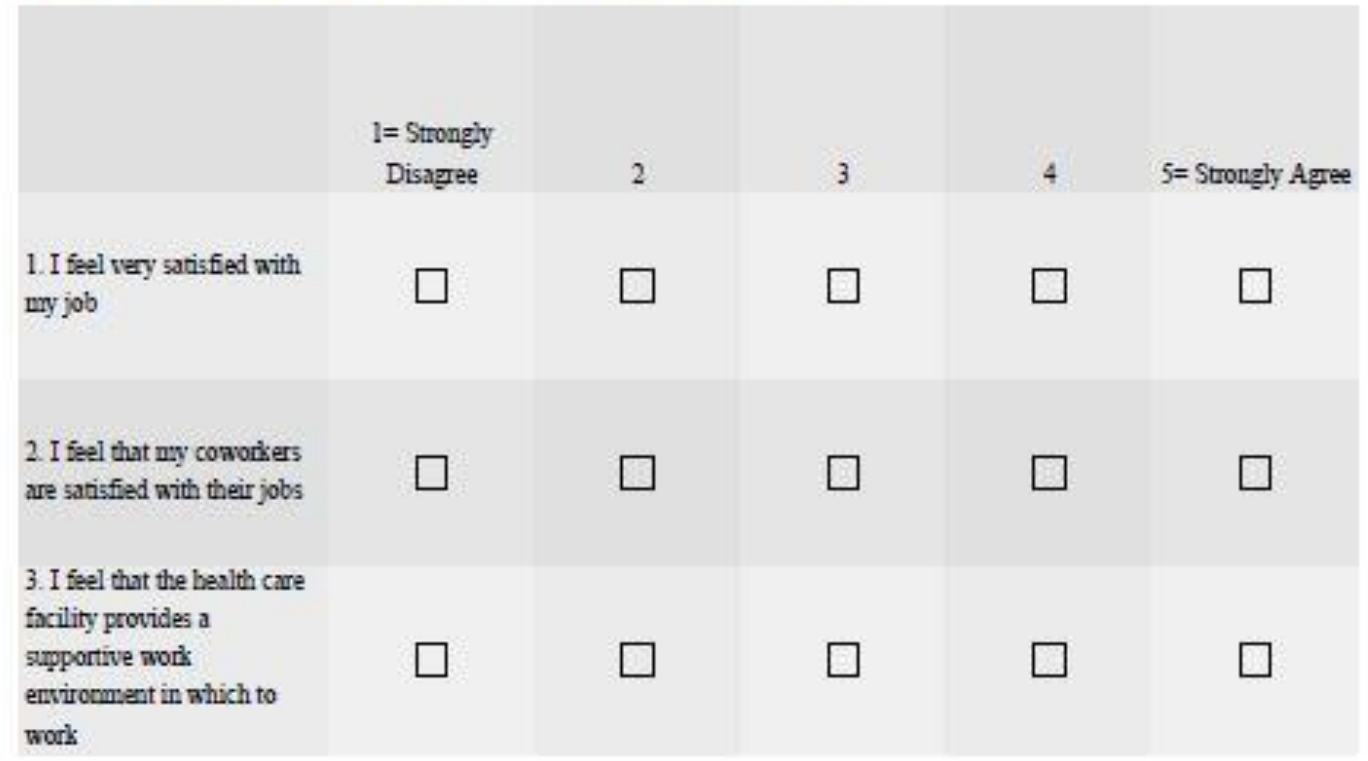

\section{Work Environment}

Q12: How much of each lind of opportunity do you have in your present job?

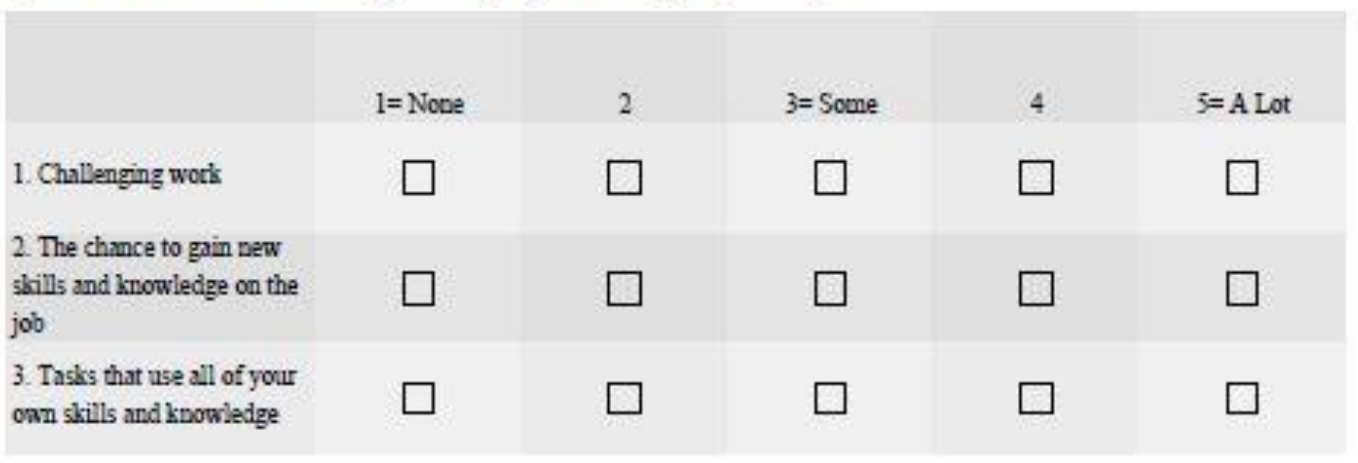

Q13: How mach Access to Information do you have in your present job?

1. The current state of the
hospital
2. The values of top
manngement
$\begin{aligned} & \text { 3. The goals of top } \\ & \text { management }\end{aligned}$


Q14: How mach Access to Support do you have in your present job?

$\begin{array}{lccc}\text { 1. Specific information } & \text { I= Nobe } & 2 & \text { 3= Some }\end{array}$

Q15: How much Access to Resources do you have in your present job?

$\begin{array}{lcccc}\text { 1. Time available to do } & 1=\text { None } & 2 & \text { 3= Some } & 4 \\ \text { necessary paperwork } & \square & \square & \square & \square \\ \text { 2. Time available to } & \square & \square & \square & \square \\ \text { accounplish job recuirements } \\ \begin{array}{l}\text { 3. Acquiring temporary help } \\ \text { when needed }\end{array}\end{array}$

Q16: How much of each lind of opportunity do you have in your present job?

1. Overall, my current work
enviroument empowers me
to accomplish my work in an
effective manner
$\begin{aligned} & \text { 2. Overall, I consider my } \\ & \text { Disagee } \\ & \text { workplace to be an } \\ & \text { eumowering enviromment }\end{aligned}$

\section{Psychological Capital}

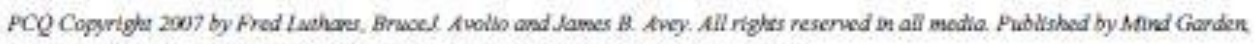

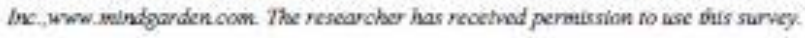


Q17: Below are statements that describe bow you may think about yourself RIGHT NOW. Use the following scale to indicate your level of agreement or disagreement with each statement.

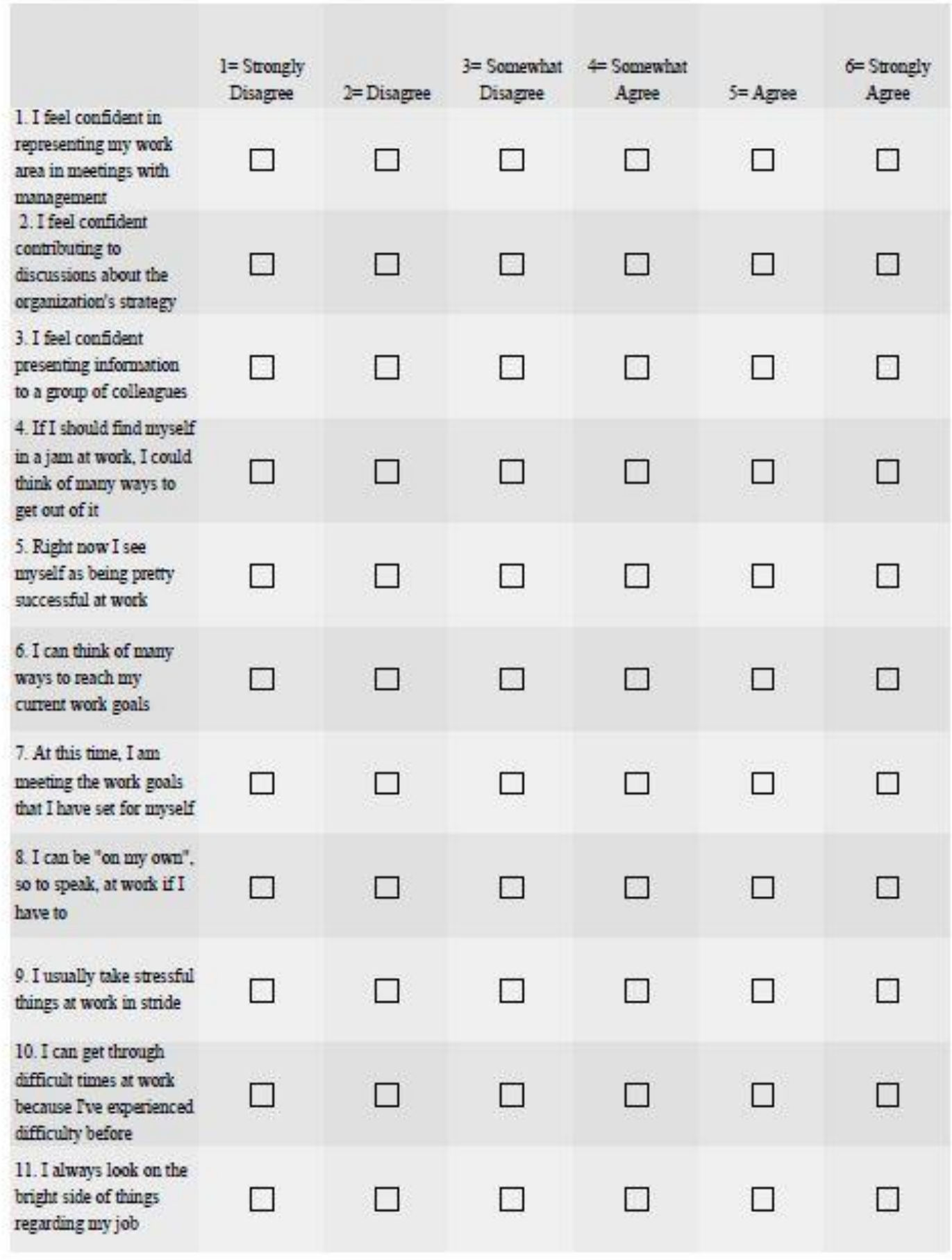

Page 6 or 8 
12. Im optimistic about what will happen to me in the funure as it pertains to work

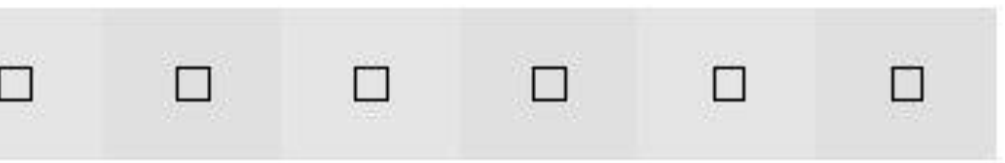

\section{Turnover Intentions}

Q18: Use the following scale to indicate your level of agreement or disagreement with each statement.

1. I would leave my present
position
$\begin{aligned} & \text { 2. I plan to leave my present } \\ & \text { position as soon as possible } \\ & \text { 3. I plan to stay with my } \\ & \text { present position as long as } \\ & \text { possible } \\ & \text { 4. Under no circumstances } \\ & \text { will I voluntarily leave uny } \\ & \text { present position } \\ & \text { 5. I would like to leave my } \\ & \text { present orgarization } \\ & \text { 6. I plan to leave my present } \\ & \text { organization as soon as } \\ & \text { possible } \\ & \text { 7. I plan to stay with my } \\ & \text { present organization as long } \\ & \text { as possible } \\ & \text { 8. Under no circumstances } \\ & \text { will I voluntarily leave my } \\ & \text { present organization }\end{aligned}$

\section{Consent for Draw Prize}

Q19: I cousent to have my name eutered iuto the draw for a $1 / 200$ chance to win a $\$ 100.00$ spa gift card.

$\bigcirc$ yes $O$ no 
Q20: If you answered "yes" to entering the draw for the $\$ 100$ gift certificate fo

Spa, please email Sarah

McDermid-Flabbil

This email will be stored in a separate file from the surveys. A

winner will be selected at random after the conclusion of the survey period The file will be deleted thereafter.

Thank you for your parriclpation 
Appendix F: Advance Notice (SITE B)

\title{
FACTORS INFLUENCING TURNOVER INTENTIONS OF NEW GRADUATE NURSES EMPLOYED IN FLOAT POOLS: RECRUITMENT EMAIL LETTER/ADVANCE NOTICE
}

\author{
Ryerson University
}

To all New Graduate Nurses working in the Resource Team Float Pool,

This message is being sent as an advance notice of my upcoming study.

My name is Sarah McDermid-Flabbi and I am a Masters in Nursing (MN) student at Ryerson University. I am currently conducting a study for my master's thesis which will be overseen by my thesis advisor, Dr. Nancy Purdy. The purpose of this study is to explore and describe some of the factors such as job satisfaction, work environment and positive psychological resources that impact turnover intentions among new graduate nurses (NGNs) employed in float pools at the

Participation in the study is voluntary and involves completing a short web-based survey provided to you via your email. The survey will take no longer than 15 minutes and can be completed at a private location of your choice. These questions will include demographic data and your perceptions of job satisfaction, the work environment, positive psychological resources and turnover intentions.

I am currently seeking volunteers to participate in this study. In recognition of your support in this research study, participants who complete the survey will have a chance to win a $\$ 100.00$ spa gift card.

You will receive another email in a week providing the link to the study, letter of information and consent form for participating in a research study for your reference.

Please do not hesitate to contact me by email should you have any questions about the study.

Thank you in advance for your participation in this research.

Regards,

Sarah McDermid-Flabbi, RN, BScN, MN student, Daphne Cockwell School of Nursing, Ryerson University

Version date: 14-05-2018 


\section{Appendix G: Invitation to Participate (SITE B)}

TO: Float Pool RNs (sent to the Nurse Manager who will forward as general distribution to float pool nurses)

FROM: Sarah McDermid-Flabbi, RN, BScN, MN student, Student Investigator

SUBJECT: Invitation to Participate- Nursing Research Study- Factors Influencing Turnover Intentions

(Date)

To all New Graduate Nurses working in the Resource Team Float Pool,

Within the last week, you were sent an advanced notice of this study. New graduate nurses employed in the float pool have been asked to participate in a research study examining factors influencing turnover intentions. Your perspectives and experiences are vital to the development of strategies and policies that have the potential to improve retention rates within the nursing profession and optimize nursing care delivery. Further details pertaining to the study are found in the attached letter of information and consent form.

Participation in the study involves completing an online survey that should take no more than 15 minutes to complete. Please find attached the consent form to participate in a research study for your reference.

Please contact the student investigator by email at _ should you have any questions about the study or have misplaced this information.

If you agree to participate, please use the link to the online survey listed below.

\section{Link to study survey:}

\section{https://survey.ryerson.ca:443/s?s=7029}

The survey needs to be completed at one time and you will not be able to return to the survey at a later date. Please be sure to answer each question completely.

In recognition of your support in this research study, participants who complete the survey will have a chance to win a $\$ 100.00$ spa gift card.

Thank you for your support.

Sarah McDermid-Flabbi, RN, BScN, MN Student,

Daphne Cockwell School of Nursing, Ryerson University

Version date: $14-05-2018$ 


\section{Appendix H: Reminder Email \#1 (SITE B)}

TO: Float Pool RNs (sent to the Nurse Manager who will forward as general distribution to float pool nurses)

FROM: Sarah McDermid-Flabbi, RN, BScN, MN Student, Student Investigator

SUBJECT: Reminder 1-Nursing Research Study- Factors Influencing Turnover Intentions

(Date)

To all New Graduate Nurses working in the Resource Team Float Pool,

Mindful of your busy schedules, you may not have had the opportunity to complete the webbased survey for the study titled "Factors Influencing Turnover Intentions of New Graduate Nurses Employed in Float Pools". Your perspectives and experiences related to job satisfaction, the work environment, positive psychological resources and turnover intentions are very important. The results of the study will be used to inform strategies to improve the workplace and thereby retention rates within the nursing profession to optimize nursing care delivery.

Participation in the study is voluntary and involves completing an online survey that should take no more than 15 minutes. If you agree to participate, please visit the website listed below.

Please find attached the consent form to participate in a research study for your reference. Please contact the student investigator by email should you have any questions about the study or have misplaced this information.

\section{Link to study survey:}

\section{https://survey.ryerson.ca:443/s?s=7029}

The survey must be completed at one time and you will not be able to return to the survey at a later date. Please be sure to answer each question completely.

In recognition of your support in this research study, participants who complete the survey will have a chance to win a $\$ 100.00$ spa gift card.

Thank you for your participation.

Sarah McDermid-Flabbi, RN, BScN, MN Student

Daphne Cockwell School of Nursing, Ryerson University

Version date: 15-05- 2018 


\section{Appendix I: Final Reminder Email (SITE B)}

\section{Email - FINAL Reminder}

TO: Float Pool RNs (sent to the Nurse Manager who will forward as general distribution to float pool nurses)

FROM: Sarah McDermid-Flabbi, RN, BScN, MN Student, Student Investigator

SUBJECT: Final Reminder -Nursing Research Study- Factors Influencing Turnover Intentions

(Date)

To all New Graduate Nurses working in the

Resource Team Float Pool,

Mindful of your busy schedules, you may not have had the opportunity to complete the webbased survey for the study titled "Factors Influencing Turnover Intentions of New Graduate Nurses Employed in Float Pools". Your perspectives and experiences related to job satisfaction, the work environment, positive psychological resources and turnover intentions are very important. The results of the study will be used to inform strategies to improve the workplace and thereby retention rates within the nursing profession to optimize nursing care delivery.

Participation in the study is voluntary and involves completing an online survey that should take no more than 15 minutes. Please find attached the consent form to participate in a research study for your reference.

Please contact the student investigator by email at

have any questions about the study or have misplaced this information.

If you agree to participate, please visit the website listed below.

\section{Link to study survey:}

\section{https://survey.ryerson.ca:443/s?s=7029}

The survey needs to be completed at one time and you will not be able to return to the survey at a later date. Please be sure to answer each question completely.

In recognition of your support in this research study, participants who complete the survey will have a chance to win a $\$ 100.00$ spa gift card.

\section{This is the final reminder to participate in the study.}

Thank you for your participation.

Sarah McDermid-Flabbi, RN, BScN, MN Student

Daphne Cockwell School of Nursing, Ryerson University

Version date: 15-05- 2018 


\title{
Appendix J: ObjectPlanet's Opinio Online Survey (SITE B)
}

\section{Factors Influencing Turnover Intentions}

\author{
Introduction
}

WHAT YOU ARE REING ASKED TO DO

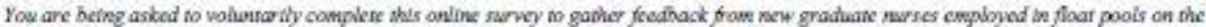

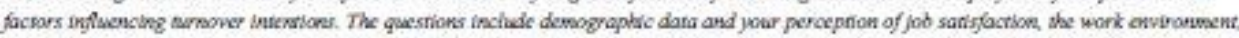

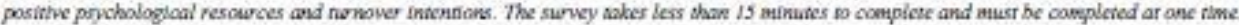

"**Af guestions must he answered before clioking "finish"? ***

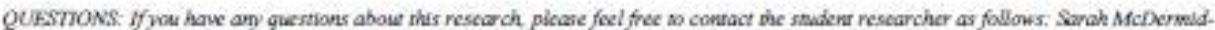
Flabbl:

If you have questions about your righes as a research participant or any enhical issues relased to this study thar jou wish no discuss with sameane nor dinectly involved with the stuady, you may call the Chat

Byerson Lhatuersity Research Prhics Board at

CONFLRMTION OF AGREFMENT

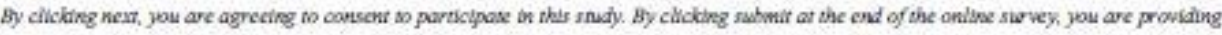

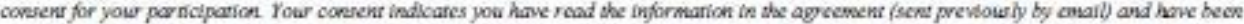

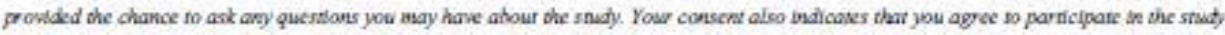

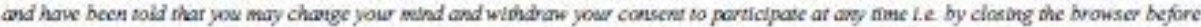

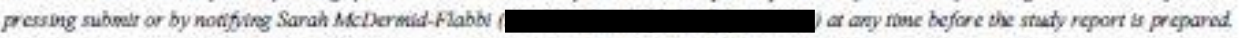
You have been grven a cogy of the consent agresment (sent prewousty by emali). You have been told that by agrecing wo this covesent agreement you are nor gintug up any of your kgal righs.

Thonk you.

\section{Demographics}

Q1: Gender
Male
Femsle
Other
Prefer not to answer

\section{Q2: Age in years}
Q3: Current Employment Status
() Full Time
O Part Time
O Cosual 
Q4: How many years have you been a Registered Nurse (RN)?

Q5: How long have you been a nurse in your current position?

Q6: Which warsing float pool cluster were you hired into?

Acute Care Nursing Resource Team (ACNRT) O Critical Care Nursing Resource Teum (CONRT)

Other

If you have chosen "other", please specify:

Q7: Highest level of education.

College Diplows $\bigcirc$ Bachelors Degree $\bigcirc$ Masters Degree $\bigcirc$ other

If you have chosen "other', please specify:

-

Q8: Please Respond to the following open ended questious:

Please identify your reasous for staying in your current position. 
Q9: What would be reasous to leave your current position or organization?

Q10: If you have thought about leaving the position or organization, what new position would you be seeling and why? (If applicable)

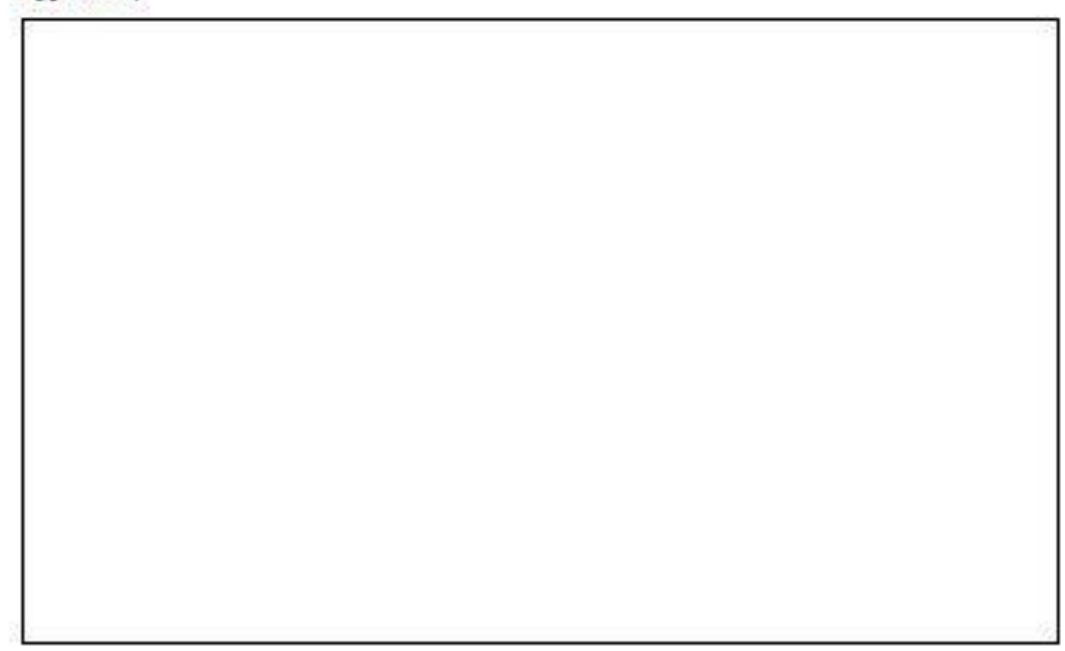

\section{Job Satisfaction}

Page 3 of 8 
Q11: Please indicate the extent to which you agree or disagree with each statement.

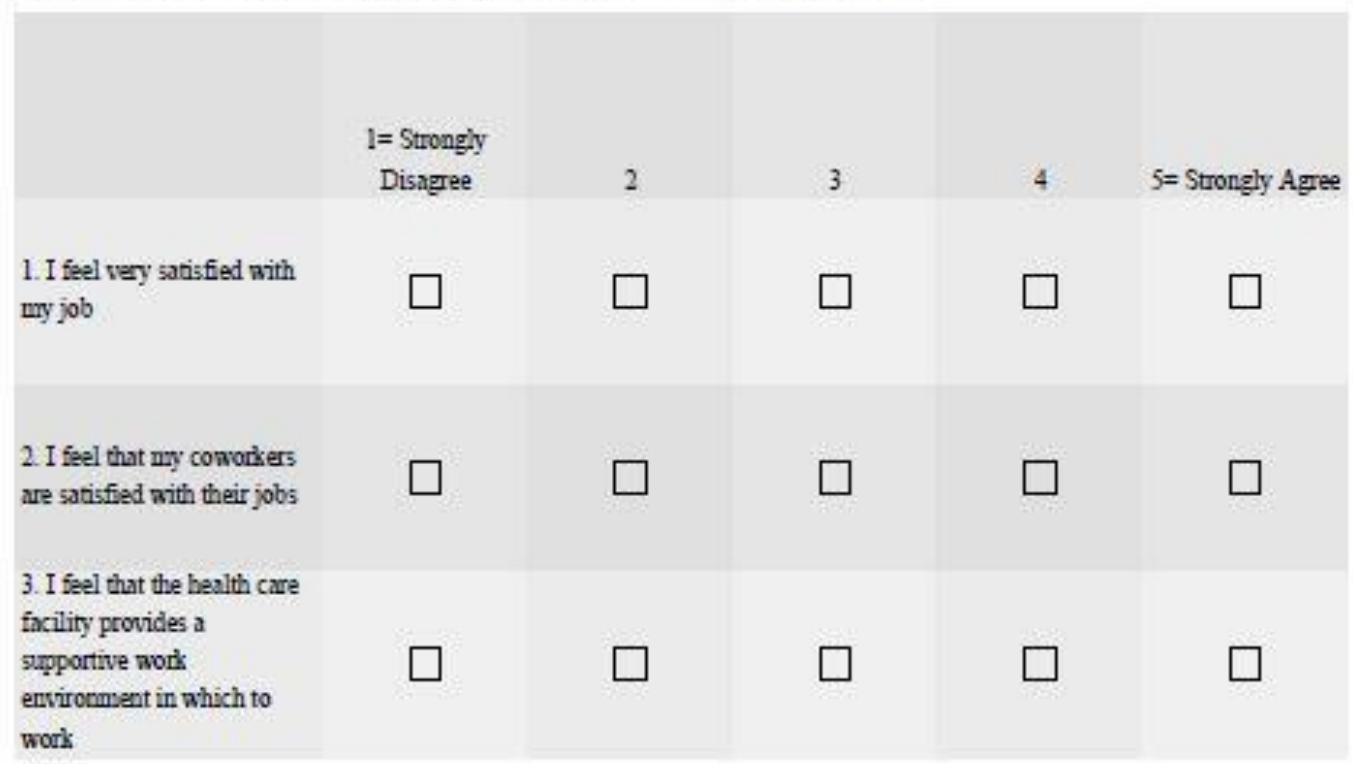

Work Environment

Q12: How moch of each lind of opportunity do you have in your present job?

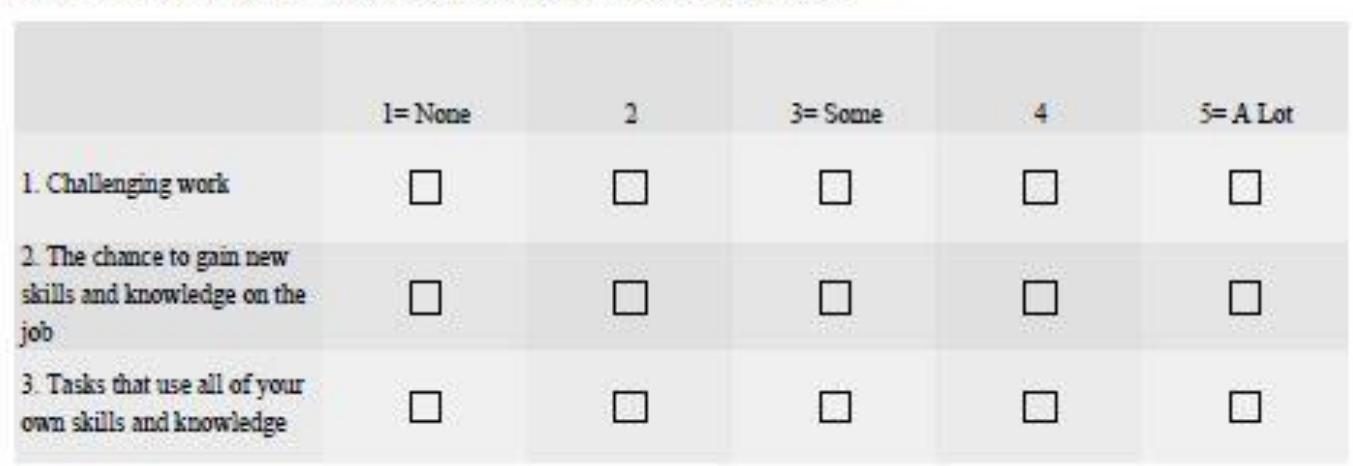

Q13: How much access to information do you have in your present job?

1. The cament state of the
hospital

Page 4 or 8 
Q14: How mach access to support do you have in your present job?

$\begin{aligned} & \text { 1. Specific informsation } \\ & \text { about things you do well }\end{aligned}$
2. Specific coumsents about
things you could improve
$\begin{aligned} & \text { 3. Helpful hints or problem } \\ & \text { solving advice }\end{aligned}$

Q15: How moch access to resources do you have in your present job?

1. Time available to do
$\begin{aligned} & \text { necessary paperwotk } \\ & \text { 2. Timse available to } \\ & \text { accomplish job recuirements } \\ & \text { 3. Acquiring teryporary help } \\ & \text { when needed }\end{aligned} \quad \square$

\section{Global Empowerment}

Q16: How much of each kind of opportunity do you have in your present job?

\begin{tabular}{|c|c|c|c|c|c|}
\hline & $\begin{array}{c}\text { I = Strongly } \\
\text { Disagree }\end{array}$ & 2 & 3 & 4 & $5=$ Strongly Agree \\
\hline $\begin{array}{l}\text { 1. Overall, my current work } \\
\text { envirocment empowers me } \\
\text { to accomplish my wotk in an } \\
\text { effective manner }\end{array}$ & $\square$ & $\square$ & $\square$ & $\square$ & $\square$ \\
\hline $\begin{array}{l}\text { 2. Overall, I consider my } \\
\text { workplace to be an } \\
\text { empowering enviromment }\end{array}$ & $\square$ & $\square$ & $\square$ & $\square$ & $\square$ \\
\hline
\end{tabular}

\section{Pșychological Capital}

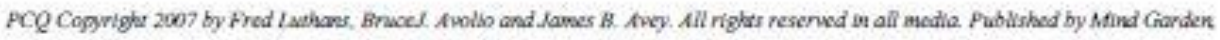

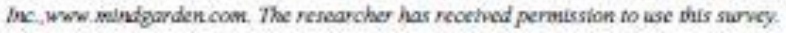


Q17: Below are statements that describe how you may think about yourself RIGHT NOW. Use the following scale to indicate your level of agreement or disagreement with each statemeut.

\begin{tabular}{|c|c|c|c|c|c|c|}
\hline & $\begin{array}{l}\text { I= Strongly } \\
\text { Disagree }\end{array}$ & 2= Disagree & $\begin{array}{c}3=\text { Somewhat } \\
\text { Disagree }\end{array}$ & $\begin{array}{l}4=\text { Somewhat } \\
\text { Agree }\end{array}$ & $5=$ Agree & $\begin{array}{c}\sigma=\text { Strongly } \\
\text { Agree }\end{array}$ \\
\hline $\begin{array}{l}\text { 1. I feel confident in } \\
\text { representing my work } \\
\text { area in meetings with } \\
\text { management }\end{array}$ & & $\square$ & $\square$ & $\square$ & $\square$ & $\square$ \\
\hline $\begin{array}{l}\text { 2. I feel confident } \\
\text { contributing to } \\
\text { discussions about the } \\
\text { organizatiou's strategy }\end{array}$ & & & $\square$ & $\square$ & $\square$ & $\square$ \\
\hline $\begin{array}{l}\text { 3. I feel confident } \\
\text { presenting information } \\
\text { to a group of colleagues }\end{array}$ & & [ & [ & $\square$ & $\square$ & $\square$ \\
\hline $\begin{array}{l}\text { 4. If I should find nyself } \\
\text { in a jam at work, I could } \\
\text { think of many ways to } \\
\text { get out of it }\end{array}$ & & & & & & $\square$ \\
\hline $\begin{array}{l}\text { 5. Right now I see } \\
\text { nyself as being pretty } \\
\text { successful at work }\end{array}$ & & & & E & & L \\
\hline $\begin{array}{l}\text { 6. I can think of many } \\
\text { ways to reach my } \\
\text { current work goals }\end{array}$ & & $\square$ & $\square$ & $\square$ & $\square$ & $\square$ \\
\hline $\begin{array}{l}\text { 7. At this time, I am } \\
\text { meeting the work goals } \\
\text { that I have ser for myself }\end{array}$ & [ & L & & $\square$ & $\square$ & $\square$ \\
\hline $\begin{array}{l}\text { 8. I can be "on my own". } \\
\text { so to speak, at work if I } \\
\text { have to }\end{array}$ & & ⿷ & & $\square$ & $\square$ & $\square$ \\
\hline $\begin{array}{l}\text { 9. I usually take stressful } \\
\text { things at work in stride }\end{array}$ & & & & $\square$ & $\square$ & $\square$ \\
\hline $\begin{array}{l}\text { 10. I can get through } \\
\text { difficult times at work } \\
\text { because Tre experienced } \\
\text { difficulty before }\end{array}$ & & & & & $\square$ & $\square$ \\
\hline $\begin{array}{l}\text { 11. I always look on the } \\
\text { bright side of things } \\
\text { regarding my job }\end{array}$ & & E & $\square$ & $\square$ & $\square$ & $\square$ \\
\hline
\end{tabular}


Turnover Intentions

Q18: Use the following scale to indicate your level of agreement or disagreement with each statement.

\begin{tabular}{|c|c|c|c|c|c|}
\hline & $\begin{array}{l}\text { l= Strongly } \\
\text { Disagree }\end{array}$ & 2 & 3 & 4 & $5=$ Strongly Agree \\
\hline $\begin{array}{l}\text { 1. I would like to lesve my } \\
\text { present position }\end{array}$ & $\square$ & $\square$ & $\square$ & $\square$ & $\square$ \\
\hline $\begin{array}{l}\text { 2. I plan to leave my present } \\
\text { position as soon as possible }\end{array}$ & & & $\square$ & & ⿷ \\
\hline $\begin{array}{l}\text { 3. I plan to stay with my } \\
\text { present position as long as } \\
\text { possible }\end{array}$ & & & L & & \\
\hline $\begin{array}{l}\text { 4. Under no circumstances } \\
\text { will I voluntarily leave my } \\
\text { present position }\end{array}$ & $\square$ & $\square$ & $\square$ & $\square$ & $\square$ \\
\hline $\begin{array}{l}\text { 5. I would like to leave my } \\
\text { present organization }\end{array}$ & & & & & \\
\hline $\begin{array}{l}\text { 6. I plan to leave uny present } \\
\text { organization as soon as } \\
\text { possible }\end{array}$ & & & [ & L & \\
\hline $\begin{array}{l}\text { 7. I plan to stay with my } \\
\text { present organization as long } \\
\text { as possible }\end{array}$ & $\square$ & ⿷ & $\square$ & $\square$ & $\square$ \\
\hline $\begin{array}{l}\text { 8. Under no circumstances } \\
\text { will I voluntarily leave my } \\
\text { present organization }\end{array}$ & $\square$ & $\square$ & $\square$ & $\square$ & $\square$ \\
\hline
\end{tabular}

\section{Consent for Draw Prize}

Q19: I consent to have my name entered into the draw for a $1 / 200$ chance to win a $\$ 100.00$ spa gift card.

$\bigcirc$ yes $\bigcirc$ no 
Q20: If you auswered "yes" to entering the draw for the $\$ 100$ gift certificate for $\quad$ Spa, please email Sarah McDermid-Flabbi This email will be stored in a separate file from the surveys. A winner will be selected at random after the conclusion of the survey period The file will be deleted thereafter.

Thank you for your parncipation 
Appendix K: Letter of Information and Consent Form (SITE A)

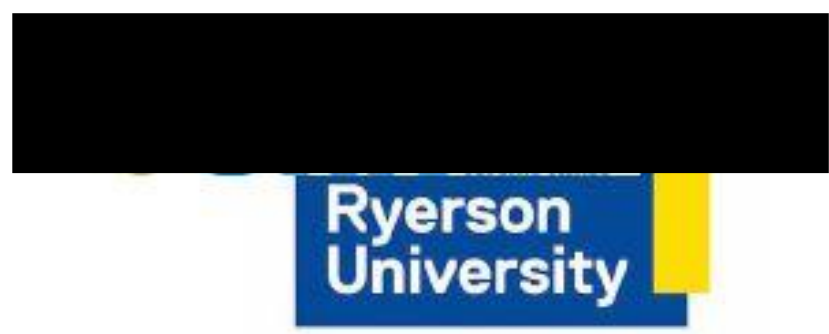

\section{CONSENT FORM TO PARTICIPATE IN A RESEARCH STUDY}

\section{Study Title:}

Factors Influencing Turnover Intentions of New Graduate Nurses Employed in Float Pools.

Investigator:

Principal Investigator: Helen Kelly, RN, MScN

Student Investigator: Sarah McDermid-Flabbi, RN, BScN, MN student

\section{Contact Information:}

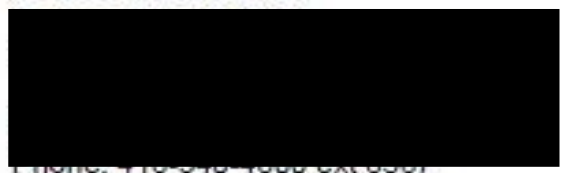

Sponsor:

Ryerson University

Introduction:

You are being asked to take part in a research study examining factors influencing turnover intentions. Your perspectives and experiences are vital to the development of strategies and policies that have the potential to improve retention rates within the nursing profession and optimize nursing care delivery. Please read the information about the study presented in this form. The form includes details on study's risks and benefits that you should know before you decide if you would like to take part. You should take as much time as you need to make your decision. You should ask the investigator to explain anything that you do not understand and make sure that all of your questions have been answered before signing this consent form. Before you make your decision, feel free to talk about this study with anyone you wish including your friends, family. Participation in this study is voluntary. 


\section{Background/Purpose:}

Nursing turnover is becoming a matter of increasing priority attributed to global nursing shortages, aging nurse and patient populations, and the ever-changing complexity of demands in healthcare (O'Brien Pallas et al., 2010). Although tumover and retention of nurses have been studied extensively, little is known about the factors that influence turnover intentions of new graduate nurses who are often employed in float pools (Anderson et al., 2009; Beecroft et al., 2008).

The purpose of this study will be to explore and describe the relationship between job satisfaction, work environment and psychological capital (PsyCap) on turnover intentions of new graduate nurses (NGNs) employed in float pools in acute care hospitals.

\section{Study Design:}

This quantitative study employs a descriptive cross-sectional, correlational and non-experimental design where approximately 200 registered nurse participants will be invited to complete an online survey (less than 15 minutes to complete).

The consent to participate is provided in advance within the recruitment emails. Confirmation of consent is implied through completion and submission of the online survey.

\section{Study Visits and Procedures:}

You will be asked to complete and submit a short online survey (approximately 15 minutes in length). Your consent to participate is acknowledged by your submission of the completed survey. The survey questions are related to your experience of job satisfaction, work environment, positive psychological resources and turnover intentions.

\section{Risks:}

Taking part in this study has no known risks. Your employment will not be affected and your manager will not be made aware of your participation within this study. Please call the investigator if you have any questions or concerns.

\section{Benefits:}

You may not directly benefit from being in this study. Information learned from this study may help inform organizational strategies to improve the retention of New Graduate Nurses in the future. 


\section{Reminders and Responsibilities:}

You will receive up to 4 messages via email including an advanced notice, an invitation to participate and 2 reminder messages. An introductory message will identify the research team, the purpose of the study and approximate amount of time required to complete the questionnaire. The email will contain a personalized message with the letter of information, consent form and a hyperlink to complete the online survey. A reminder email will follow two weeks later and a final reminder email will be sent after another two weeks.

\section{Confidentiality:}

Personal Health Information

If you agree to join this study, the study doctor and his/her study team collect only the information they need for the study. Personal health information is any information that could identify you and includes your:

- name,

- email address

- age

The following people may come to the hospital to look at the study records and at your personal health information to check that the information collected for the study is correct and to make sure the study is following proper laws and guidelines:

- Representatives of the Research Ethics Board

The study doctor will keep any personal health information about you in a secure and confidential location for 10 years.

\section{Study Information that Does Not Identify You}

Any information about you that is sent out of the hospital will have a number and will not show any information that directly identifies you.

In addition, any electronic files containing personally identifiable information such as participant provided emails for the draw will be stored on a separate secure file on the share drive, accessible only by the primary investigator and not shared with any members of the research team until data is anonymized.

Your participation in this study will not be known to your supervisor and will not affect your employment.

\section{Costs and Reimbursement}

There is no cost to participate in this study. At the end of the survey, you will be asked if you agree to have your name entered into a draw to win a $\$ 100$ gift certificate for Spa. 


\section{Voluntary Participation:}

Your participation in this study is voluntary. You may decide not to be in this study, or to be in the study now, and then change your mind later. You may leave the study at any time.

\section{Withdrawal from the Study:}

You may withdraw from the study at any time. If you decide to withdraw from the study prior to data analysis, all data obtained from you will be deleted.

\section{Costs and Reimbursement:}

Cost of questionnaire is free for use by graduate students (confirmed with MindGarden on September $25^{\text {th }}, 2017$ ). This project is unfunded. Project costs will be paid out personally by student researcher. There is no cost to participate in this study.

A recruitment incentive to completing the online survey is a chance to win a $\$ 100.00$ gift certificate for a spa treatment (odds of winning approximately $1 / 200$ participants). At the end of the survey, you will be asked if you agree to have your name entered into the draw. The winner will be contacted via email. All email addresses will be stored separate from survey results. The winner will be notified via email. The file of email addresses will be deleted thereafter.

\section{Rights as a Participant:}

Participation in research is completely voluntary and you can withdraw your consent at any point up to clicking the submit button at the end of the survey. However, because the survey is anonymous, once you click the submit button at the end of the survey the researchers will not be able to determine which survey answers belong to you so your information cannot be withdrawn after that point.

Please note, that by clicking submit at the end of the study you are providing your consent for participation. By consenting to participate you are not waiving any of your legal rights as a research participant and you do not give up any of your legal rights against the investigators, sponsor or involved institutions for compensation, nor does this form relieve the investigators, sponsor or involved institutions of their legal and professional responsibilities.

\section{Conflict of Interest:}

The investigator has an intellectual interest in completing this study. The study and the student researcher do not hold any supervisory role for potential participants. 
Questions about the Study:

If you have any questions or concems for any reason, please contact the student investigator: Sarah McDermid-Flabbi at

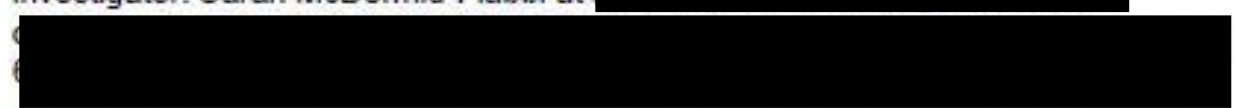

If you have any questions about your rights as a research participant or have concerns about this study, call the Chair of the Research Ethics Board the Research Ethics office number at $\quad$ or the Ryerson Ethics Board at The REB is a

group of people who oversee the ethical conduct of research studies. not part of the study team. Everything that you discuss will be kept confidential.

Please keep a copy of this form for your own records. 


\section{Appendix L: Letter of Information and Consent Form (SB)}

\section{RESEARCH ETHICS BOARD (REB) \\ LETTER OF INFORMATION/INFORMED CONSENT TO PARTICIPATE IN A RESEARCH STUDY}

Full Study Title: Factors Influencing Turnover Intentions of New Graduate Nurses Employed in Float Pools.

Principal Investigator Interim Patient Care Manager, ACNRT, CCNRT \& Centralized Scheduling,

Student Investigator: Sarah McDermid-Flabbi, RN, MN Candidate,

Sponsor: Ryerson University

\section{INFORMED CONSENT}

You are being asked to consider participating in a research study. A research study is a way of gathering information on a treatment, procedure or medical device or to answer a question about something that is not well understood. This form explains the purpose of this research study, provides information about the study survey, the tests and procedures involved, possible risks and benefits, and the rights of participants.

Please read this form carefully and ask any questions you may have. You may have this form and all information concerning the study explained to you. You may take as much time as you wish to decide whether or not to participate within the allotted study period. Feel free to discuss it with your friends and colleagues. The study staff will tell you if there are any study timelines for making your decision. Please ask the study staff or one of the investigator(s) to clarify anything you do not understand or would like to know more about. Make sure all your questions are answered to your satisfaction before deciding whether to participate in this research study. Participating in this study is your choice (voluntary). You have the right to choose not to participate, or to stop participating in this study at any time.

\section{WHY IS THIS STUDY BEING DONE?}

The purpose of this study is to explore and describe the relationship between job satisfaction, work environment and psychological capital (PsyCap) on turnover intentions of new graduate nurses (NGNs) employed to float pools in acute care hospitals. Results from this study may address gaps identified in the current literature surrounding nursing turnover and the unique cohort of NGNs employed to float pools.

WHAT ARE THE RESPONSIBILITIES OF STUDY PARTICIPANTS? 
You will be asked to complete and submit a short online survey (approximately 15 minutes in length). The survey questions are related to your experience of job satisfaction, work environment, positive psychological resources and turnover intentions.

By clicking submit at the end of the study you are providing your consent for participation. You can withdraw your consent at any point up to clicking the submit button at the end of the survey. However, once you click the submit button at the end of the survey the researchers will not be able to determine which survey answers belong to you so your information cannot be withdrawn after that point. If you choose to withdraw, your choice will not have any effect on your employment status.

\section{WHAT ARE THE RISKS OR HARMS OF PARTICIPATING IN THIS STUDY?}

There are no known or foreseeable risks to participating in this study.

\section{WHAT ARE THE BENEFITS OF PARTICIPATING IN THIS STUDY?}

You may or may not benefit directly from participating in this study. Information learned from this study may help inform organizational strategies to improve the retention of New Graduate Nurses in the future.

\section{HOW WILL MY INFORMATION BE KEPT CONFIDENTIAL?}

To ensure privacy, participants may complete the online survey in the privacy of their own home or any place and time of their preference. To ensure confidentiality, completed surveys will be uploaded to a secure, password restricted share drive. "Study data" is information about you including demographic data (age, gender, education, employment status) that is collected for the study, but that does not directly identify you. Any study data about you that is collected will have a code and will not contain your name or email address, or any information that directly identifies you. When the results of this study are published, your identity will not be disclosed. The list of participant emails collected for the incentive draw will only be accessible to the investigator and kept in a separate file from the surveys. All study files will be maintained in a secure password restricted share drive as an electronic document and deleted or destroyed after the prescribed retention period appointed by Ryerson University.

\section{WHAT ARE THE RIGHTS OF PARTICIPANTS IN A RESEARCH STUDY?}

If you have any questions about this study you may contact the person in charge of this study (Student Investigator) Sarah McDermid-Flabbi at

$$
\text { or the (Principal Investigator) }
$$

Interim Patient Care Manager, ACNRT, CCNRT \& Centralized Scheduling at 
The

Research Ethics Board has reviewed this study. If you have questions about your rights as a research participant or any ethical issues related to this study that you wish to discuss with someone not directly involved with the study, you may call the Chair Ethics Board at

\section{DOCUMENTATION OF INFORMED CONSENT}

Participant

By reading this consent form and completing the online survey and clicking "finish" at the end of the survey, I confirm that:

- This research study has been fully explained to me and all of my questions answered to my satisfaction

-I understand the requirements of participating in this research study

- I have been informed of the risks and benefits, if any, of participating in this research study

- I have been informed of any alternatives to participating in this research study

- I have been informed of the rights of research participants

- I have read each page of this form

Please keep a copy of this form for your own records. 


\title{
Appendix M: Ryerson REB Approval
}

Ryerson

University

\section{Protocol View}

\author{
APPLICATION CHECKLIST \\ Protocol Submitted By: sarah.modermidfiabbi \\ Submission Status: Approved \\ REB : $2018-116$ \\ Title of Research Proposal \\ Factors Influencing Tumover Intentions of New Graduate Nurses Employed to Float Pools. \\ SECTION 1 - COMMENTS TO CHAIR \\ Comments to Chair
}

Requirements 1. Recruitment and Selection a) In your UHN application, under "Recruitment Non-Patients", you noted that the tools to be used to identify potential participants "will be completed later." Please provide details on the recruitment process. At the time of initial submission, this documentation was a reminder to myself. However I have acknowledged I will be recruiting ONLY RNS in the nursing float pool via emails provided in submission. The demographic section of the online survey will determine the inclusion and exclusion criteria for new graduate nurses within this float pool. *As this application has already been approved by UHN, I am unable to re-enter this information in the CAPCR online document. (I hope this explanation along with supporting documents will suffice). The demographic questionnaire was developed by the student investigator to provide a descriptive profile by measuring the variables of interest for the NGN nursing sample. Questions included information about the respondent's gender, age, specialty units, highest level of education, employment status, years of work experience as an RN, and anticipated length of stay in current position and in the organization. *Please see attached recruitment information via protocol document submitted to UHN for your reference. 2. Consent Form a)The named PI on the consent form is Helen Kelly, while the protocol names Nancy Purdy. Please explain the discrepancy and amend the documents for consistency as needed. As per UHN's request, Helen Kelly is acting as PI for the site as she is an expert in research conduction in the Collaborative Academic Practice (CAP) research department at UHN. As a member of the Collaborative Academic Practice leadership team, Helen plays an important role in the development and management of research infrastructure, which supports academic scholarship in the New Knowledge and Innovation portfolio. Along with operational responsibilities for research staff and studies, she is involved in the development and evaluation of research education, supports the review and approval of research from the 14 disciplines in the Collaborative Academic Practice portfolio at UHN, provides research consultation and education to staff and students, and mentors novice research teams. Nancy Purdy is my thesis supervisor overseeing my study, however, will not act as PI for the study site itself. In my submission, I state Helen Kelly as PI in all submitted documents. Nancy Purdy is named in my submission of investigators as my Thesis Supervisor. b) The consent form states that UHN may access participants' personal health information (in the form of contact details and demographic information). Please provide details on the purpose of collecting this information and how you plan to access it. Demographic information is already collected directly from participants in the survey, so it is not clear why you (or UHN representatives) would need access to their files. This is stated at the end of the online survey. It is optional for participants to enter for the study incentive draw for a spa gift card. The participant has been asked to email the student researcher with contact information only if they would like to be entered for the draw. Only the winner will be contacted with this information provided, all contact information will be kept in a separate encrypted file and deleted thereafter. The student researcher will solely access this information. 3. Privacy and Confidentiality a) As noted above, the plan to collect PHI requires a rationale. If you plan to collect it from the participants' employers, this requires a consideration of the associated risks to confidentiality. Please comment. Please see above comment. Participant contact information will be voluntarily collected from participant themselves, from employers.

SECTION 2 - INTRODUCTION \& INVESTIGATORS

\section{Principal Investigator}

First Name: $\quad$ Sarah

Last Name: McDermid-Flabbi

Institution: Ryerson University

Academic Title:

Department/Office: Nursing

Email:

Telephone Number

Type: 


\section{Appendix N: SITE A REB Approval}

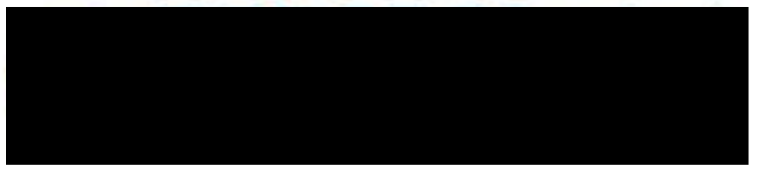

NOTIFICATION OF REB INITIAL APPROVAL

Date: $\quad$ March 21, 2018

To:

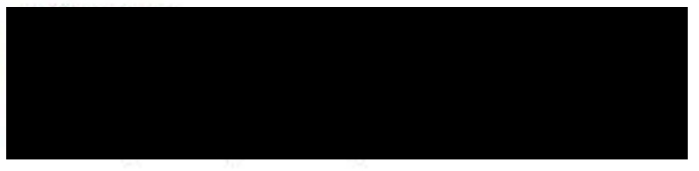

Re:

17-6099

Factors Influencing Turnover Intentions of New Graduate Nurses Employed to Float Pools

REB Review Type:

REB Initial Approval Date:

REB Expiry Date:
Delegated

March 21, 2018

March 21, 2019

Documents Approved:

\begin{tabular}{|l|l|l|}
\hline Document Name & Version Date & Version ID \\
\hline Consent Form & March 15, 2018 & $\# 4$ \\
\hline Final Reminder (Email \#4) & March 15, 2018 & $\# 4$ \\
\hline Email Reminder 1 (Email \#3) & March 15, 2018 & $\# 4$ \\
\hline $\begin{array}{l}\text { Invitation to Participate Email } \\
\text { (Email \#2) }\end{array}$ & March 15, 2018 & $\# 4$ \\
\hline Recruitment Letter (Email \#1) & March 15, 2018 & $\# 4$ \\
\hline Opinio Online Survey & March 15, 2018 & $\# 4$ \\
\hline Protocol & December 29,2017 & \\
\hline
\end{tabular}

The Research Ethics Board approves the above mentioned study as it has been found to comply with relevant research ethics guidelines, as well as the Ontario Personal Health Information Protection Act (PHIPA), 2004. 
Best wishes on the successful completion of your project.

Sincerely

conair,

Co-Chair, Research Ethics Board

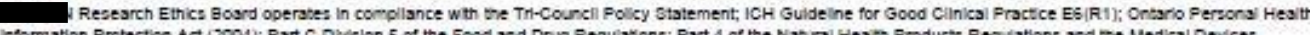
information Protection Act (2004); Part C Divalon 5 of the Food and Drug Regulasons; Part 4 of the Nabural Heato Froducta Regulationa and the Medical Devices

Repulatons of Health Canada. The approval and the vews of the REs have been documented in writh

Furthermore, members of the Research Ethics Board who are named as investlgabsca in reesarch studies do not participate in discusalona reisted bo, nor wote on such studles when they are presented to the REs. 


\section{Appendix O: SITE B REB Approval}

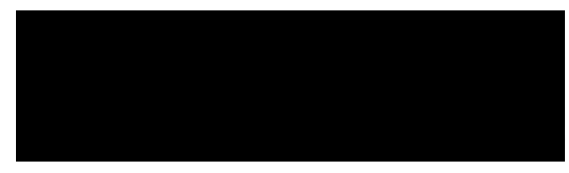

To:

Patient Care Manager

From:

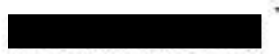

Date: July 19,2018

Subject: $\quad$ Factors Influencing Turnover Intentions of New Graduate Nurses Employed to Float Pools

Project Identification Number: 160-2018

Approval Date: July 19, 2018

Expiry Date: July 19, 2019

The Rescarch Ethics Board of has conducted a Delegated Board review of the research study referenced above and approved the involvement of human participants. REB members involved in the research project or who have declared a conflict do not participate in the review, discussion or decision.

The approval of this study includes the following documents:

- Protocol dated December 29, 2017

- Information letter dated July 13, 2018

- Advance Notice Email dated July 14, 2018

- Email Invitation dated July 14, 2018

- Reminder Email dated July 14, 2018

- Final Reminder Email dated July 14, 2018

- Survey (received May 15, 2018)

As Principal Investigator you are responsible for the ethical conduct of this study which may be subject to review by Quality Assurance and Education. The study must comply with current legislation outlined in the Ontario Personal Health Information Protection Act (PHIPA) and all acts, regulations, guidelines and policies that govern this research. Note that regional or provincial 'shared 'systems' that may be accessible from Sunnybrook systems (e.g. cGTA/Connecting Ontario from SunnyCare) cannot be used for research purposes.

The REB requires immediate notification of internal serious adverse events and significant deviations, submission of a renewal form prior to the approval expiry date, and notification of study closure.

The Research Ethics Board

Division 3 of the Food and Drug Regulations, Part 4 of the Natural Health Products Regulations, and Part 3 of the

Medical Devices Regulations. All Health Canada regulated trials at Sunnybrook are conducted by a Qualified Investigator.

Fully affiliated with 
The REB and Research Ethics Office are in support of facilitating the progress of ethical research and thank you in advance for your efforts to protect research participants. Best wishes for a successful project.

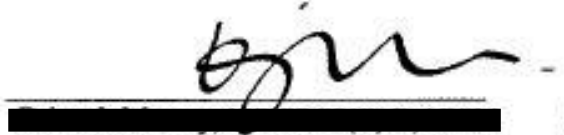

Chair, Research Ethics Board OR fint

Vice-Chair, Research Ethics Board 


\section{References}

Al-Hussami, M., Darawad, M., Saleh, A., \& Hayajneh, F. A. (2014). Predicting nurses' turnover intentions by demographic characteristics, perception of health, quality of work attitudes. International Journal of Nursing Practice, 20(1), 79-88. doi:10.1111/ijn.12124

Anderson, T., Linden, L., Allen, M., Gibbs, E. (2009). New graduate RN work satisfaction after completing an interactive nurse residency. Journal of Nursing Administration 39 (4), 165-169.

Antunes, A. C., Caetano, A., \& Pina e Cunha, M. (2017). Reliability and construct validity of the Portuguese version of the psychological capital questionnaire. Psychological Reports, 120(3), 520-536. doi:10.1177/0033294116686742

Avey, J. B., Luthans, F., \& Youssef, C. M. (2010). The additive value of positive psychological capital in predicting work attitudes and behaviors. Journal of Management, 36(2), 430452. doi:10.1177/0149206308329961

Avey, J. B., Reichard, R. J., Luthans, F., \& Mhatre, K. H. (2011). Meta-analysis of the impact of positive psychological capital on employee attitudes, behaviors, and performance. Human Resource Development Quarterly, 22(2), 127-152. doi:10.1002/hrdq.20070

Avey, J. B., Luthans, F., \& Jensen, S. (2009). Psychological capital: A positive resource for combating employee stress and turnover. Human Resource Management, 48, 677-693.

Avey, J. B., Luthans, F., Smith, R. M., \& Palmer, N. F. (2010). Impact of positive psychological capital on employee well-being over time. Journal of Occupational Health Psychology, $15,17-28$.

Azanza, G., Domínguez, África, Moriano, J., \& Molero, F. (2013). Positive psychological 
capital. Validation of the Spanish version of the PCQ questionnaire. Anales De Psicología / Annals of Psychology, 30(1), 294-

301.https://doi.org/10.6018/analesps.30.1.153631

Bandura, A. (1997). Self-efficacy: The exercise of control. New York, NY, US: W H Freeman/Times Books/ Henry Holt \& Co.

Bates, K. J. (2013). Floating as a reality: Helping nursing staff keep their heads above water. Medsurg Nursing: Official Journal of the Academy of Medical-Surgical Nurses, 22(3), 197.

Baumann, A., Hunsberger, M., \& Crea-Arsenio, M. (2011). Workforce integration of new graduate nurses: Evaluation of a health human resources employment policy. Healthcare Policy/Politiques De Santé, 7(2), 47-59. doi:10.12927/hcpol.2011.22662

Baumann, A., Crea-Arsenio, M., Akhtar-Danesh, N., Fleming-Carroll, B., Hunsberger, M., Keatings, M., ... Kratina, S. (2016). Strategic workforce planning for health human resources: A nursing case analysis. Canadian Journal of Nursing Research, 48(3-4), 9399. doi:10.1177/0844562116680715

Beecroft, P. C., Dorey, F., \& Wenten, M. (2008). Turnover intention in new graduate nurses: A multivariate analysis. Journal of Advanced Nursing, 62(1), 41-52. doi:10.1111/j.13652648.2007.04570.x

Birch, S., O’Brien-Pallas, L., Alksnis, C., Tomblin-Murphy, G., Thomson, D. (2003). Beyond demographic change in human resources planning: an extended framework and application to nursing. Journal of Health Services Research and Policy, 8, 225-229.

Boamah, S. A., Read, E. A., \& Spence Laschinger, H. K. (2016). Factors influencing new graduate nurse burnout development, job satisfaction and patient care quality: A timelagged study. Journal of Advanced Nursing, 73(5), 1182-1195. doi:10.1111/jan.13215 
Boamah, S. A., \& Laschinger, H. (2016). The influence of areas of worklife fit and work-life interference on burnout and turnover intentions among new graduate nurses. Journal of Nursing Management, 24(2), E164-E174. doi:10.1111/jonm.12318

Brewer, C. S., Kovner, C. T., Greene, W., Tukov Shuser, M., \& Djukic, M. (2012). Predictors of actual turnover in a national sample of newly licensed Registered Nurses employed in hospitals. Journal of Advanced Nursing, 68(3), 521-538.

doi:10.1111/j.1365-2648.2011.05753.x

Brunetto, Y., Rodwell, J., Shacklock, K., FarrWharton, R., \& Demir, D. (2016). The impact of individual and organizational resources on nurse outcomes and intent to quit. Journal of Advanced Nursing, 72(12), 3093-3103. doi:10.1111/jan.13081

Burr, S., Stichler, J., \& Poeitler, D. (2011). Establishing a mentoring program. Nursing for Women's Health, 15(3),215-224.

Camerino D., Conway P., van der Heijden B., Estryn-Be' har M.,Costa G. \& Hasselhorn H. (2008) Age-dependent relationships between work ability, thinking of quitting the job, and actual leaving among Italian nurses: a longitudinal study. International Journal of Nursing Studies, 45(11), 1645-1659.

Canadian Institute for Health Information. Regulated Nurses: Canadian trends, 2006 to 2010. Ottawa, ON: CIHI; 2011.

Canadian Institute for Health Information. Regulated Nurses, 2017: Canada and Jurisdictional Highlights. Ottawa, ON: CIHI; 2018.

Chen H., Chu C., Wang Y. \& Lin L. (2008) Turnover factors revisited: A longitudinal study of Taiwan-based staff nurses. International Journal of Nursing Studies, 45(2), 277-285.

Chernomas, W. M., Care, W. D., McKenzie, J. L., Currie, J. \& Guse, L. (2010). "Hit the ground 
running": Perspectives of new nurses and nurse managers on role transition and integration of new graduates. Nursing Leadership, 22(4), 70-86.

doi:10.12927/cjn1.2010.21598

Claydon, L. S. (2015). Rigour in quantitative research. Nursing Standard (Royal College of Nursing (Great Britain): 1987), 29(47), 43. doi:10.7748/ns.29.47.43.e8820

Cohen, J. (1988). Statistical Power Analysis for the Behavioral Sciences (2nd Edition). Hillsdale, NJ: Lawrence Earlbaum Associates.

Cook, J.V., Dickinson, H.O., Eccles, M.P. (2009). Response rates in postal surveys of healthcare professionals between 1996 and 2005: an observational study. BioMed Central Health Services. Research. 9 (1), 160.

Coomber, B., Barriball, K.L. (2007). Impact of job satisfaction components on intent to leave and turnover for hospital-based nurses: a review of the research literature. International Journal of Nursing Studies, 44, 297-314.

Combs, G. M., Milosevic, I., Jeung, W., \& Griffith, J. (2012). Ethnic identity and job attribute preferences: The role of collectivism and psychological capital. Journal of Leadership \& Organizational Studies, 19(1), 5-16. doi:10.1177/1548051811433359

Dawkins, S., Martin, A., Scott, J., \& Sanderson, K. (2013). Building on the positives: A psychometric review and critical analysis of the construct of psychological capital. Journal of Occupational and Organizational Psychology, 86(3), 348-370. doi:10.1111/joop.12007 
Dillman, D. A. (2000). Mail and Internet Surveys: The Tailored Design Method (2nd ed.). New York: Wiley 464 pp.

Donaldson, S. I., \& Ko, I. (2010). Positive organizational psychology, behavior, and scholarship: A review of the emerging literature and evidence base. The Journal of Positive Psychology, 5(3), 177-191. doi:10.1080/17439761003790930

Duchscher, J.E.B. (2012). From surviving to thriving: Navigating the first year of professional nursing practice. Saskatoon, Canada. Nursing the Future.

Duckworth, A. L., Steen, T. A., \& Seligman, M. E. P. (2005). Positive psychology in clinical practice. Annual Review of Clinical Psychology, 1(1), 629-651. doi:10.1146/annurev.clinpsy.1.102803.144154

Dziuba-Ellis, J. (2006). Float pools and resource teams: A review of the literature. Journal of Nursing Care Quality, 21(4), 352-359. doi:10.1097/00001786-200610000-00013

Etikan, I., Musa, S.A., Alkassim, R (2015). Comparison of Convenience Sampling and Purposive Sampling. American Journal of Theoretical and Applied Statistics. 5(1) 14. doi: 10.11648/j.ajtas.20160501.11

Federal/Provincial/Territorial Advisory Committee on Health Delivery and Human Resources, \& Federal/Provincial/Territorial Advisory Committee on Health Delivery and Human Resources (ACHDHR). (2007). A framework for collaborative pancanadian health human resources planning (Rev. Mar. 2007. ed.) Advisory Committee on Health Delivery and Human Resources.

Flinkman, M., \& Salanterä, S. (2015). Early career experiences and perceptions - a qualitative exploration of the turnover of young Registered Nurses and intention to leave the nursing profession in Finland. Journal of Nursing Management, 23(8), 1050-1057. 
doi:10.1111/jonm.12251

Galletta, M., Portoghese, I., Battistelli, A., \& Leiter, M. P. (2013). The roles of unit leadership and nurse-physician collaboration on nursing turnover intention. Journal of Advanced Nursing, 69(8), 1771-1784. doi:10.1111/jan.12039

Gayathri, N, Karthikeyan, P. (2014). Positive Organizational Behaviour and Positive Psychology- Allegations for individual growth development in firms. Indian Journal of Research. 3(10). 148-149.

Good, E., \& Bishop, P. (2011). Willing to walk: A creative strategy to minimize stress related to floating. Journal of Nursing Administration, 41(5), 231-234.

Gray, J., Groves, S., \& Sutherland, S. (2017). Burns and Grove's the Practice of Nursing Research (8 ${ }^{\text {th }}$ edition.). St. Louis, Missouri. Elsevier.

Guay, J., Bishop, S. E., \& Espin, S. (2016). New graduate RNs' perceptions of transitioning to professional practice after completing Ontario's new graduate guarantee orientation program. The Journal of Continuing Education in Nursing, 47(1), 37-44. doi:10.3928/00220124-20151230-10

Hackman, J. R., \& Oldham, G. R. (1975). Development of the Job Diagnostic Survey. Journal of Applied Psychology, 60, 159-170.

Hairr, D. C., Salisbury, H., Johannsson, M., \& Redfern-Vance, N. (2014). Nurse staffing and the relationship to job satisfaction and retention. Nursing Economic\$, 32(3), 142

Hayes, L. J., O’Brien-Pallas, L., Duffield, C., Shamian, J., Buchan, J., Hughes, F., \& North, N. (2012). Nurse turnover: A literature review-an update. International Journal of Nursing Studies, 49(7), 887-905. doi:10.1016/j.ijnurstu.2011.10.001

Health Canada. (2004). Health human resources: Balancing supply and demand. Health Canada. Health Force Ontario. (2011). Nursing Graduate Guarantee initiative for new graduate nurses 
educated in Canada. Retrieved from

http://www.healthforceontario.ca/en/Home/Nurses/Training_|_Practising_In_Ontario/Nur sing_S rategy/Nursing_Graduate_Guarantee

Hsiu, H.-F., \& Shannon, S. E. (2005). Three Approaches to Qualitative Content Analysis. Qualitative Health Research, 15(9), 12771288. https://doi.org/10.1177/1049732305276687

Hudgins, T. A. (2016). Resilience, job satisfaction and anticipated turnover in nurse leaders. Journal of Nursing Management, 24(1), E62-E69. doi:10.1111/jonm.12289

Ileana Petrescu, A., \& Simmons, R. (2008). Human resource management practices and workers' job satisfaction. International Journal of Manpower, 29(7), 651-667. doi:10.1108/01437720810908947

Institute for Work and Health (2015). Selection bias. Retrieved from https://www.iwh.on.ca/what-researchers-mean-by/selection-biasJoint Commission on Accreditation of Healthcare Organizations. (2002). Nursing shortage poses serious health care risk: Joint Commission expert panel offers solutions to national health care crisis. Retrieved from http://www.jcaho.org/news+room/news+release+archives/nursing+shortage.html

Josephson M., Lindberg P., Voss M., Alfredsson L. \& Vingard E. (2008) The same factors influence job turnover and long spells of sick leave-a 3-year follow-up of Swedish nurses. The European Journal of Public Health 18(4), 380-385.

Kaddourah, B. T., Khalidi, A., Abu-Shaheen, A. K., \& Al-Tannir, M. A. (2013). Factors impacting job satisfaction among nurses from a tertiary care centre. Journal of Clinical Nursing, 22(21-22), 3153-3159. doi:10.1111/jocn.12261 
Kanter, R.M. (1977). Men and Women of the Corporation. Basic Books, New York.

Kanter, R.M. (1993). Men and Women of the Corporation, 2nd ed. Basic Books, New York.

Keepnews, D. M., Brewer, C. S., Kovner, C. T., \& Shin, J. H. (2010). Generational differences among newly licensed Registered Nurses. Nursing Outlook, 58(3), 155-163. doi:10.1016/j.outlook.2009.11.001

Kenny, P., Reeve, R., \& Hall, J. (2016). Satisfaction with nursing education, job satisfaction, and work intentions of new graduate nurses. Nurse Education Today, 36, 230. doi:10.1016/j.nedt.2015.10.023

Kim, S.-W., Price, J. L., Mueller, C. W., \& Watson, T. W. (1996). The Determinants of Career Intent Among Physicians at a U.S. Air Force Hospital. Human Relations, 49(7), 947976. https://doi.org/10.1177/001872679604900704

Kovner, C. T., Brewer, C. S., Fatehi, F., \& Jun, J. (2014). What does nurse turnover rate mean and what is the rate? Policy, Politics, \& Nursing Practice, 15(3-4), 64-71. doi:10.1177/1527154414547953

Larson, N., Sendelbach, S., Missal, B., Fliss, J. \& Caillard, P. (2012). Staffing patterns of scheduled unit staff nurses vs. float pool nurses: A pilot study. MEDSURG Nursing, 21(1), 27-39.

Laschinger, H. K. S., \& Havens, D.(1996). Staff nurse work empowerment and perceived control over nursing practice: Conditions for work effectiveness. Journal of Applied Psychology, 26, 27-35.

Laschinger, H.K.S., Finegan, J., Shamian, J., \& Casier, S. (2000). Organizational trust and empowerment in restructured healthcare setting: Effects on staff nurse commitment. Journal of Nursing Administration, 30(9), 413-425. 
Laschinger, H. K. S., Finegan, J., Shamian, J., \& Wilk, P. (2004). A longitudinal analysis of the impact of workplace empowerment on work satisfaction. Journal of Organizational Behavior, 25, 527-545.

Laschinger, H.K.S. \& Wong, C. (2007). A Profile of the structure and impact of nursing management in Canadian hospitals. Ottawa, ON: Canadian Health Services Research Foundation.

Laschinger, H. K. (2008). Effect of empowerment on professional practice environments, work satisfaction, and patient care quality: Further testing the nursing worklife model. Journal of Nursing Care Quality, 23(4), 322-330.

doi:10.1097/01.NCQ.0000318028.67910.6b

Laschinger, H. K. S., Wilk, P., Cho, J., \& Greco, P. (2009). Empowerment, engagement, and perceived effectiveness in nursing work environments: Does experience matter? Journal of Nursing Management, 17, 636-646.

Laschinger, H. K. S. (2012). Job and career satisfaction and turnover intentions of newly graduated nurses. Journal of Nursing Management, 20(4), 472-484. doi:10.1111/j.13652834.2011.01293.X

Laschinger, H. K. S., Grau, A. L., Finegan, J., \& Wilk, P. (2012). Predictors of new graduate nurses' workplace well-being: Testing the job demands-resources model. Health Care Management Review, 37(2), 175.

Laschinger H.K.S., Wong C.A. \& Grau A.L. (2013) Authentic leadership, empowerment and burnout: a comparison in new graduates and experienced nurses. Journal of Nursing Management 21(3), 541-552.

Laschinger, H. K., Cummings, G., Leiter, M., Wong, C., MacPhee, M., Ritchie, J., . . Read, E. (2016). Starting out: A time-lagged study of new graduate nurses' transition to practice. International Journal of Nursing Studies, 57, 82-95. 
doi:10.1016/j.ijnurstu.2016.01.005

Lautizi, M., Laschinger, H. K. S., \& Ravazzolo, S. (2009). Workplace empowerment, job satisfaction, and job stress among Italian mental health nurses: An exploratory study.Journal of Nursing Management, 17, 446-452.

Lavoie-Tremblay, M., O’Brien-Pallas, L., Gelinas, C., Desforges, N., \& Marchionni, C. (2008). Addressing the turnover issue among new nurses from a generational viewpoint. Journal of Nursing Management, 16(6), 724-733. doi:10.1111/j.1365-2934.2007.00828.x

Lebanik, L., \& Britt, S. (2015). Float pool nurses come to the rescue. Nursing, 45(3), 50-53. doi:10.1097/01.NURSE.0000460715.73128.ea

Leech, N. L., Barrett, K. C., \& Morgan, G. A. (2008). SPSS for intermediate statistics: Use and interpretation (3rd ed.). Mahwah, NJ, US: Lawrence Erlbaum Associates Publishers

Leiter, M. P., Price, S. L., \& Spence Laschinger, H. K. (2010). Generational differences in distress, attitudes and incivility among nurses: Generational differences among nurses. Journal of Nursing Management, 18(8), 970-980. doi:10.1111/j.13652834.2010.01168.x

Leon-Perez, J. M., Antino, M., \& Leon-Rubio, J. M. (2016). The Role of Psychological Capital and Intragroup Conflict on Employees' Burnout and Quality of Service: A Multilevel Approach. Frontiers in psychology, 7, 1755. doi:10.3389/fpsyg.2016.01755

Lin, C., \& Chang, C. (2015). Job satisfaction of nurses and its moderating effects on the relationship between organizational commitment and organizational citizenship behaviors. Research and Theory for Nursing Practice, 29(3), 226.

Linzer, P., Tilley, A.M., \& Williamson, M.V. (2011). What floats a float nurse's boat? Creative Nursing, 17(3), 130-138. 
Lorenz, T., Beer, C., Pütz, J., \& Heinitz, K. (2016). Measuring psychological capital:

Construction and validation of the compound PsyCap scale (CPC-12). PloS One, 11(4), e0152892. doi:10.1371/journal.pone.0152892

Luthans, F. (2002a). The need for and meaning of positive organizational behavior. Journal of Organizational Behavior, 23, 695-706.

Luthans, F. (2002b). Positive organizational behavior: Developing and managing psychological strengths. Academy of Management Executive, 16, 57-72.

Luthans, F., Aviolo, B. J., Avey, J. B., \& Norman, S. M. (2007). Positive psychological capital: Measurement and relationship with performance and satisfaction. Personnel Psychology, 60(3), 541-572. doi:10.1111/j.1744-6570.2007.00083.x

Luthans, F., \& Youssef, C. M. (2007). Emerging positive organizational behavior. Journal of Management, 33(3), 321-349. doi:10.1177/0149206307300814

Luthans, F., Norman, S. M., Avolio, B. J., \& Avey, J. B. (2008). The mediating role of psychological capital in the supportive organizational climate: Employee performance relationship. Journal of Organizational Behavior, 29(2), 219-238. doi:10.1002/job.507

Luthans, F., Avey, J. B., Clapp-Smith, R., \& Li, W. (2008). More evidence on the value of Chinese workers' psychological capital: A potentially unlimited competitive resource? The International Journal of Human Resource Management, 19(5), 818-827. doi:10.1080/09585190801991194

Mills, J., Woods, C., Harrison, H., Chamberlain-Salaun, J., \& Spencer, B. (2017). Retention of early career Registered Nurses: The influence of self-concept, practice environment and resilience in the first five years post-graduation. Journal of Research in Nursing, 22(5), 372-385. doi:10.1177/1744987117709515 
Mobley, H. (1977)."Intermediate linkages in the relationship between job satisfaction and employee turnover." Journal of applied psychology .62.2

Morrow, S. (2009). New graduate transitions: Leaving the nest, joining the flight. Journal of Nursing Management, 17(3), 278-287. doi:10.1111/j.1365-2834.2008.00886.x

Muha, T. M., \& Manion, J. (2010). Using positive psychology to engage your staff during difficult times. Nurse Leader, 8(1), 50-54. doi:10.1016/j.mnl.2009.12.002

Newman, A., Ucbasaran, D., Zhu, F., \& Hirst, G. (2014). Psychological capital: A review and synthesis. Journal of Organizational Behavior, 35(S1), S120-S138. doi:10.1002/job.1916

Norman, S. M., Avolio, B. J., \& Luthans, F. (2010). The impact of positivity and transparency on trust in leaders and their perceived effectiveness. The Leadership Quarterly, 21(3), 350364. doi:10.1016/j.leaqua.2010.03.002

Numminen, O., Leino-Kilpi, H., Isoaho, H., \& Meretoja, R. (2017). Development of nurses' professional competence early in their career: A longitudinal study. Journal of Continuing Education in Nursing, 48(1), 29-39. doi:10.3928/00220124-20170110-08

O'Brien-Pallas, L., \& Canadian Health Services Research Foundation. (2007). Health human resources modelling: Challenging the past, creating the future Canadian Health Services Research Foundation.

O’Brien-Pallas, L., Murphy, G. T., Shamian, J., Li, X., \& Hayes, L. J. (2010). Impact and determinants of nurse turnover: A pan-Canadian study. Journal of Nursing Management, 18(8), 1073-1086. doi:10.1111/j.1365-2834.2010.01167.x

ObjectPlanet Inc. (2017). Opinio. Retrieved from http://www.objectplanet.com/opinio/ Parker, V., Giles, M., Lantry, G., \& McMillan, M. (2014). New graduate nurses' experiences in their first year of practice. Nurse Education Today, 34(1), 150-156. 
doi:10.1016/j.nedt.2012.07.003

Peterson, J., McGillis Hall, L., O'Brien-Pallas, L., \& Cockerill, R. (2011). Job satisfaction and intentions to leave of new nurses. Journal of Research in Nursing, 16(6), 536-548. doi:10.1177/1744987111422423

Pineau Stam, L. M., Spence Laschinger, H. K., Regan, S., \& Wong, C. A. (2015). The influence of personal and workplace resources on new graduate nurses' job satisfaction. Journal of Nursing Management, 23(2), 190-199. doi:10.1111/jonm.12113

Price, S.L. (2015). Bridging the generational divide. The Canadian Federation of Nurses Unions. Retrieved from https://www.nursesunions.ca

Price, J.L., \& Mueller, C.W. (1990) Economic, Psychological, and Sociological Determinants of Voluntary Turnover. Journal of Behavioral Economics, 19, 321-335. https://doi.org/10.1016/0090-5720(90)90034-5

Price, J.L., and C. W. Mueller. Absenteeism and Turnover Among Hospital Employees. Greenwich, CN: JAI Press, 1986a.

Price, J. L., \& Kim, S.W., (1993). The relationship between demographic variables and intent to stay in the military: Medical personnel in a U.S. air force hospital. Armed Forces and Society, 20, 125-144

Purdy, N., Laschinger, H. K., Finegan, J., Kerr, M., \& Olivera, F. (2010). Effects of work environments on nurse and patient outcomes. Journal of Nursing Management, 18(8), 901-913. doi:10.1111/j.1365-2834.2010.01172.x

Rainess, M., Archer, W., Hofmann, L., \& Nottingham, E. (2015). Empowering float nurses. Nursing Management, 46(2), 15-19. doi:10.1097/01.NUMA.0000460046.94309.d0 Regan, S., Wong, C., Laschinger, H. K., Cummings, G., Leiter, M., MacPhee, M., . . Read, E. 
(2017). Starting out: Qualitative perspectives of new graduate nurses and nurse leaders on transition to practice. Journal of Nursing Management, 25(4), 246-255.

doi:10.1111/jonm.12456

Rhéaume, A., Clément, L., \& LeBel, N. (2011). Understanding intention to leave amongst new graduate canadian nurses: A repeated cross-sectional survey. International Journal of Nursing Studies, 48(4), 490-500. doi:10.1016/j.ijnurstu.2010.08.005

Roach, J. A., Tremblay, L. M., \& Carter, J. (2011). Hope floats: An orthopaedic tip sheet for float pool nurses. Orthopaedic Nursing, 30(3), 208-12.

Rudman, A., Gustavsson, P., \& Hultell, D. (2014). A prospective study of nurses' intentions to leave the profession during their first five years of practice in Sweden. International Journal of Nursing Studies, 51(4), 612. doi:10.1016/j.ijnurstu.2013.09.012

Saks, A. M., \& Gruman, J. A. (2011). Organizational socialization and positive organizational behaviour: Implications for theory, research, and practice. Canadian Journal of Administrative Sciences / Revue Canadienne Des Sciences De l'Administration, 28(1), 416. doi:10.1002/cjas.169

Seligman, M. E. P., \& Csikszentmihalyi, M. (2000). Positive psychology: An introduction.American Psychologist, 55(1), 5-14. doi:10.1037/0003-066X.55.1.5

Shinners, J., Alejandro, J. A. N., Frigillana, V., Desmond, J., \& LaVigne, R. (2016). Quality improvement: Creating a float pool specialty within a new graduate residency. Medsurg Nursing: Official Journal of the Academy of Medical-Surgical Nurses, 25(2), 79-82.

Smith, L. M., Andrusyszyn, M. A., \& Spence Laschinger, H. K. (2010). Effects of workplace 
incivility and empowerment on newly-graduated nurses' organizational commitment. Journal of Nursing Management, 18(8), 1004-1015. doi:10.1111/j.13652834.2010.01165.x

Snyder, C. R., Irving, L., \& Anderson, J. R. (1991). Hope and health: Measuring the will and the ways. C. R. Snyder, \& D. R. Forsyth (Eds.), Handbook of social and clinical psychology: The health perspective. 285-305. Elmsford, NY: Pergamon Press.

Soper, D. (2006). Calculator: A-priori Sample Size for Student t-Tests. Retrieved July 15, 2018, from https://www.danielsoper.com/statcalc/calculator.aspx?id=47\

Sousa, V. D., Driessnack, M \& Mendes, I. A. C. (2007). An overview of research designs relevant to nursing: Part 3: Mixed and multiple methods. Revista Latino-Americana De Enfermagem, 15(5), 1046-1049. doi:10.1590/S0104-11692007000500025

Spetz, J., \& Herrera, C. (2010). Changes in nurse satisfaction in California, 2004 to 2008. Journal of Nursing Management, 18(5), 564. doi:10.1111/j.13652834.2010.01117.x

Staiger, D. O., Auerbach, D. I., \& Buerhaus, P. I. (2012). Registered Nurse labor supply and the recession--are we in a bubble? The New England Journal of Medicine, 366(16), 1463.

Stajkovic, A. D., \& Luthans, F. (1998). Self-efficacy and work-related performance: A metaanalysis. Psychological Bulletin, 124(2), 240-261. doi:10.1037/0033-2909.124.2.240

Straw, C. N. (2018). Engagement and retention in float pools: Keeping the team above water. Nursing Management (Springhouse), 49(10), 30-36. doi:10.1097/01.NUMA.0000546201.01962.0d

Streubert, H.J. and Carpenter, D.R. (2011) Qualitative Research in Nursing: Advancing the Humanistic Imperative. Wolters Kluwer, Philadelphia. 
Sun, T., Zhao, X. W., Yang, L. B., \& Fan, L. H. (2012). The impact of psychological capital on job embeddedness and job performance among nurses: A structural equation approach. Journal of Advanced Nursing, 68, 69-79.

Suzuki E., Itomine I., Saito M., Katsuki T. \& Sato C. (2008) Factors affecting the turnover of novice nurses at university hospitals: a two-year longitudinal study. Japan Journal of Nursing Science, 5(1), 9-21.

Tabachnick, B. G., \& Fidell, L. S. (2007). Using Multivariate Statistics (5th edition.). New York: Allyn and Bacon.

Tei-Tominaga, M. (2013). Factors related to the intention to leave and the decision to resign among newly graduated nurses: A complete survey in a selected prefecture in Japan. Environmental Health and Preventive Medicine, 18(4), 293-305. doi:10.1007/s12199-012-0320-8

Tellez, M. (2012). Work satisfaction among California Registered Nurses: A longitudinal comparative analysis. Nursing Economic\$, 30(2), 73-81.

Tomblin Murphy, G., Kephart, G., Lethbridge, L., O’Brien-Pallas, L., \& Birch, S. (2009). Planning for what? challenging the assumptions of health human resources planning. Health Policy, 92(2-3), 225-233. doi:10.1016/j.healthpol.2009.04.001

Van Bogaert, P., Peremans, L., Van Heusden, D., Verspuy, M., Kureckova, V., Van de Cruys, Z., \& Franck, E. (2017). Predictors of burnout, work engagement and nurse reported job outcomes and quality of care: A mixed method study. BMC Nursing, 16(1), 5. doi:10.1186/s12912-016-0200-4

VanGeest, J., Johnson, T.P., (2011). Surveying nurses: Identifying strategies to improve participation. Evaluations and the Health Professions. 34 (4), 487. 
Van Hoeven, L. R., Janssen, M. P., Roes, K. C. B., \& Koffijberg, H. (2015). Aiming for a representative sample: Simulating random versus purposive strategies for hospital selection.BMC Medical Research Methodology, 15(1), 90. doi:10.1186/s12874-0150089-8

Wang, L., Tao, H., Ellenbecker, C. H., \& Liu, X. (2012). Job satisfaction, occupational commitment and intent to stay among Chinese nurses: A cross-sectional questionnaire survey. Journal of Advanced Nursing, 68(3), 539-549. doi:10.1111/j.13652648.2011.05755.x

Wing, T., Regan, S., \& Spence Laschinger, H. K. (2015). The influence of empowerment and incivility on the mental health of new graduate nurses. Journal of Nursing Management, 23(5), 632-643. doi:10.1111/jonm.12190

Yu, M., \& Kang, K. J. (2016). Factors affecting turnover intention for new graduate nurses in three transition periods for job and work environment satisfaction. The Journal of Continuing Education in Nursing, 47(3), 120. doi:10.3928/00220124-20160218-08

Yu, M., \& Lee, H. (2018). Impact of resilience and job involvement on turnover intention of new graduate nurses using structural equation modeling: Turnover intention of new nurses. Japan Journal of Nursing Science, 15(4), 351-362. doi:10.1111/jjns.12210 